Portland State University

PDXScholar

Fall 11-21-2019

\title{
Support From Inside Out: Exploring Whether Various Social Supports Assist in Reducing Prison Rule Violations
}

Sarah Renee Lazzari

Portland State University

Follow this and additional works at: https://pdxscholar.library.pdx.edu/open_access_etds

Part of the Criminology Commons, and the Social Work Commons Let us know how access to this document benefits you.

Recommended Citation

Lazzari, Sarah Renee, "Support From Inside Out: Exploring Whether Various Social Supports Assist in Reducing Prison Rule Violations" (2019). Dissertations and Theses. Paper 5335.

https://doi.org/10.15760/etd.7208

This Dissertation is brought to you for free and open access. It has been accepted for inclusion in Dissertations and Theses by an authorized administrator of PDXScholar. Please contact us if we can make this document more accessible: pdxscholar@pdx.edu. 
Support From Inside Out:

Exploring Whether Various Social Supports Assist in Reducing Prison Rule Violations

\author{
by \\ Sarah Renee Lazzari \\ A dissertation submitted in partial fulfillment of the \\ requirements for the degree of \\ Doctor of Philosophy \\ in \\ Social Work and Social Research \\ Doctoral Dissertation Committee: \\ Keva M. Miller, Chair \\ Junghee Lee \\ Marian Harris \\ Melissa Thompson
}

Portland State University

2019 
(C) 2019 Sarah Renee Lazzari 


\begin{abstract}
Scholars argue that prison rule violations are a way to assess whether individuals are engaging in prosocial behaviors. Individuals who engage in prosocial behaviors, during periods of incarceration, are less likely to engage in behaviors that result in official rule violations. Decreasing rule violations is one way to work towards a safer prison environment, while also preparing individuals for release. The current study uses cross-sectional data form the 2004 Survey of Inmates in State and Federal Facilities, in order to examine whether multiple types of prisons programs, which will be framed as various types of social supports, influence the frequency of rule violations. The goal was to assess whether various types of social supports influenced behaviors, while also examining whether behaviors changed as social supports increased. Individuals, who admitted to committing at least one major rule violation, were included in the sample $(\mathrm{N}$ $=5,943)$. Hierarchical regressions were run to assess how the combination of various social supports, race, educational attainment, and time served impacted total rule violations. Results suggest that there is not a statistically significant association between increased social supports and rule violations. Findings show that having a work assignment significantly decreased rule violations, and that White participants committed fewer rule violations. Implications for future research, policy, and practice are presented.
\end{abstract}




\section{Dedication}

This is for all of the men and women who are currently, or who have been, separated from their support networks during periods of incarceration.

And to my son, Donovan, mommy did all of this for you. We did it! 


\section{Acknowledgements}

I am truly grateful for the numerous social supports who have held my hand along this arduous journey. Thank you for being in my corner! I could not have accomplished this goal without each of you.

To my committee, I am so grateful for the guidance and support along the way. I have had a few major hiccups along the way. You never left my side, and you reassured me that this goal was possible. Dr. Keva Miller, this has been a long process. Thank you for never giving up on me. Hopefully, one day, my writing voice will catch up to my speaking voice. Dr. Junghee Lee, your guidance as the PhD director has been such a bright light, through this tough journey. Thank you for every bit of kindness. Dr. Melissa Thompson, thank you for providing insights from a different perspective, across disciplines. And last but not least, Dr. Marian Harris. You provided support from across universities and state lines. Thank you for being willing to join my team, and for providing such consistent support throughout the journey.

Stephanie Sundborg and Sandy Leotti, my fellow PhDers. Thank you for sharing your projects with me and helping me process these various steps along the way. Stephanie, you got through this process years before I did. Thanks for being a guide along the way. Sandy, thank you for helping me get through this first hiring process.

To the men and women incarcerated in Oregon. Thank you for allowing me to trespass on your life behind prison walls. You have given me insights and understandings that have drastically changed my perspectives. Thank you for sharing your experiences regarding such personal relationships and dynamics. 
To the men and women working behind prison walls in Oregon, thank you for allowing me to be a part of your world. I have a very different sense of realities facing correctional officers and service providers. This work in incredibly complex and challenging.

Randy Geer, Kelly Raths, Carolyn Schnoor, Tom O’Conner, and Kelly Arrington, where to even begin with all of you. You have been guides and mentors for me, as I have explored corrections. Thank you for taking the time to sit and talk with me. I have learned so much from each of you, and I am so grateful for each of your perspectives. I have been able to witness how each of you navigate corrections. I will forever carry a piece of each of you, as I continue to my work.

To my family. I could not have done this without you. Mom and dad, I am writing about the importance of social supports. You have always been by my side supporting me along each endeavor. I can never thank you enough. Mom, thanks for reading through this long body of work, and for finding all of the minute errors that my brain just skipped right over. Thank you for helping me with Donovan, so that I could focus and get work done! Marcie and Jeannie, I know you both believe in me more than I do. Thank you for always being there to help me navigate academia and life. Marcie, thanks for editing each and every version of each and every chapter of this Dissertation, and thank you for all of the "get your butt in gear" nudges along the way. 
TABLE OF CONTENTS

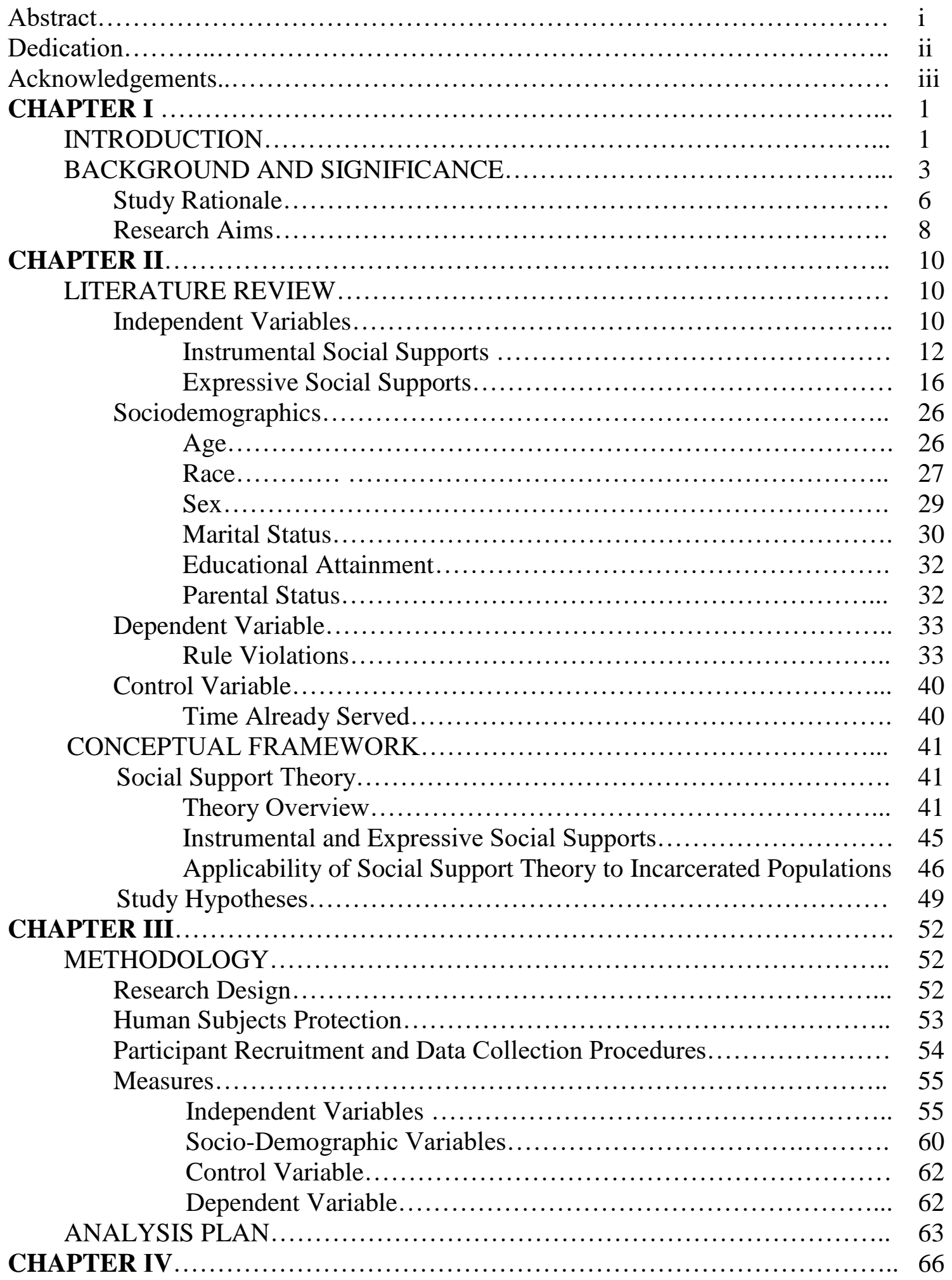




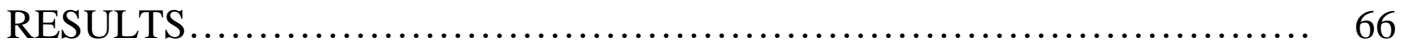

Descriptive Sample Characteristics................................. 66

Bivariate Analysis................................................... 68

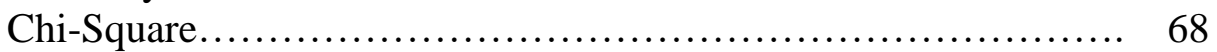

Independent-Samples T-Tests............................... 70

Correlations................................................. 74

Multivariate Analysis............................................ 76

Hierarchical Regression.................................. 76

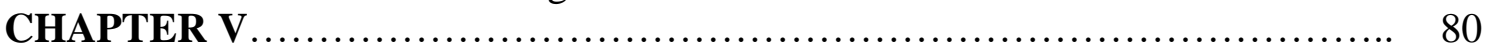

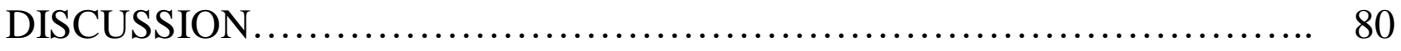

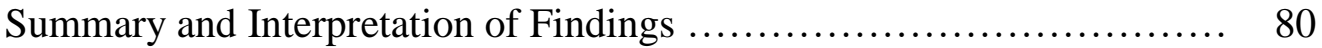

Discussion of Research Aim 1.............................. 81

Discussion of Research Aim 2 ............................ 87

Discussion of Research Aim 3 ............................. 88

Discussion of Research Aim 4 ............................. 90

Discussion of Research Aim 5............................... 92

Discussion of Research Aim 6................................ 92

STUDY LIMITATIONS AND STRENGTHS .......................... 93

IMPLICATIONS AND RECOMMENDATIONS ......................... 95

Implications and Recommendations for Future Research................ 95

Implications and Recommendations for Practice ........................ 99

Implications and Recommendations for Policy........................ 103

CONCLUSIONS....................................................... 106

References ............................................................. 110

Appendix A Instrumental and Expressive Social Supports.......................... 143

Appendix B. Overall Model ................................................ 144

Appendix C. Cullen's (1994) Social Support Paradigm............................... 145

Appendix D. Rule Violations and The Resulting Disciplinary Actions ............... 146

Appendix E. Rule Violations Included in The Study............................ 147

Appendix F. Sample Descriptive Statistics....................................... 148

Appendix G. Chi Square Tests between Sex and Social Supports .................... 149

Appendix H. Chi Square Tests between Race and Social Supports ................. 150

Appendix I. Independent-Sample T-Tests Comparing Males and Females............ 151

Appendix J. Independent-Sample T-Tests Comparing People of Color and Whites... 152

Appendix K. Whether Participation in Social Supports Influence Rule Violations... 153

Appendix L. Correlation Matrix for Study Variables............................... 154

Appendix M. Correlation Matrix for Social Supports and Total Rule Violations..... 155

Appendix N. Hierarchical Regression Predicting Total Rule Violations............. 156

Appendix O. Hypothesis Testing Results......................................... 157 


\section{CHAPTER I \\ INTRODUCTION}

Each year, the United States spends almost 81 billion dollars on corrections (Wagner \& Rabuy, 2017). The state prison system alone spends upwards of 43 billion dollars on 2.3 million incarcerated men and women [Prison Policy initiative (PPI), 2019; Mai \& Subramanian, 2017; Wagner \& Rabuy, 2017]. The majority of these funds are allocated to correctional officers' salaries rather than direct services to assist criminal justice sanctioned individuals. Approximately one billion dollars are dedicated to direct services such as education, employability and job training, and family-based programs (Sedgley, Scott, Williams, \& Derrick, 2010), which assist with the prison transition and long-term reintegration upon release (Bell \& Lindekugel, 2015; Boman \& Mowen, 2017; Cochran, 2012; Colvin, 2007; Lahm, 2009a; Martos-Garciá et al., 2009; Meek \& Lewis, 2014; Steiner \& Meade, 2016; Tewksbury, Connor, \& Denney, 2014). Direct services and programs help incarcerated individuals obtain the skills they need to navigate through their prison experience in a prosocial manner, while also providing tools that will assist individuals be more successful upon their return to society (Mai \& Subramanian, 2017). In addition, these services are essential in reducing behaviors that often lead to disciplinary sanctions, or rule violations, during incarceration (Ray et al., 2017).

While numerous studies have examined the impacts of prison and correction programs, few have adequately examined what combination of programs provide the crucial elements of social support that might best assist incarcerated individuals with adjustment to prison life. Research has primarily focused on the independent outcomes of 
participation in education programs (Brazzell et al., 2009; Cho \& Tyler, 2013; Kim \& Clark, 2013; Pompoco et al., 2017), job training (Celinska \& Sung, 2014; Jiang et al., 2005), religious programs (Camp, Daggett, Kwon, \& Kelin-Saffran, 2008; Celinska \& Sung, 2014; Clear \& Sumter, 2008; Jiang et al., 2005; Kerley, Copes, Tewksbury, \& Dabney, 2011; Kerley, Matthews, \& Blanchard, 2005), parenting programs (Eddy, Martinez, Burraston, 2013; Eddy et al., 2008; Harris \& Pettway, 2007; Jarvis, Graham, Hamilton, \& Tyler, 2004; Loper \& Yuerk, 2006; Meek, 2007; Sandifer, 2008) or drug and alcohol treatment (Orrick et al., 2011; Ray et al., 2017). The scholarly literature suggests that there are important differential outcomes and unique needs for incarcerated men versus incarcerated women (Hardyman \& Van Voorhis, 2004; Trejbalová \& Salisbury, 2019; Van Voorhis et al., 2008). In addition, the extant literature has not adequately addressed the needs of men and women of color (Bell, 2017; Crittenden, Koons-Witt, \& Kaminski, 2016).

Our overall lack of understanding of which programs are most effective, and for which incarcerated individuals is potentially due in part, to the human and structural components that permeate corrections. Each state has the ability to implement different programs within each of their facilities. The custody level of the prison population, the sex of the prison population, the location of the facility, the architecture, and the available "classroom" space of a facility impact which programs will be offered within a prison. Another area that needs to be examined is the differences between the availability of programs within state owned versus private prisons (Baćak \& Ridgeway, 2018). Within any given state, the programs offered at each facility can be vastly different. In addition, 
many studies solely focus on recidivism as an outcome, which is crucial for understanding long-term success. However, this does not assist in our understanding of what allows incarcerated individuals to adjust to their prison environment and routines. Correctional systems would benefit from sound empirical knowledge on what combination of social supports are most beneficial for transition into their prison environment (Andrews, Bonta, \& Hoge, 1990; Andrews, Bonta, \& Wormith, 2004; Bui \& Morash, 2010; Cobbina, Huebner, \& Berg, 2012; Cullen, 2013; 2012; Newsome \& Cullen, 2017).

\section{BACKGROUND AND SIGNIFICANCE}

During periods of imprisonment, many incarcerated men and women are able to begin building and strengthening various types of support networks. However, this is not the case for every individual. Individuals who are able to participate in various programs are given more opportunities, outside of the traditional visitation, letter writing, and phone call communications, to continue building and strengthening their support networks. Certain programs, upon completion, allow for a graduation ceremony, where sometimes an incarcerated individual is able to invite people from their outside support networks to attend a special graduation ceremony. Participation in and completion of certain programs creates a space for individuals to share their accomplishments with their support networks. These interactions begin building the confidence of the incarcerated individual and provide tools that will enable the individual to transition into their prison life, and will assist with a more successful transition back into society (Bales \& Mears, 2008; De Claire \& Dixon, 2017; Duwe \& Clark, 2013; May, Sharma \& Stewart, 2008). 
Research suggests that people who have more social supports are less likely to engage in criminal behaviors, since supportive relationships are a natural part of positive human development (Colvin, Cullen, \& Vander Ven, 2002; Cullen, 1994; Cullen, Wright, \& Chamlin, 1999; Ray et al., 2017). The importance of supportive prosocial relationships also appears to hold true for incarcerated men and women. However, it is unclear what types and/or combination of supports are most helpful for men and women during incarceration. Previous studies have made discernible determinations about the effectiveness of program participation or communication and visitations with family and friends. Unfortunately, the extant literature provides contradictory outcomes, even for the types of supports that have amassed considerable research support. For example, some studies have found that visitations decrease rule violations (Beckmeyer \& Arditti, 2014; Blevins et al., 2010; Cochran, 2012; Foster, 2012; Huebner, 2003; Poehlman et al., 2010), while other studies suggest that visitations increase rule violations (Bell \& Lindekugel, 2015; Jiang \& Winfree, 2006; Liebling, 1999; Pollock, 2004; Siennick, Mears, \& Bales, 2013). Studies also suggest that incarcerated parents adjust better to prison life when they are able to visit with their children (Arditti \& Few, 2008; Arditti \& Few, 2006; Barrick et al, 2014; Beckmeyer \& Arditti, 2014; Luke, 2002; McClure et al., 2015; Visher \& Travis, 2003). Casey-Acevedo and colleagues (2004) found that incarcerated parents who visited with their children engaged in more serious rule violations, and that rule violations increased as the number of children increased. Incarcerated individuals may struggle with having to repeatedly say goodbye to their loved ones at the end of a visit, and they may feel powerless to assist their loved ones who are experiencing various struggles. These 
individuals would benefit from gaining more tools, which may be provided during various program opportunities. These tools may better prepare individuals for addressing emotional burdens they experience when visiting loved ones.

As an incarcerated individual becomes more isolated from established support networks, the degree to which an individual adjusts positively to prison life is at-risk for poor outcomes (Adams, 1992; Liebling, 1999; Monahan, Goldweber, \& Cauffman, 2011; Tasca, Griffin, \& Rodriguez, 2010). The incarcerated are not the only ones impacted by how well they adjust to prison life. Family, incarcerated peers, and prison staff are also affected by how well one adjusts to the prison environment. Children may engage in more aggressive outbursts (Haskins, 2015; Murray \& Farrington, 2005), the relationship between the incarcerated parent and the free parent can become tumultuous and the free parent may experience higher levels of stress (Murray et al., 2012). In addition, when individuals successfully adjust to prison, safety increases for other incarcerated individuals and the correctional staff (Gendreau et al., 1997; Meade \& Steiner, 2013; Steiner \& Meade, 2016).

Penologists have suggested that the number of prison rule violations and the types of rule violations an individual commits, which mimic antisocial behaviors in society, are a way to measure whether an incarcerated individual engages in prosocial behaviors (Gendreau, Goggin, \& Law, 1997; Homant \& Witkowski, 2003; Jiang, Fisher-Giorlando, $\&$ Mo, 2005). Assessing frequency and type of rule violations also allows correctional agencies to better understand whether individuals are adequately adjusting to prison life (Bell \& Lindekugel, 2015; Berk, Kriegler, \& Back, 2006; Celinska \& Sung, 2014; Jiang, 
2005; Jiang, Fisher-Giorlando, \& Mo, 2005; Jiang \& Winfree, 2006; Morris \& Worrall, 2010; Tewksbury et al., 2014). One could argue that an individual, who relies on their social supports, may maintain a clear conduct record and, therefore, may be less likely to engage in antisocial behaviors that result in prison rule violations.

Social support theory articulates two types of social supports that are important for motivating individuals toward continued engagement in prosocial behaviors: instrumental supports and expressive supports. Instrumental supports are resources that may include job opportunities and economic capital, while expressive supports are emotional ties with others (Cullen, 1994; Cullen, Wright, \& Chamlin, 1999; Colvin, Cullen, \& Vander Ven, 2002; Ray et al., 2017). When incarcerated individuals participate in drug and alcohol programs, work opportunities/job training, or other educational programs, they begin to build instrumental supports that help sustain them during incarceration and provides tools that will assist after incarceration. Religious programs, general support group interventions, and access to family and friends through visits, phone calls, and letters promote expressive social supports that can foster overall wellbeing. Access to instrumental and expressive social supports have the ability to become motivating factors, which may decrease antisocial behaviors that result in prison rule violations (Colvin, 2007; Day, Brauer, Butler, 2015)

\section{Study Rationale}

Previous research has concentrated on whether communication with outside support networks (Bales and Mears, 2008; Barrick et al., 2014; Duwe \& Clark, 2013; Dallaire et al., 2010; Mears et al., 2012) or whether various prison programs (e.g. Bell \& 
Lindekugel, 2015; Celinska \& Sung, 2014; Lahm, 2009a; Martos-Garciá et al., 2009; Meek \& Lewis, 2014) are able to contribute to an individual's support network. However, studies continue to provide conflicting results (Benning \& Lahm, 2016; Bell \& Lindekugel, 2015; Bonner, Rodriguez, \& Sorensen, 2017; Celinska \& Sung, 2014; De Claire \& Dixon, 2017; Rocheleau, 2014; Taylor, Lee, \& Taxman, 2019). Studies have also primarily focused on whether social supports reduce recidivism, but have not focused on behaviors during incarceration (Bales and Mears, 2008; Barrick, Lattimore, \& Fisher, 2014; Cochran, 2014; Duwe \& Clark, 2013; Dallaire, Ciccone, \& Wilson, 2010; Mears, Cochran, Siennick, \& Bales, 2012; Kim \& Clark, 2013; Lahm, 2009a). Future research can illuminate similarities or differences between various subgroups of incarcerated individuals and how their access to social supports impact rule violations by identifying factors that potentially moderate outcomes (De Claire \& Dixon, 2017; Mitchell et al., 2016). For example, studies could examine the frequency of rule violations between parents versus non-parent, men versus women, women of color versus men of color, women of color versus White women, etc. Griffin and colleagues (2017) suggest that future research should examine behaviors of individuals who have committed multiple rule violations, since many studies have dichotomously comparted incarcerated men and women without a single infraction to those with one or more infractions (i.e. Colvin, 2014; Jiang, Fisher-Giorlando, 2005; Steiner \& Meade, 2016; Steiner \& Wooldredge, 2014; Van Voorhis, 1994). The majority of rule violations are committed by a specific group of incarcerated individuals, who are responsible for the 
majority of antisocial behaviors that result in official prison rule violations (DeLisi, 2003; Reidy, Cihan, \& Sorensen, 2017; Jiang et al., 2005; Reidy et al., 2017).

The current study contributes to the research literature by expanding the scope of investigation that assesses whether types of instrumental and expressive social supports independently and in combination (i.e., visitations, phone calls, prison programs, religious programs, employment programs) are associated with reduced prison rule violations. Identifying which types of supports help incarcerated individuals successfully adjust to prison life can assist prisons in creating safer prison environments for incarcerated individuals and correctional staff. The study also addresses potential differential exposure to rule violations and responses to access of social supports as determined by socio-demographics (i.e., sex, age, race, educational attainment, marital status, parental status, time served). Finally, the sample includes individuals who engaged in antisocial behaviors and received at least one official sanction for violation of prison rules.

\section{Research Aims}

The current study will examine how socio-demographics and social supports influence the frequency of rule violations committed by incarcerated men and women, who have already committed at least one major rule violation. The goals are to determine which characteristics and social supports may assist in reducing the total number of official rule violations.

The specific aims of the study are to examine the: 
1. associations between socio-demographics (i.e., sex, age, race, educational attainment, marital status, parental status, time served) and total rule violations.

2. associations between instrumental social supports (i.e., drug and alcohol programs, job/vocation related programs, and education programs) and total rule violations.

3. associations between expressive social supports (i.e., religious programs, support programs, and connection with established support networks) and total rule violations

4. aggregate impacts of instrumental and expressive supports (total social supports), and the associations with rule violations.

5. associations between aggregated instrumental and expressive social supports and rule violations, when controlling for time served.

6. whether sex and race moderate the association between aggregated social supports and total rule violations, when controlling for the amount of time already served. 


\section{CHAPTER II}

\section{LITERATURE REVIEW}

Chapter II synthesizes the research evidence on individuals' adjustments to incarceration, how prosocial/antisocial behaviors contribute to prison adjustments, and factors that may reduce adverse behaviors that results in rule violations. The literature review begins with a description of instrumental and expressive social supports. Table 1 lists the specific types of programs and whether they were categorized as instrumental or expressive social supports. The extant literature on how socio-demographics are associated with the frequency of rule violations is highlighted. Prison rule violations (dependent variable) are then described and defined. In addition, time already served is explored as a control variable between participation in various programs and prison rule violations. The conceptual model, which defines social support theory as the organizing ideology, is then discussed. Following the organizing theory discussion, the research hypotheses are introduced. The hypotheses state the specific independent variables, socio-demographic variables, dependent variable, and control variable that were assessed

during the study. Figure 1 shows the overall model of potential variables described within the literature review. Finally, significant limitations to literature and gaps in current research are discussed throughout the literature review.

\section{Independent Variables-Instrumental and Expressive Social Supports}

Many studies have argued that involvement in prison programs assists in adjusting to prison life (see e.g. Clear \& Sumter, 2008; Cochran, 2012; Lahm, 2009a; Martos-Garciá et al., 2009; Meek \& Lewis, 2014; Steiner \& Meade, 2016), while other 
studies have found that program participation increases the likelihood of committing rule violations (Bell \& Lindekugel, 2015; Celinska \& Sung, 2014). There is a multitude of programs available within each prison, and each prison offers different programs. This lack of uniformity to the programs offered in prisons extends throughout the country (National Institute of Justice, 2018). Program availability is based on the prison population, availability of staff to facilitate programs, availability of volunteers to run programs, interest within the prison population, or even space within the facility to house certain programs. Research on prison programming has yet to tease apart these unknowns, and has typically focused on evaluations of specific programs, and whether the program aides in rehabilitation (Crittenden \& Koons-Witt, 2017; Cullen \& Johnson, 2011; Cullen, Smith, Lowenkamp, \& Latessa, 2009; French \& Gendreau, 2006; Mackenzie, 2000), rather than an exploration of what is actually available. Unfortunately, the need for programs within prisons is so great and many incarcerated individuals are unable to participate in the programs because of long wait-lists and programs being unavailable due to lack of facilitators or space in the facility (Chamberlain, 2012).

Crittenden and Koons-Witt (2017) examined which programs were available in male and female prisons across the country. They found that women's prisons had higher levels of services in medical programming, mental health care, works assignments, educational initiatives, vocational training, and life skills programs. There was no difference between the availability of substance abuse treatment options. This is similar to Morash, Haar, and Rucker (1994) who found that women's prisons offered considerably more opportunities than male prisons. For example, in Oregon prisons, there 
are five job based programs: automotive technologies (male institution), construction technology (male institution), welding (male institution), optical training (female institution), and cosmetology (female institution) [Oregon Department of corrections (ODOC), n.d.b]. There are fourteen institutions within Oregon. Only four institutions offer these programs, and the female institution offers two out of the five programs.

\section{Instrumental Social Supports}

\section{Drug and Alcohol Programs}

One out of every five individuals who goes to prison is incarcerated for a drug offense (PPI, 2019). Approximately 65\% of incarcerated individuals meet the criteria for substance dependent [Center on Addiction and Substance Abuse (CASA), 2010], and, yet, only $11 \%$ of incarcerated individuals receive drug and alcohol treatment (CASA, 2010). Research has suggested that when incarcerated individuals have the opportunity to participate in treatment programs, rule violations may decrease and prosocial behaviors increase (Dietz, O’Connell, \& Scarpitti, 2003; Langan \& Pelissier, 2001; Warren et al., 2013). Taylor and colleagues (2019) found that incarcerated individuals who were able to participate in therapeutic communities, where they are housed in an area separate from general population and live and eat with the others in that therapeutic community, committed fewer rule violations. Individuals who participated in drug education, support groups, or other "outpatient" modalities were not associated with a lower likelihood of committing rule violations. Alternatively, Taylor, Lee, and Taxman (2019) found that participation in any kind of drug and alcohol treatment was associated with a lower 
frequency of rule violations than participation in zero types of drug and alcohol treatment.

\section{Job/Vocation Related Programs}

Research has also found that individuals who participate in prison work programs are less likely to commit rule violations (Celinska \& Sung, 2014; Jiang et al., 2005). Historically, work assignments have included prison industry, maintenance work within the institution (e.g. food service, building maintenance, office administration, and public works), and agriculture (Crittenden, Koons-Witt, \& Kaminski, 2016; Flanagan, 1989). Many scholars argue that work assignments have been made available to the “appropriate” or select gender or racial/ethnic group (Franklin, 2008; Grana, 2010; Morash, Haar, \& Rucker, 1994). Correctional agencies need to continue examining the decisions behind which groups of incarcerated individuals are given access to which types of programs, and whether there are gendered and racial stereotypes guiding those decisions.

In 1994, Oregon passed the Prison Reform and Inmate Work Act, which required that incarcerated individuals be engaged in a combination of forty work and/or education hours every week (ODOC, n.d.b). Then, in 1999, the passing of Ballot Measure 68 allowed for the creation of Oregon Correctional Enterprises (OCE), since the need for work opportunities, drastically increased (OCE; 2019). OCE became a semi-independent state agency and acted as a private sector business. OCE has the following industries: Contact centers; detention furnishings; dormitory furnishings (purchased by OR universities); office furniture; laundry services; metal fabrication; park equipment; print, 
mail, scan documents, and survey creation; prison blues (clothing for the prison population); signage; textiles; transportation equipment; and upholstered goods. Various OCE opportunities exist throughout the majority of Oregon prisons, based upon the prison population, prison location, and need for work within the specific prisons. Their products are available for purchase by the public, and are used throughout Oregon's prisons.

\section{Education Programs}

Involvement in educational programs also help incarcerated individuals adjust to their prison environment (Brazzell et al., 2009; Cho \& Tyler, 2010; Pompoco et al., 2017). Across the country, nearly 12 million dollars is allocated to fund educational programs within $84 \%$ of state prison facilities (Brazzell et al., 2009). Many prisons offer literacy, adult basic education, general equivalency degree programs, and even college courses (Brazzell et al., 2009; Pompoco et al., 2017). Participating in prison education programs provides structured time for incarcerated individuals, engage individuals in the pursuit of job searching, and provide opportunities for individuals to begin considering higher education (Pompoco et al., 2017). Educational opportunities are crucial for prison populations, whose aggregate educational attainment remains significantly lower than the general U.S. population (Allred, Harrison, \& O’Connell, 2013; BJS, 2003; Crayton \& Neuster, 2008; Harlow, 2003; United States Census Bureau, 2017; Wade, 2007).

Cho and Tyler (2010) found that just participating in Adult Basic Education may not be enough to reduce recidivism, but, rather, it required a combination of educational and life skills programs. Alternatively, other research suggests that participating in and 
completing any educational program reduces the likelihood of prison rule violations and decreases the odds of recidivating (Duwe \& Clark, 2014; Jensen \& Reed, 2006; Lahm, 2009b; Pompoco et al., 2017; Steurer, Smith, \& Tracy, 2001). Other research suggests that participating in specific prison educational programs, namely college education, has the potential to reduce prison misconducts (Lahm, 2009). Crittenden and Koons-Witt (2017) found that incarcerated individuals with less than a high school diploma were more likely to participate in educational programs.

Pompoco and colleagues (2017) examined the impacts of participation in educational programs. They assessed how participation in general education classes, college classes, or vocational training/apprenticeship programs affected prison rule violations. Only the outcomes for the incarcerated men were provided because the participation for incarcerated women was so low. They found that participation in vocational training did not influence rule violations. Incarcerated individuals who participated in college classes showed a much lower rate of any violent rule violations, than those who did not take college classes. Finally, Graduate Equivalent Degree (GED) completers had lower rates of violent rule violations than those who had not completed a GED (Pompoco et al., 2017). However, their rates of rule violations were higher than individuals who had taken college courses (Pompoco et al., 2017). Teasing apart the impact of educational programs on prison rule violations is complicated, and the outcomes vary, due to the lack of uniformity with program availability. 


\section{Expressive Social Supports}

\section{Religious Programs}

Religious programs are another source of social support for incarcerated men and women. Studies have found that individuals who participate in religious programs are less likely to commit rule violations or be involved in physical altercations (Camp, Daggett, Kwon, \& Kelin-Saffran, 2008; Celinska \& Sung, 2014; Clear \& Sumter, 2008; Jiang et al., 2005; Kerley, Copes, Tewksbury, \& Dabney, 2011; Kerley, Matthews, \& Blanchard, 2005). Camp and colleagues (2015) found that incarcerated individuals who participated in religious programs were less likely to be involved in violent rule violations. Similar to many other variables, there are contradictory outcomes. Rocheleau (2014) found that incarcerated individuals who relied on religion, as a coping mechanism, were more likely to commit rule violations. The contradictions between studies many not be related to participation in religious programing, specifically, but that there may be more opportunities to be involved with anti-social peers. While education programs, employment programs, and parenting programs have specific end goals with the potential to graduate from the program, religious programs are ongoing and available to most individuals within a prison. Incarcerated individuals may have different motivations for participating in programs with a definitive completion versus programs that are ongoing.

\section{Support Programs}

$\underline{\text { Inmate led support groups }}$

Missing from the extant literature is a discussion surrounding the influence of inmate led support groups on rule violations. Many institutions utilizes support groups 
and clubs that are led by other incarcerated individuals. For example, after providing evidence to Oregon Department of Corrections, surrounding the desire and need for incarcerated fathers to have a fathers' support group, Snake River Correctional Institution implemented a program where incarcerated fathers are able to support each other, with the guidance of a staff facilitator (ODOC, 2015). This type of program does not have data reinforcing the potential outcomes, but when you ask the fathers about this type of support, they argue that the support group is more important than other curriculum based programs. These type of programs offer an informal source of social support that may provide considerable assistance as individuals attempt to adjust to prison life. The original study asked about participation in inmate led support groups, but there was no description of what this meant or what types of programs were included in this variable. Future studies should examine the role of these less formal sources of expressive social supports.

\section{Classes in parenting or childrearing skills}

Brosens and colleagues (2016) found that incarcerated parents were less likely to participate in prison programs. Incarcerated mothers, when compared to incarcerated fathers, were more likely to participate in parenting classes (Crittenden \& Koons-Witt, 2017; Franklin, 2008; Glaze \& Maruschak, 2008; Lee, 2000; Morash \& Robinson, 2002). Incarcerated women, when compared to incarcerated men, may be viewed as the more viable caregiver for children upon release (Crittenden \& Koons-Witt, 2017). Correctional agencies may not be providing incarcerated men and incarcerated women the same access to programs focused on rebuilding and building relationships with family and children 
outside prison. The lack of access to tools that assist incarcerated parents may provide a glimpse into why incarcerated parents may be more likely to commit rule violations, when compared to non-parents (Casey-Acevedo, Bakken, \& Carle, 2004).

\section{Connection with Established Support Networks}

$\underline{\text { Visitation }}$

Prison visitations, which provide access to social support networks outside of prison walls, are building blocks for successful reintegration back into the community (Berg \& Huebner, 2011; Cobbina et al., 2012). Many scholars have argued that utilizing visitations may be a cost-effective rehabilitation tool, which creates a safer prison environment by decreasing the total number of rule violations and strengthening community relationships for incarcerated individuals (Blevins et al., 2010; Huebner, 2003; Phelps, 2011; Poehlman et al., 2010). Prisons throughout the country utilize visitations as a way for incarcerated individuals to maintain contact with their friends and family. Unfortunately, research continues to produce contradictory results as to whether

prison visits are helpful for incarcerated individuals (Beckmeyer \& Arditti, 2014; Bell \& Lindekugel, 2015; Blevins et al., 2010; Cochran, 2012; Foster, 2012; Huebner, 2003; Jiang \& Winfree, 2006; Liebling, 1999; Poehlman et al., 2010; Pollock, 2004; Siennick, Mears, \& Bales, 2013). Similarly, an overwhelming number of researchers argue that visitations are an important rehabilitative component for both men and women, and have the potential to reduce recidivism, while also aiding in adjustment to life behind prison walls (Arditti \& Few, 2008; Arditti \& Few, 2006; Barrick et al, 2014; Beckmeyer \& Arditti, 2014; Luke, 2002; McClure et al., 2015; Visher \& Travis, 2003). 
Researchers have examined prison visitations from a multitude of viewpoints: whether visitations can reduce recidivism (Bales and Mears, 2008; Barrick et al., 2014; Mears et al., 2012; Mitchell et al., 2016), whether visits can reduce the number of prison rule violations (Cochran, 2012; Hensely, Koscheski, \& Tewkdsbury, 2002; Jiang, FisherGiolando, \& Mo, 2005; Jiang \& Winfree, 2006; Lahm, 2008; Siennick et al., 2013), or even whether visitations are supportive for children (Arditti \& Few, 2008; Luke, 2002; Houck \& Loper, 2002; Monahan et al., 2011; Poehlmann, 2005; Poehlman et al., 2010; Tuerk \& Loper, 2006). Cochran (2012) found unique subgroups of incarcerated individuals who commit rule violations based upon how frequently they receive visits. Cochran (2012) suggested that individuals who receive visits that are more frequent are less likely to be in the "high misconduct" group, when compared with individuals who received no visits or infrequent visits.

Lindsey and colleagues (2017) examined the role visitations played in mediating the dynamics between how far the incarcerated individual was located from their homes and the frequency of rule violating behaviors. Many studies have found that incarcerated individuals feel more socially isolated knowing that they are housed in a facility far from their loved ones, and in turn commit more rule violations (Blevins, Listwan, Cullen, \& Jonson, 2010; Lindsey, Mears, Cochran, Bales, \& Stults, 2017; Mears, Cochran, Siennick, \& Bales, 2012). Social support theory also suggests that the lack of access to the support networks that provide resources and emotional support will increase rule violations (Cullen, 1994). Lindsey and colleagues (2017) found an interesting curvilinear relationship between the distance of the prison from support networks and the frequency 
of rule violations. The study results suggest that there is a positive relationship between distance and rule violations up to 350 miles. Incarcerated individuals who live more than 350 miles from their identified support networks show decreased rule violations. However, the researchers did find that visitations do mediate the relationship between distance from support networks and rule violations, but they also found that these outcomes were not as strong when the age of the incarcerated individual is considered (Lindsey et al., 2017). Younger incarcerated individuals may experience stronger adverse effects when placed in facilities further from their support networks, because visitations may become less frequent.

Correctional officers have demonstrated mixed reactions to facilitating prison visitations. Correctional officers sometimes view visitations as more trouble than they are worth and do not make the visitation environment comfortable for incarcerated individuals or their loved ones (Dixey \& Woodall, 2012). Researchers still do not know which type of visits work best, for whom, and at what point during an incarceration. Cochran (2014) argues that incarcerated individuals who are visited early on in their sentence are better able to adjust to prison life, and that incarcerated individuals who are visited consistently are the least likely to recidivate. These results suggest that facilitating visits between incarcerated individuals and their loved ones is a crucial rehabilitative tool that may assist in creating a safer environment for correctional officers and incarcerated men and women.

Research has also uncovered that the type of visitor influences the effects of the visit. Studies suggest that visits with friends (Bales \& Mears, 2008; Duwe \& Clark, 2013; 
Duwe \& Johnson, 2016; Mears et al., 2012), spouse/significant other (Bales \& Mears, 2008; Mears et al., 2012), clergy (Duwe \& Clark, 2013; Duwe \& Johnson, 2016), mentors (Duwe \& Clark, 2013; Duwe \& Johnson, 2016), and fathers (Bales \& Mears, 2008; Duwe \& Clark, 2013) significantly reduce overall recidivism. Duwe and Clark (2013) found that visits from mentors had the greatest recidivism reduction, while visits from ex-spouses increased recidivism. Interestingly, Liu, Pickett, \& Baker (2014) found that incarcerated individuals who received visits from more types of visitors and had a larger overall visitation frequency perceived that their social ties were still strong, during their incarceration. Visits with children, "other" family members, and larger numbers of different types of visitors" were associated with a higher likelihood of post release employment. Interestingly, many studies do not measure the impacts of visits with just the children, because caregivers typically accompany the children.

Regular visits between children and incarcerated parents assist in maintaining the child-parent relationships, and may be a way to mediate the negative impacts of parental incarceration (Ross, Khashu, \& Wamsley, 2004), while allowing the incarcerated parent to hold on to their identity as a parent (Hairston, 1988). Yet, many visiting rooms in prisons are very stark and uncomfortable for the visiting families, and traveling to isolated correctional facilities may be very expensive for the families, thereby limiting the frequency of visitations (Arditti, 2003; Arditti \& Few, 2006; Arditti, Lambert-Shute, \& Joest, 2003; Loper , Carlson, Levitt, \& Scheffel, 2009). Incarcerated parents, especially those who had lived with their children prior to incarceration, also identify that the caregivers of the children may not be comfortable with bringing the children into the 
prisons for regular visits (Lazzari, Miller, \& Lee, 2019; Martin, 2000). Social workers also express hesitation at bringing children to prisons, since the punitive atmosphere of a prison can be a "disturbing environment" (Kahl, 1998, p. 43). Moreover, Tuerk and Loper (2006) suggest that face-to-face visits can be stress inducing for the incarcerated parent, since they have no control over when or how frequently their children are able to visit. Conversely, Lee, Sansone, Swanson, and Tatum (2012) found that even for incarcerated fathers with life sentences, a positive relationship surfaced between the frequency of visits and positive views of the relationship with their children.

Research has shown that communication, of all types, between the incarcerated parent and their children has the ability to decrease some of the negative impacts of parental incarceration (Cunningham, 2001; Dallaire, Ciccone, \& Wilson, 2010; Hairston, 2002; Harris \& Pettway, 2007; Loper \& Tuerk, 2006; Monahan et al., 2011; Meek, 2007; Nickel, Garland, \& Kane, 2009; Poehlmann, Dallaire, Loper, \& Shear, 2010). Poehlmann and colleagues (2010) found that communication between incarcerated parents and their children potentially improves the children's development, increases the caregivers' mental health and/or physical health, and decreases incarcerated parents' levels of stress. Visher and Travis (2003) found that any type of communication between incarcerated parents and their children had positive outcomes. However, many incarcerated parents and the children's caregivers do not want the children exposed to the prison environment (Hairston, 2002), possibly due to media images of what prison is like, past negative experiences with prison visitations, or the complexities of the challenges in attempting to maintain relationships during periods of incarceration. Similarly, meeting with children 
during traditional visitations may increase incarcerated parents' stress, and in turn, increase the number of rule violations committed by incarcerated parents, particularly incarcerated mothers (Casey-Acevedo, Bakken, \& Karle, 2004). And yet, incarcerated mothers have a smoother transition into their prison environment when they visit with their children (Arditti \& Few, 2008; Arditti \& Few, 2006; Barrick et al, 2014; Beckmeyer \& Arditti, 2014; Luke, 2002; McClure et al., 2015; Visher \& Travis, 2003), but are less likely than incarcerated fathers to have visits with their children (Tasca, 2016). Further research is needed regarding the impact of parent-child visitations, since studies continue to present conflicting outcomes regarding the impact of parent-child visitations on prison adjustment (Houck \& Loper, 2002; Jiang et al., 2005; Jiang \& Winfree, 2006).

Interpreting the results of studies examining prison visitations is complicated. The results vary by the gender of the incarcerated individual, by who was visiting, by the type of visit, and by how close the visits were to the incarcerated individual's release from prison (Mitchell, Spooner, Jia, \& Zhang, 2016). While there have been significantly more studies examining the results of visitations for incarcerated men, the studies have not focused primarily on the experiences of incarcerated fathers with their children. A major challenge is the differences between fathers and the frequency of visits with their children, based upon whether they lived with/or spent time with their children prior to incarceration (Geller, 2013). Therefore, children may be lumped in with other family members, within a family visit variable (Barrick et al., 2014; Mears et al., 2012). We must also remember that not all incarcerated women are mothers and not all incarcerated men are fathers. However, while correctional agencies throughout the country do not 
have exact numbers, over 2.7 million children are impacted by parental incarceration in the U.S. (The PEW Charitable Trusts, 2010).

\section{$\underline{\text { Phone Calls }}$}

Along with visitations, phone calls have been identified as a necessary support for incarcerated individuals (Jiang, Fisher-Giorlando, \& Mo, 2005; Rocheleau, 2015). Phone calls have also shown to increase incarcerated parents' confidence in their parenting skills, when compared with face-to-face visits, since visits can be emotionally difficult for many reasons (Celinska \& Siegal, 2010; Poehlmann, Dallaire, Loper, \& Shear, 2010). Due to the challenges of visits and the costs associated with traveling long distances to a correctional facility, incarcerated parents may not have a monthly visit with their family, but they are more likely to have at least one phone call (Loper, Carlson, Levitt, \& Scheffel, 2009). As the number of phone calls increase, research has found that prison rule violations decrease (Jiang, Fisher-Giorlando, \& Mo, 2005; Jiang \& Winfree, 2006).

Phone calls can also be incredibly expensive and can cause financial hardships for social supports outside the prison walls (Bouchet, 2008; La Vigne, Davies, \& Brazzell, 2008). Wagner and Jones (2019) found that price of phone calls have a wide range, based upon the phone company who contracts with each prison. Phone calls from incarcerated individuals range from about \$3-\$22 for a fifteen-minute phone call (Wagner \& jones, 2019). At the same time, phone calls help incarcerated parents maintain positive relationships with their children, decrease parenting stress, and reduce prison rule violations for parents and non-parents (Jiang \& Winfree, 2006; Poehlmann, 2005; Tuerk \& Loper, 2006). Infrequent visits and phone calls are not sufficient to 
develop strong bonds between incarcerated individuals and their support networks (Gray, Mays, \& Stohr, 1995).

While some studies have shown negative consequences for visitations and phone calls, the majority have found that communication of any kind contributes to building support networks for incarcerated individuals. The challenge is for correctional agencies to find ways in which they are able to support these forms of community building. One solution is to integrate these various forms of communication into current rehabilitation programs offered within a specific prison. Similarly, prisons should provide opportunities for incarcerated individuals and their support networks to communicate in various ways, since this may be a cost-effective tool in reducing prison rule violations and recidivism (Barrick, Lattimore, \& Visher, 2014). Figuring out cost-effective ways to increase communication between incarcerated individuals and their support networks may be especially crucial for high-risk offenders who have been unable to build prosocial support networks before leaving the prison environment (Duwe \& Johnson, 2016).

Prison research is constantly faced with the challenge of attempting to disentangle the complexities surrounding prison life. Each prison is unique and offers a wide variety of programs. Unfortunately, this limits our ability to compare outcomes across studies. No two prisons are the same, and no two prisons offer the same programs. Caution must be utilized comparing outcomes since incarcerated individuals have varied experiences within the same state, let alone within different states. Similarly, if an incarcerated individual has substance abuse issues, they are more likely to need vocational training 
and employment, which is often not assessed, when deciding which individuals participate in which program (Chamberlain, 2012).

Correctional administrators are able to implement various programs, with the goal of decreasing rule violations and providing tools that incarcerated individuals need to continue building support networks (Martin \& Kaledis, 2010). Visitations help incarcerated individuals build/rebuild prosocial support networks, with the hopes that those networks will encourage change during their incarceration and subsequent release (Arditti \& Few, 2008; Barrick et al., 2014; Bowen \& Mowen, 2017; Cobbina et al., 2012; Duwe \& Clark, 2013; Liu et al., 2014; Mears, Cochran, Siennick, \& Bales, 2012; Meek \& Lewis, 2014). Other prison programs aid incarcerated individuals with learning how to build supportive relationships with peers and volunteers, while also addressing individual challenges (Celinska \& Sung, 2014; Dye, Aday, Farney, \& Raley, 2014; Gonzalez, Romero, \& Cerbana, 2007; Lahm, 2009a; Martos-Garciá et al., 2009; Meek \& Lewis, 2014). For the five-percent who will not be released from prison, building support networks, both inside and outside of prison, may help ease the pain of their lifelong incarceration (Clear \& Sumter, 2008; Dye et al., 2014). The experiences of those with life sentences is an area of study that has received limited attention, due to the fact that many studies are focused on how to reduce recidivism (Kazemian \& Travis, 2015).

\section{Socio-demographics}

Age

Many studies have found that as incarcerated individuals age, they commit fewer rule violations (Blackburn \& Trulson, 2010; Bonner, Rodriguez, \& Sorensen, 2017; 
Camp, Gaes, Langan, \& Saylor, 2003; Celinska \& Sung, 2014; Cunningham \& Sorensen, 2007; DeLisi et al., 2010; Gaes, Wallace, Gilman, Klein-Saffran, \& Suppa, 2002; Griffin \& Hepburn, 2006; Harer \& Langan, 2001; Jiang \& Winfree, 2009; Kuanliang, Sorensen, \& Cunningham, 2008; Rocheleau, 2013; Steiner, Butler, \& Ellison, 2014; Steiner \& Wooldredge, 2009; Walters \& Crawford, 2013; Valentine, Mears, \& Bales, 2015; Wooldredge, Griffin, \& Pratt, 2001). As incarcerated individuals age and learn to cope with their prison environment, they become more likely to utilize tools that enable them to deal with their stressors in a way that aligns with prison rules (Leban, Cardwell, Copes, \& Brezina, 2016).

Race

Communities of color are significantly overrepresented within U.S. prison populations (Alexander, 2010; Bureau of Justice statistics, 2015; Carson, 2014; Ocen, 2013; PPI, 2019; Rampey et al., 2016). This is especially true for African Americans who account for $13 \%$ of the United States population, yet account for $40 \%$ of the United States prison population (PPI, 2019). These stark inequalities point to sociocultural and political implications that must be considered when attempting to understand the influence of race/ethnicity on the frequency of rule violations (Bell, 2017). Research has yet to uncover consistent findings regarding how race influences the frequency of prison rule violations (Griffin, Lee, Vito, \& Walker, 2017). Studies have found that race is a predictor of prison rule violations (Bell \& Lindekugel, 2015; Benning \& Lahm, 2016 ; DeLisi, 2003; Celinska \& Sung, 2014; Jiang, 2006; Jiang \& Winfree, 2009; Lahm, 2016; Morris \& Worrall, 2010; Rocheleau, 2014; Schenk \& Fremouw, 2012; Steiner \& 
Wooldredge, 2009). Other studies suggest that the personal feelings of individual correctional officers may also affect which incarcerated individuals are given formal rule violations versus informal consequences (Bell, 2017). Similarly, the prison environment and the racial makeup of the prison may also influence whether a White or black incarcerated individual is more likely to behave in a way that results in a rule violation (Griffin, Lee, Vito, \& Walker, 2017).

While the literature continues to produce mixed outcomes, a large body of work continues to suggest that in general, people of color are more likely to commit more frequent rule violations (Benning \& Lahm, 2016; Bonner, Rodriguez, \& Sorensen, 2017; Celinska \& Sung, 2014; Jiang \& Winfree, 2006; Jiang \& Winfree, 2009; Reidy, Cihan, \& Sorensen, 2017; Steiner \& Wooldredge, 2009). However, the research is mixed and some studies suggest that the gender of the non-White incarcerated individual makes a difference. Some studies argue that individuals who are male and a person of color are more likely to commit more frequent rule violations (Bonner, Rodriguez, \& Sorensen, 2017; Celinska \& Sung, 2014), while others suggest individuals who are female and a person of color commit more rule violations when taking other predictors into consideration (Benning \& Lahm, 2016; Bonner, Rodriguez, \& Sorensen, 2017).

More specifically, studies have shown that Hispanic males commit more rule violations (Bell \& Lindekugel, 2015; Celinska \& Sung, 2014); while other studies suggest Hispanic males are less likely to commit rule violations (Rocheleau, 2014). Bonner, Rodriguez, and Sorensen (2017) found that Hispanic males commit fewer rule violations than Black males, but that Hispanic males commit more rule violations than 
White males. However, they found that when other controls are accounted for (i.e., gender, age, educational attainment, prior prison terms, sentence length, time served, and crime of conviction), Blacks still committed the most rule violations, but Hispanics committed fewer rule violations than Whites. Research needs to continue examining how broader social policies are influencing the prison experiences of people of color, particularly black incarcerated individuals. Researchers have argued that the traditional theories of crime are limited by over generalizations of why people commit crime. More attention should be paid to why blacks specifically are not insulated by things like educational attainment, age, prior prison terms, etc. (Bonner, Rodriguez, \& Sorensen, 2017).

Sex

While consensus has not been reached regarding whether males or females commit more prison rule violations, studies indicate that an individual's sex influences the amount and type of rule violations (Celinska \& Sung, 2014; Cunningham, Sorensen, Vigen, \& Woods, 2011; Taylor, Lee, \& Taxman, 2019). Newer studies have found that incarcerated women commit more rule violations than men (Bonner, Rodriguez, \& Sorensen, 2017; Taylor, Lee, \& Taxman, 2019). Other studies have found no difference in the rule violations committed by male or female incarcerated individuals (Bell \& Lindekugel, 2015; Camp et al., 2003; Steiner \& Wooldredge, 2014). Steiner and Ellison (2014), when reviewing the extant literature, found one quarter of the studies indicated women committed more, one quarter showed women were less likely, and half of the studies produced non-significant results. A recent study by Reidy, Cihan, \& Sorrensen 
(2017) suggests that the patterns of rule violations committed by men and women is similar. They found that the majority of incarcerated women are more likely to commit more rule violations as young, newly incarcerated individuals, but that overtime the frequency of rule violations decreases. A small proportion of incarcerated individuals are responsible for the majority of continued violent rule violations, while most incarcerated individuals commit very few rule violations (De Lisi, 2016; Reidy, Cihan, \& Sorensen, 2017; Reidy \& Sorensen, 2017). What future studies need to continue unraveling is whether incarcerated men and women adjust successfully to prison life for different reasons (Reidy, Cihan, \& Sorensen, 2017; Salisbury et al., 2009; Steiner \& Wooldredge, 2009; Warren et al., 2002; Wright et al., 2007).

There is a push to examine the intersection of race/ethnicity and sex. Bell (2017) found that non-White females are more likely to commit violent rule violations when compared to White females. Bell (2017) also suggested that non-White women commit violent rule violations at a disproportionate rate, suggesting that future research should investigate the combined roles of race and sex when examining frequency and type of rule violations. Bonner, Rodrigues, and Sorensen (2017) produced contradictory outcomes. They propose that all females, regardless of race/ethnicity, committed more rule violations than their male counterparts.

\section{Marital Status}

Literature surrounding the needs of incarcerated women, in particular, has focused on gender-responsivity (Salisbury \& Van Voorhis, 2007; Salisbury \& Van Voorhis, 2009; Salisbury, Van Voorhis, \& Spiropoulos, 2009; Wright \& Salisbury, 2007). Gender- 
responsivity research suggests there are different needs, regarding relationships, for incarcerated males and females, and that these specific gendered considerations influence how well incarcerated men and women are able to adjust to prison life. While relationships are crucial for both incarcerated men and women, they are impacted by these relationships in unique ways. Similarly, relationships inside prison, with correctional officers, staff, and other incarcerated individuals, may also prove to be important for incarcerated men, but even more so for incarcerated women (Wright \& Salisbury, 2007). For example, Jiang and Winfree (2006) found that being married only reduced prison rule violations for men and that married women committed more rule violations.

Wright and Salisbury, (2007) looked at gender specific reasons behind incarcerated women's rule violations. They found that incarcerated women, who had non-supportive relationships at the time of their entrance into prison, had fewer rule violations than women who entered prison with supportive relationships. This suggests that prison gave women with stressful relationships, a break from the conflict, while women who had been in supportive relationships were feeling the loss of support due to incarceration. Incarcerated men, on the other hand, appear to have reduced violations when they maintain a married status (Bales \& Mears, 2008; Celinska \& Sung, 2014). Other studies suggest that both incarcerated men and women are protected by being married (Celinska \& Sung, 2014; Rocheleau, 2014; Siennick, Bales, \& Mears, 2013). 


\section{Educational Attainment}

Incarcerated men and women are less likely to engage in behaviors that result in official rule violations when they enter prison with higher levels of education (Berg \& De Lisi, 2006; Lahm, 2017; Schenk \& Fremouw, 2012). Research has shown that individuals who have less than at least a GED are more likely to commit rule violations (Steiner et al., 2014). These findings may be a result of someone being more likely to subscribe to conventional behavioral norms, when they have more education (Lahm, 2017; Steiner \& Wooldredge, 2009).

\section{Parental Status}

Parenting behind prison walls is complicated. Oftentimes incarcerated mothers were the primary caregivers of the children and continue to parent from behind prison walls, while the incarcerated fathers were generally not the primary caregivers of their children (Celinska \& Siegal, 2010; Glaze \& Maruschak, 2009; Hoffman, Byrd, \& Kightlinger, 2010; Mumola, 2000). Previous studies have examined whether various types of visitations, communication, and program participation assist incarcerated parents in adjusting to prison life by committing fewer rule violations. The results are mixed and vary based upon whether the study was examining incarcerated moms or incarcerated dads. While the experiences of members of incarcerated populations has historically been normed on the experiences of male prison populations, the experiences of incarcerated parents has been more frequently examined by understanding the experiences of incarcerated women (Pierce, 2015). 
Jiang and Winfree (2006) found that incarcerated fathers and mothers committed rule violations at the same rate. Alternatively, Wright and Salisbury (2007) found that parental stress predicted rule violations, but only up to 6 months into a prison sentence, suggesting that parental stress decreases over time. Others argue that as the incarcerated parents spend more time away from their children, their rates of rules violations increase (Thompson \& Loper, 2005). As incarcerated parents spend more time separated from their families, their anger over the separation may cause them to act out. Incarcerated mothers, in particular, may especially rely on support from their friends and families, during periods of incarceration (Jiang \& Winfree, 2006; Celinska \& Sung, 2014), since they are more likely than incarcerated men to be parents (Glaze \& Maruschak, 2010)

\section{Dependent Variable}

\section{Rule Violations}

In an effort to maintain order within prisons, there are rules of conduct that incarcerated individuals are required to follow. When they successfully adjust to prison life and accept the rules of conduct, the safety of a prison increases (Gendreau et al., 1997; Meade \& Steiner, 2013; Steiner \& Meade, 2016). Research has uncovered opposing outcomes regarding which incarcerated individuals and which programs assist with success prison adjustment. Conflicting outcomes may result from how research studies operationalize rule violations (Griffin et al., 2017), since each State creates a unique system of rule violations.

Studies have found that older, married men are less likely to commit rule violations (Celinska \& Sung, 2014; Rocheleau, 2014; Steiner \& Wooldredge, 2014), 
while incarcerated married women are more likely to commit rule violations (Jiang, 2005; Jiang \& Winfree, 2006; Wright, Salisbury, and Van Voorhis, 2009). Similar to outcomes for incarcerated males, studies have found that younger females have a more difficult time adjusting to prison life and commit more rule violations (Cunningham, Reidy, \& Sorensen, 2016; O'Keefe \& Schnell, 2007; Reidy, Cihan, \& Sorenson, 2017; Steiner et al., 2014). Research suggests that incarcerated women are less violent than incarcerated men and that incarcerated women tend to adjust more successfully to prison life (Craddock, 1996; Harer \& Langan, 2001; Jiang \& Winfree, 2006; Warren et al., 2004). Studies have also suggested that there are different reasons why incarcerated men and women engage in behaviors that lead to official rule violations. Incarcerated women tend to be plagued by historical "triple threat" traumas including substance abuse, physical and sexual abuse, and mental health disorders (Bloom \& Covington, 2009; Dalley \& Michels, 2009; DeHart, 2008; Reidy, Cihan, \& Sorenson, 2017; Salisbury \& Van Voorhis, 2009; Van Voorhis, Wright, Salisbury, \& Bauman, 2010; Wright, Van Voorhis, Salisbury, \& Bauman, 2012). Programming needs of incarcerated men and incarcerated women will vary, due to the unique and complex histories that incarcerated women tend to share. However, both incarcerated men and women, who are involved in a multitude of prison programs, are more likely to adjust more successfully to their prison environment (Lahm, 2009a; Martos-Garciá et al., 2009; Meek \& Lewis, 2014; Rocheleau, 2014). In addition, incarcerated women with longer sentences, who have previously spent time in prison, comply more readily to prison rules than incarcerated men with longer 
sentences who had previously served time (Gover et al., 2008). Yet Reidy, Cihan, and Sorenson (2017) found that sentence length was not associated with rule violations.

Many studies have also examined the association between race/ethnicity and the frequency and type of rule violations committed (Celinska \& Sung, 2014; Harer \& Steffensmeier, 1996; Jiang, 2005; Jiang \& Winfree, 2006; Morris \& Worrall, 2010; Rocheleau, 2014; Steiner \& Wooldredge, 2009; Griffin et al., 2017). Researchers have argued that black incarcerated individuals commit more rule violations (Celinska \& Sung, 2014; Jiang, 2005; Jiang et al., 2005; Jiang \& Winfree, 2006; Steiner \& Wooldredge, 2009). Other studies have found that blacks commit fewer rule violations (Berg \& DeLisi, 2006; Day et al., 2015). Similarly, studies have also uncovered discrepancies with the frequency of rule violations committed by Hispanic individuals. Studies have found that Hispanic incarcerated individuals commit more rule violations (Bell \& Lindekugel, 2015; Berg \& DeLisi, 2006; Celinska \& Sung, 2014), while Rocheleau (2014) found that Hispanics are actually the least likely to commit rule violations. People of color may experience the most difficulty adjusting to prison life. Some caution is needed when interpreting these findings, since reviews of the literature also suggest that many studies have produced non-significant results related to race/ethnicity and the frequency of rule violations (Steiner et al., 2014). Prisons are microcosms of the larger society, which may reflect racial prejudices within a city, or even the larger state. Griffin and colleagues (2017) suggest that there are nuances to why certain individuals commit rule violations. Criminal behaviors exhibited during incarceration may also reflect the criminal subculture of an individual, and thereby, reflect the criminal behaviors exhibited 
prior to incarceration (Irwin \& Cressey, 1962). There is a need for future research to tease apart the circumstances driving why individuals engage in rule violating behaviors. Race/ethnicity is not the only factor associated with rule violations, and research needs to continue teasing apart the associated contextual and situational factors.

Understanding which individuals are more likely to commit rule violations is complicated. As criminologists have identified the need to assess the unique correctional rehabilitation needs of incarcerated females versus incarcerated males (Salisbury \& Van Voorhis, 2009; Steffensmeier \& Allan, 1996; Van Voorhis, Wright, Salisbury, \& Bauman, 2010), studies have found limited variations between male and female prison rule violations (Reidy, Cihan, \& Sorenson, 2017; Steiner \& Wooldredge, 2014). One major difference is that the majority of women were the primary caregivers of their underage children prior to their incarceration (Glaze \& Maruschak, 2010). The importance of these relationships and the maintenance of their motherly roles are crucial for these women.

As incarcerated individuals become more isolated from their support networks, their ability to adjust to prison life decreases (Adams, 1992; Liebling, 1999; Monahan, Goldweber, \& Cauffman, 2011; Tasca, Griffin, \& Rodriguez, 2010), and the likelihood of engaging in anti-social behaviors increases (Bell \& Lindekugel, 2015; Berk, Kriegler, \& Back, 2006; Celinska \& Sung, 2014; Jiang, 2005; Jiang \& Winfree, 2006; Morris \& Worrall, 2010; Tewksbury et al., 2014). While behaviors that lead to rule violations are similar throughout the United States, each state classifies various rule violations according to its own system. These violations range from gambling and giving prison 
employees false information to sexual assault or assault on staff. Studies have attempted to tease apart which types of prison programming help reduce overall rule violations. Research suggests that younger males (Celinska \& Sung, 2014; Jiang, Fisher-Giorlando, \& Mo, 2005; Jiang \& Winfree, 2006; Steiner \& Wooldredge, 2009; Toman, Cochran, Cochran, \& Bales, 2015) who are single (Jiang, 2005; Jiang et al., 2005; Jiang \& Winfree, 2006; Rocheleau, 2014), have low educational attainment (Bell \& Lindekugel, 2015; Celinska \& Sung, 2014), and have shorter sentences (Griffin, Lee, Vito, \& Walker, 2017; Toman et al., 2015) are more likely to commit rule violations. However, Steiner, Butler, and Ellison (2014), who reviewed the extant literature, found that one quarter of the studies suggest that women commit more rule violations, while $50 \%$ of the studies produced non-significant results. A more comprehensive understanding of which correctional programs and visitations are best able to assist incarcerated men and women successfully adapt to prison life and commit fewer rule violations, is still needed.

Each state has the ability to map out specific rule violations and the resulting consequences. Within ODOC, for example, there are specific rule violations that can result in a major or minor rule violation. If the rule violation is so minor that it does not constitute a major or minor rule violation, a correctional officer can assign a conduct order, which can remove any privileges for no longer than 72 hours [Oregon Secretary of State (OSOS), n.d.]. There are four categories of major rule violations and two categories of minor rule violations.

California Department of Corrections and Rehabilitation (CDCR), on the other hand, has a slightly different format to rule violations. There are seven divisions of rule 
violations with corresponding consequences. Similar to ODOC, there is a range of resulting consequences that may follow the hearing. This presents major challenges when attempting to compare across states since different language and different ranges of consequences are linked to different types of rule violations. See Table 3 for a side-byside comparison of ODOC and CDCR.

There are limitations to utilizing rule violations as an outcome variable. How minor rule violations are enforced varies from each prison and each correctional officer (Light, 1990; Poole \& Regoli, 1980). Major violations are handled similarly, but where one officer may write up an individual for minor behaviors, another officer may decide that the behavior does not warrant the same consequences. Similarly, based upon the risk level of the incarcerated individual, placement will be in a facility best able to handle their behaviors (Steiner \& Meade, 2016). Incarcerated individuals, who are classified as higher risk, will be placed in higher security facilities that more closely monitor behaviors (Berk et al., 2006; Steiner et al., 2014; Steiner \& Meade, 2016). Another major limitation is which individuals are included as participants. In many studies, the participating individuals have an average of less than one rule violation (Colvin, 2014; Jiang, Fisher-Giorlando, 2005; Steiner \& Meade, 2016; Steiner \& Wooldredge, 2014; Van Voorhis, 1994).

The creation of a rehabilitative environment requires that correctional officers remain somewhat flexible, while also utilizing their own discretion, which often contradicts the paramilitary structure of most correctional agencies (Cullen, Link, Wolfe, \& Frank, 1985). Correctional officers may focus on warehousing the growing prison 
population, and not necessarily on rehabilitative efforts (Feeley \& Simon, 1992). Research needs to more fully understand how correctional officer discretion and correctional rehabilitation philosophies of specific prisons impact research, which utilizes the frequency of rule violations as an outcome variable. There are limited options when attempting to assess prosocial behaviors within the prison system. All prisons are monitoring behaviors, but how those behaviors are monitored varies within each prison. How behaviors are monitored will also vary based upon the security level of the institution. Prisons with higher security levels will be scrutinizing behaviors much more closely than a minimum security releasing facility, where individuals are given more privileges. While the overarching goal of prisons is public safety, prisons should also offer opportunities that assist incarcerated individuals in their efforts to make positive long-term changes (Byrne, Hummer, \& Stowell, 2008; Rocheleau, 2014). Providing programs that give more incarcerated individuals the tools to begin making positive and long-term changes requires creative usage of available resources within specific prisons, while also maintaining control over the population.

Prison management is complex, and requires correctional officers to assess the philosophies, behaviors, and political ideologies of the prison population, staff, and volunteers (Dilulio 1991; Morris, Carriaga, Diamond, Piquero, \& Piquero, 2012). Similarly, the prison environment and how correctional officers utilize official rule violations directly influences behaviors of the prison population (Camp, Gaes, Langan, \& Saylor, 2003). Correctional officers with longer tenure and officers who identify as people of color have been identified as better able to resolve conflicts without resulting in 
an official rule violation (Britton, 1997; Hepburn, 1985; Jacobs \& Kraft, 1978;

Lombardo, 1981). The use of official rule violations provides a guide for approved behaviors, which should aide incarcerated individuals as they adjust to their prison environment (Sykes, 1958).

The rule violation system is long and arduous and may not provide the immediate feedback individuals need to make behavioral changes (Viglione, Lerch, Rudes, \& Taxman, 2017). Correctional officers may choose not to utilize official rule violations because individuals are then given a hearing (which may not occur immediately) where they have the ability to defend their behaviors, which may or may not be followed by official disciplinary actions (Viglione et al., 2017). Similarly, correctional officers may be unaware of certain rule violations that occur, or the correctional officers or administration may choose not to record certain low-level rule violations (Daggett \& Camp, 2009; Wolf, Blitz, Shi, Siegel, \& Bachman, 2007). Correctional officers are given immense discretion in when and how to use the official rule violations, and when to apply formal versus informal consequences, since the goal is also to assist incarcerated individuals in their abilities to choose better behaviors.

\section{Control Variable}

\section{Time Already Served}

Individuals with sentence lengths longer than three years are more likely to commit increased rule violations (Berk, Kriegler, \& Back, 2006; Celinska \& Sung, 2014). Steiner and Wooldrege (2009) suggest that rather than using sentence length, a more accurate way to capture differences is to look at how much time an individual has already 
spent on their current prison sentence. Utilizing time served as a control measure helps to balance out the fact that as sentence length increases, so do the opportunities to commit rule violations.

Casey-Acevedo and Bakken (2001) divided incarcerated females into two groups: short term and long term. The short-term group had served less than 18 months. The long-term group had been incarcerated longer than 18 months. They found that the shortterm group committed more rule violations than the long-term group, who showed a pattern of decline as their time served increased. However, when examining violent rule violations, the long-term group was responsible for committing more of these types of rule violations. Interestingly, they also found that the average yearly rate of rule violations was significantly lower than the yearly average of the long-term group (CaseyAcevedo \& Bakken, 2001).

\section{CONCEPTUAL FRAMEWORK SOCIAL SUPPORT THEORY}

\section{Theory Overview}

Durkheim (1897) suggested that the weakening of social ties and movement away from social norms and collective consciousness causes the destruction of our moral guidance, which creates stress. The individual loses any social restraint, and acts in a way that serves his/her own self-interest, without thought of others. Durkheim blamed the modernization of society for the weakening of social ties. Scholars, however, moved away from the idea that modernization of our society is what causes the weakening of ties. Instead, they began to argue that the absence of these crucial social ties is what cause 
the individual to lose his/her identity and confusion around social norms (Vaux, 1988). Bowlby (1969) argued that the early social bonds, usually created within the first year of life, are what establish important attachment behaviors. These early attachments with the caregiver, primarily the mother, are not automatic and may be dependent upon social supports available to the mother (Ainsworth, 1979; Crockenberg, 1981; Vaux, 1988).

These theories, related to social bonds and attachments, allowed for scholars to begin focusing on what these social supports were, and how having more social supports might be viewed as a positive tool for people. As social support theory began to take shape from the early bond and attachment theories, three scholars stood out as the theory moved beyond the idea of early attachments. Cassel $(1974 ; 1976)$ argued that social supports influence the presence of stress-related diseases. Stressful environmental conditions caused the dissolution of social supports, which made individuals that much more susceptible to illnesses (Vaux, 1988). He also argued that while there was a definite need to reduce stressful environmental factors, a more appropriate intervention would have included increasing social supports.

Caplan (1974) agreed that as support systems increase, mental health becomes more stable as a result of these social supports. Caplan, however, did not suggest that support systems were limited to biological family, but that the aggregate support system could include friends, neighbors, other church members, clergy, and other community groups (Vaux, 1988). Caplan (1974) did suggest that support systems are helpful in the following ways: they increase resources that assist when dealing with emotional/psychological stressors, they assist in sharing the responsibilities related to 
demanding situations, and they provide specific resources (money and skills) that assist with stressful situations. These supports provide the necessary tools to deal with everyday stressors, specific crises, and major life transitions (Vaux, 1988).

Cobb (1976) pursued Caplan's approach to understanding social supports, but concretely articulated a specific definition for social support. He suggested, during his Presidential Address for the American Psychosomatic Society, that social supports are pieces of information that lead an individual to believe that he/she is: (1) "cared for and loved," (2) “esteemed and valued," and (3) a part of a "network of communication and mutual obligation" (Cobb, 1976, p. 300). The first type of information is the emotional support that comes from a loving two-way relationship, where both people feel they can trust the other in the relationship. The second type of information is gained as a person gains confidence as others compliment the individual in public arenas. Finally, the last type of information is a result of shared knowledge by group members of an identified network. At birth, Cobb (1976) argues that individuals receive their initial supports from loved ones. As people age and venture out into the world, they gain more supports from school, work, our community, etc. Then, as people prepare for the end of life phase, social support tends to come from immediate family, as was experienced during infancy.

Historically, social support theory has not been utilized to explain why certain incarcerated individuals are better able to adjust to their prison environment. Control theories have dominated the literature on criminal behaviors and crime and have focused on social control methods (Colvin \& Pauly, 1983; Gottfredson \& Hirschi, 1990; Gagan, 1989; Sampson \& Laub, 1993), rather than what is considered a more humane approach 
to why crime occurs (Cullen, Wright, \& Chamlin, 1999). Cullen, Wright, \& Chamlin (1999) argue that control theories have focused on policies whose response to crime involves imposing negative consequences rather than imposing a supportive action for a person. More recently, scholars have drawn upon the deprivation and importation models to explain prison adjustment (Ellis, Grasmick, \& Gillan, 1974; Gover, Perez, \& Jennings, 2008; Jiang et al., 2005; Tasca et al., 2010; Thomas \& Foster, 1973). These models continue to be utilized as a way to create a better understanding of why certain individuals commit more rule violations (Griffin, Lee, Vito, \& Walker, 2017; Kigerl \& Hamilton, 2016). The deprivation model suggests that the prison environment is what most strongly influences an individual's ability to adjust to prison life, while the importation model suggests that the characteristics and experiences prior to prison will influence his/her prison adjustment. Researchers are slowly turning towards another way to explain prison adjustment, since no single model fully explains why certain individuals are more likely to more successfully adjust to prison life (Griffin et al., 2017; Reidy, Cihan, \& Sorenson, 2017; Steiner et al., 2014).

Researchers have continued to explore the role of social supports during stressful transitions and major life experiences. Cullen (1994) defines a social support paradigm that suggests that as social supports increase, criminal behaviors are less likely to occur (See Table 2 for Cullen's propositions, Appendix C p.145). This version of social support theory assumes that supportive relationships are a natural part of positive human development (Colvin et al., 2002; Cullen, Wright, \& Chamlin, 1999). Cullen's (1994) articulation of a social support theory for crime appears to follow Cobb's (1976) 
articulation, which asserts that social support comes from information that is perceived by the individual. The more an incarcerated individual perceives that they are supported, loved, valued, and a part of a larger network, the less likely they are to engage in criminal behaviors.

\section{Instrumental and Expressive Supports}

Cullen suggests that social support includes both instrumental and expressive social supports (Colvin et al., 2002; Cullen, 1994). Instrumental social supports are having people/support networks that can be relied upon to assist with finding employment, housing, financial resources, etc. For incarcerated individuals, this may mean having other incarcerated individuals who may be able to recommend them for a good prison job or outside supports who are able to provide money on their accounts for food or personal hygiene items at the canteen. Expressive social supports include people with whom the incarcerated individual is able to express and process his/her emotions. For incarcerated individuals, an example would be participating in some form of inmate led support group, where individuals are able to process their experiences with visitations, addictions, separation from families, etc. Applying social support theory to the prison environment seems to follow, since rule violations are forms of "criminal behavior" behind prison walls. Social support theory suggests that when an incarcerated individual is supported by their support networks (both inside and outside of the prison environment), the individual will choose to engage in more prosocial behaviors (Cullen, 1994), and may be more likely to cooperate with correctional officers and prison rules (Jiang et al., 2005). Studies have begun providing support for this theory, and suggest that 
incarcerated individuals with more social supports commit fewer rule violations (Berg \& Delisi, 2006; DeLisi, Berg, \& Hochstetler, 2004; Jiang et al., 2005).

\section{Applicability of Social Support Theory to the Incarcerated Population}

The idea that social supports have the ability to support change is describing a change process that an individual experiences (Cid \& Martí, 2017). The creation of strong social supports during incarceration can assist individuals in adjusting more successfully to prison life, and may provide the necessary supports for individuals releasing back into society. Social supports may have the ability to change the criminal behaviors that have become a part of an individual's identity (Cullen, 1994). As individuals become more confident and comfortable with their supports, they are able to turn towards their prosocial supports, rather than criminal behaviors. Cid and Martí (2017) found that even when individuals have difficulties finding work, maintaining relationships, or assuming other important adult-roles, the presence of pro-social supports allow people to maintain pro-social behaviors upon release from prison.

Social support research has suggested that the loss of identified support networks, even without the presence of strong bonds, is one of the hardest losses for incarcerated men and women (Adams, 1992; Cochran, 2014; La Vigne, Naser, Brooks, \& Castro, 2005; Liebling, 1999; Monahan et al., 2011; Tasca et al., 2010). Research has found that even if an incarcerated person perceives a visitor as supportive, there are positive outcomes (Meyers et al., 2017). Bonds are built through visitations and involvement in programs, which strengthens the sense of maintaining social supports through consistent involvement with social supports (Cullen, 1994). These supports have the ability to assist 
incarcerated individuals in adjusting to their prison environment, and decreasing rule violations through the strengthening of their self-control (Cochran, 2014; Cullen et al., 1999; Meyers et al., 2017). Alternatively, inconsistent connection with social supports has the ability to decrease self-control, which may in turn increase rule violations (Colvin et al., 2002; Cullen, 1994). Therefore, consistent visitations and program participation appear to be important for prosocial behaviors and interactions (Colvin et al., 2002).

Social supports appear to have an additive effect; incarcerated individuals who receive visits are also more likely to participate in prison programs (Rose, 2004). However, prisons may have rules stating that in order to participate in specific event visits or specific programs, an incarcerated individual must maintain clear conduct. Similarly, the closeness of the relationship between the incarcerated individual and the visitor may affect whether the visit provides a positive outcome, such as reduced rule violations (Meyers et al., 2017). Certain subgroups of incarcerated individuals may have more access to their outside social supports, as well as social supports within the prison.

Incarcerated women tend to have more social supports than incarcerated men (Jiang \& Winfree, 2006). Women are typically more relationship orientated, and male prisons are steeped in power dynamics and coercion (Jiang \& Wifnree, 2006). Therefore, incarcerated women may be more likely to have the ability and space to strengthen and build upon their expressive social supports (Jiang \& Winfree, 2006; Zingraff, 1980). The extant literature continues to provide evidence that incarcerated men and women have unique needs based upon their gender and the variations in their prison environments (Salisbury \& Van Voorhis, 2009; Steffensmeier \& Allan, 1996; Van Voorhis, Wright, 
Salisbury, \& Bauman, 2010). These dynamics need to be explored in order to continue assisting incarcerated individuals as they build and strengthen their support networks, which may assist in creating a safer prison environment.

In Cullen's (1994) articulation of social support theory, he does not describe whether instrumental or expressive social supports play a larger role in individuals choosing to engage in more prosocial behaviors. Similarly, there is not a "dosage" or amount of instrumental or expressive social supports that creates the threshold of how many social supports or what amount of social supports is enough. Also missing is how to incorporate certain types of supports as either instrumental or expressive. Cullen suggests that instrumental social supports are skills and tools that assist individuals navigate normal society, while expressive social supports are emotional connections and a give and take that occurs between people in positive relationships. Therefore, the current study will differentiate between programs that provide a sort of education or tools to navigate society as they release as instrumental social supports, and expressive social supports will be programs that allow for a give and take between incarcerated individuals and their peers or a give and take between incarcerated individuals and their loved ones.

As individuals work to adjust to the new routines of prison life, rehabilitation occurs when the environment is one that allows for personal growth and development (Harding, 2014). Incarcerated individuals must feel safe enough in order to allow themselves to be vulnerable, and allow change to occur. Rocheleau (2015) found that incarcerated individuals who are able to rely upon their instrumental and expressive social supports are less likely to engage in violent behaviors. Researchers have found that 
prison itself creates better criminals (Nagin, Cullen, \& Johnson, 2005). Harding (2014) argues that if community social service agencies provide environments that are safe and allow for growth, then correctional agencies should be held to similar standards. There should be a challenge to create prison environments that are rehabilitative and provide opportunities to engage with social networks both inside and outside of prison.

\section{Study Hypotheses}

The aim of the study is to assess whether various types of social supports affect the frequency of prison rule violations. Specifically, are social supports, both inside and outside of prison able to decrease the total number of rule violations committed by incarcerated individuals. In order to assess how well social support theory explains decreased rule violations, instrumental and expressive social supports will be assessed individually and as a combined total of social supports. Finally, the study will assess whether a person's sex or race/ethnicity moderates the association between total social supports and total rule violations, when controlling for time already served. The proposed hypotheses are as follows:

Hypothesis 1. Individual demographics will have significant effects on total rule violations. The following effects will be found:

1a. Females will have fewer rule violations than males.

1b. Older individuals will have fewer rule violations than younger incarcerated individuals.

1c. White individuals will have fewer rule violations than individuals of color.

1d. Individuals who have graduated from high school, GED, or higher degree will have fewer rule violations than those with less than a high school diploma or GED. 
1e. Incarcerated individuals who are married will have fewer rule violations than those not married.

1f. Incarcerated parents will have fewer rule violations than incarcerated individuals who are not parents.

1g. Individuals with longer periods of time already served will have more rule violations than individuals with less time served.

Hypothesis 2. Various types of instrumental social supports will decrease total rule violations. The following effects will be found (See Table 1/Appendix A.p. 143 for a full list of included programs):

2a. Participation in drug and alcohol programs will decrease total rule violations.

2b. Participation in job/vocational related programs will decrease total rule violations.

2c. Participation in education programs will decrease total rule violations.

Hypothesis 3. Various types of expressive social supports will decrease the total rule violations. The following effects will be found (See Table 1/Appendix A. p. 143 for a full list of included programs):

3a. Participation in religious programs will decrease total rule violations.

3b. Participation in support programs will decrease rule violations.

3c. Connection with established support networks will decrease rule violations

Hypothesis 4. Individuals who are engaged with more instrumental social supports will have committed fewer rule violations.

Hypothesis 5. Individuals who are engaged with more expressive social supports will have committed fewer rule violations.

Hypothesis 6. Individuals who are engaged with more instrumental and expressive social supports will have committed fewer rule violations.

Hypothesis 7. When controlling for time already served, women, who are engaged with more social supports, will have committed fewer rule violations. 
Hypothesis 8. When controlling for time already served, Whites, who are engaged with more social supports, will have committed fewer rule violations. 


\section{CHAPTER III METHODOLOGY}

This chapter describes the research design and data, which used the 2004 Survey

of Inmates in State and Federal Facilities (Bureau of Justice Statistics, 2007). The original study is discussed, including a description of the original data collection. The processes taken to assure protection of the human participants is also explained. Following obtainment of study approval, detailed descriptions of independent variables, demographic variables, the dependent variable, and the control variable are presented. Finally, the analysis plan for the current study is outlined.

\section{Research Design}

The current study was a secondary data analysis of the 2004 Survey of Inmates in State and Federal Correctional Facilities (Bureau of Justice Statistics, 2007). The crosssectional data were initially collected through a two stage sampling procedure. The specific prisons were chosen during Stage 1, which was followed by the participant selection, during Stage 2. Computer assisted telephone interviews were conducted from October 2003 through May 2004. The response rate for Federal and State prison inmates were $89.1 \%$ and $84.6 \%$ respectively. The primary purpose of the study was to create a better understanding of incarcerated populations throughout the United States, as well as being able to understand these dynamics over time. The data is not collected yearly. The data was collected in 1974, 1979, 1986, 1991, 1997, 2004, and 2016. The 2016 data is not widely available, as of yet, and was not available for analysis at the Inter-university Consortium for Political and Social Research (ICPSR). To achieve the study's purpose, 
researchers asked participants to provide information regarding their: current offense, sentence characteristics, criminal history, personal demographics, family background, prior drug and alcohol use and treatment programs, gun possession and use, prison activities, rule violating behaviors, and other program participation.

The series of data collection gives the United States Department of Justice a glimpse into the lives and experiences of incarcerated individuals throughout the United States. There are two versions of the data available to users: a public version that has removed all identifying variables and a restricted version that requires a researcher to complete a Restricted Data Usage Agreement. For the current study, the public, identifier free version was utilized.

\section{Human Subjects Protection}

The current study is using publicly accessible data files that are de-identified and not restricted. ICPSR did not require approval to analyze the data, since the current study was not utilizing restricted data. If a researcher wants to access files that are restricted, the researcher must first complete an Institutional Review Board (IRB) application and must then complete a Data Use Agreement Application with ICPSR. Therefore, the researcher pursued IRB approval through Portland State University, but did not have to obtain the Data Use Agreement from ICPSR. The researcher, after submitting appropriate documents to Portland State University's IRB, was informed that an official review was not required, since the data was de-identified and not restricted by ICPSR, per Title 45 CFR Part 46. 


\section{Participant Recruitment and Data Collection Procedures}

The 2004 Survey of Inmates in State and Federal Correctional Facilities included interviews with 18,185 incarcerated men and women in United States state and federal prisons. There were 14,499 men and women interviewed from state facilities and 3,686 from federal facilities. The current study analyzes answers from respondents who were in state prisons and self-disclosed they were written up or found guilty of at least one rule violation during their period of incarceration. As a cross check, the researcher also examined total rule violations and excluded persons who had zero rule violations.

The current study created a more holistic model that explores whether multiple types of social supports assist incarcerated individuals in reducing overall rule violations. Rehabilitation does not occur without supports both inside and outside the prison. These supports include other inmates, officers, volunteers, and program staff, which have been identified as important sources of support for incarcerated individuals (Lazzari, Miller, \& Lee, 2019). Similarly, previous studies have produced contradictory results, suggesting the need for continued examination of rule violating behaviors. A better understanding of these dynamics can assist in creating a potentially safer prison environment (Steiner et al., 2014). The current study also examined whether sex or race moderate the association between combined instrumental and expressive social supports and rule violations. See Figure 1 for the full conceptual model. 


\section{Measures}

\section{Independent Variables}

\section{Instrumental Social Supports}

Drug and alcohol programs. The participants were asked a number of questions about various types of drug and alcohol treatment programs. Sometimes the participants were asked about drug treatment/programs and alcohol treatment/programs separately. Some participants, who said 'no' they had not participated in drug/alcohol treatment or drug/alcohol programs, responded that they had participated in specific types of drug alcohol treatment or drug/alcohol programs. The drug and alcohol programs variable combined any treatment for alcohol and any treatment for drugs into any treatment for alcohol or drug use, and then combined participation in alcohol programs and participation in drug programs into participated in any alcohol or drugs program. Initially these were left as potentially continuous variables, but were recoded into dichotomous variables $($ No $=0$; Yes $=1)$. The two dichotomous variables were then combined to create a variable that assessed whether the individual had participated in any drug/alcohol treatment or program $(\mathrm{No}=0 ; \mathrm{Yes}=1)$. Drug and alcohol treatment and programs were included as instrumental social supports due to the presence of cognitive behavioral components of the treatment and because these types of programs give incarcerated individuals new tools to deal with what may be contributing to their decisions to use drugs or alcohol.

Job/Vocation Related Programs. Two job/vocation related variables were created. The first was whether the participant had participated in an intervention for 
future employment. A dichotomous variable was created $(\mathrm{No}=0 ; \mathrm{Yes}=1)$. The variable was created by combining whether the individual had participated in employment counseling and/or had participated in vocational or on the job training. Finally, a variable was created to assess whether someone had a work assignment $(\mathrm{No}=0 ; \mathrm{Yes}=1)$. The first two variables represent whether the participant had participated in these programs at any point during their current incarceration. The work assignment variable had a series of questions about the nature of the job. Each participant was asked if they worked on or off the prison grounds, what their job entailed, and how they were compensated. There was a follow up question, which asked how many hours the participant worked in the past week. The assumption is that the participants were asked if they currently, at the time of the interview, had a work assignment. Job related programs are included within instrumental social supports because they are able to learn new skills, trades, or allows them to continue building their resume.

Education Programs. Two dichotomous education related variables were created. The first was whether the participant had participated in any life skills and community adjustment programs $(\mathrm{No}=0 ;$ Yes $=1)$. This first variable combined whether the individual had participated in any life skills and community adjustment programs and whether they had participated in any other prerelease programs. Second, a variable was created to assess whether the individual had completed their GED or any other education program during their current incarceration $($ No $=0 ;$ Yes $=1)$. The GED question was the other one worded as whether the individual had completed their GED during this current incarceration. All other questions only ask about participation and not 
about completion of a specific program. Education programs are included within instrumental social supports because they are gaining more tools for future employment an potentially planting the seeds for a desire for continued education, which opens more doors for future careers.

Types of Instrumental Supports. Three variables were created to assess participation in the three types of instrumental social supports: drug and alcohol programs, job/vocational programs, and education programs. Each type of social support had two different programs included in the category. If a respondent had participated in at least one of the programs, they were coded as a 'yes' (1), and were coded as a 'no' (0) if they had not participated in either of the programs.

Total Instrumental Social Supports. A variable was created to assess total instrumental social supports. This variable ranges from 0-6. Each instrumental social support was included in this continuous variable. For every program that the individual had participated in, they received one point. See Table 1 (Appendix A, p. 143) for a full list of prison programs that are included in the analysis. This table also includes the breakdown of instrumental versus expressive social supports.

\section{Expressive Social Supports}

Religious Programs. Participants were asked whether they had participated in any religious activities, or whether they had participated in religious study groups. The current study considered these as two separate types of religious programs. Therefore, two dichotomous variables were created: Participation in religious activities $(\mathrm{No}=0$; Yes $=1)$ and Participation in a religious study group $(\mathrm{No}=0$; Yes $=1)$. Religious 
programs are included within expressive social supports because of the sharing component present within religious services, and that individuals are able to partake in a sort of "community" within the prison, which allows them to build and gain new relationships.

Support Programs. The participants were asked about other types of programs that provide specific support to individuals. Participants were asked if they had participated in any ethnic/racial organizations, inmate assistance groups, and other inmate self-help groups. The three types of assistance groups were combined into one variable which assessed whether the individual had participated in any inmate led support groups $($ No $=0 ;$ Yes $=1)$. Finally, the participants were asked about whether they had been involved in classes regarding parenting or childrearing skills $($ No $=0$; Yes $=1)$. Inmate led support groups and parenting programs are different types of supports. However, there is a sharing between incarcerated individuals that occurs in parenting classes that is similar to sharing and empathy that is built within inmate led support groups. Both of these require an individual to lower some of their protective barriers in order to give and receive support within their peer group. Therefore, these two were included as expressive social supports.

Connection with Established Support Networks. Each individual was also asked how many visits they had in the past month, and if a parent, whether their child had visited them in the past month. However, no other details about who visited the incarcerated individual were included in the original study. The current study created two visitation variables. The first is a continuous total visitations variable that included all 
missing data, 'don't know,' and 'refused' into the zero visits. Secondly, a dichotomous visitation variable was created assessing whether the individual had at least one visit (1), during the month, or not (0).

The participants were asked how many phone calls they had made during the past week. Almost half of the participants $(46.2 \%)$ had not made a single phone call to family or friends. A dichotomous variable was created to assess whether the individual had at least one phone call during the past week (1) or not (0). The current study will only utilize the dichotomous phone call variable.

Visitations and phone calls were included within expressive social supports since these allow for the incarcerated individual to continue building relationships with their loved ones.

Types of Expressive Social Supports. Three variables were created to assess participation in the three types of expressive social supports: religious programs, support programs, and connection with established support networks. Each type of social supports had two different programs included in the category. If a respondent had participated in at least one of the programs, they were coded as a 'yes' (1), and were coded as a 'no' $(0)$ if they had not participated in either of the programs.

Total Expressive Social Supports. A variable was created to assess total expressive social supports. Potential responses could range from $0-6$. Each expressive social support was included in this continuous variable.

Total Instrumental and Expressive Social Supports. The current study was also interested in understanding whether there is an additive effect, as an individual is 
involved in more programs. All of the types of programs were computed into a continuous variable assessing how many types of programs an individual has been involved with during their current prison sentence. There is a total of 12 programs included in the analysis, which means scores ranged from 0-12.

Sex. Sex was a dichotomous variable that includes females (0) and males (1). The data had many missing values, which were filled in by the original research team, based upon the prison where each participant was incarcerated. This variable did not allow participants to express their alternative gender identity. This was purely the original biological sex of an individual.

\section{Socio-Demographic Variables}

Age. The individual demographic age variable was operationalized as a continuous variable created from the original study. Three participants responded that they were zero years old and were treated as missing data, which removed them from the analysis.

Race. Race was originally captured as multiple dichotomous variables, and there was not one categorical race variable. Each individual was able to check multiple race categories. The researcher made the following changes to the race/ethnicity variables: (1) if a respondent identified as more than one race, the race demographic was categorized Other/Multiracial and (2) the separate dichotomous race variables were collapsed into one categorical race variable. The original categories of the race variable became White, black, American Indian, Asian, Hawaiian, and other/multiracial. Race was operationalized in two ways. First, the race categories was collapsed into three categories: 
White (0), black (1), and other/multiracial (2). Finally, the race variable was collapsed into a dichotomous variable, in order to assess the differences between people of color (0) and White (1).

Marital Status was originally a categorical variable that contained the following values: married, widowed, divorced, separated, never married, do not know, blank, and refused. A decision was made to collapse the widowed, divorced, and separated into one category, since these were marriages that had ended for some reason. The marital status variable was recoded into a dichotomous variable that measured whether the individual was married (1) or not married (0). There is an assumption of heteronormativity within this line of inquiry. There is no way to assess if these are same sex marriages, and the variable does not capture domestic partnerships.

Educational Attainment. During the original data collection, participants’ educational attainment was captured in a few questions. The current study created a categorical variable from the original variable. Participants were asked what the highest grade was that they had attended, prior to their current incarceration. The current study collapsed the responses into the following categories: $9^{\text {th }}$ grade or less $(0), 10^{\text {th }}$ grade $(1)$, $11^{\text {th }}$ grade (2), $12^{\text {th }}$ grade (3), and beyond high school (4). A dichotomous variable was also created to assess whether an individual had obtained a GED (1) or not (0). Respondents who answered 'don't know' or 'refused' were not included in the analysis. Similarly, participants who identified that they had attended school in a different system or a different country, and that the educational system was not comparable to the United States, were excluded from the analysis. 
Parental Status. Parental status was constructed as a dichotomous variable (Not a parent $=0 ;$ Parent $=1$ ). The original study had a variable that asked if the participant had any minor or adult children. For purposes of the current study, the variable was recoded to assess whether the individual was a parent. Minor and adult children were categorized as a child, since the current study is not assessing differences between parents with adult versus minor children.

\section{Control Variable}

Time Served. The amount of time participants had already served on their current prison was utilized as a continuous variable. The participants were asked how many months they had served up to the date of their interview.

\section{Dependent Variable}

Prison Rule Violations. Prison rule violations were utilized as the dependent variable, and was operationalized as a continuous variable. Total rule violations, was computed by adding all of the prison rule violations from each of the 13 types of rule violations included in the current study. See Table 4 (Appendix E p. 147) for rule violation types included in the study. The current study did not include minor violations or 'other violations,' since minor rule violations can be as minimal as having a messy bunk area. The current study is more concerned with rule violations that mimic antisocial behaviors that potentially lead to criminal charges or added time on their sentence.

Studies have focused on whether individuals have committed or have not committed any rule violations. Absent from the literature are studies that explore the differences between the individuals who have committed one, versus those who have committed multiple rule 
violations (Griffin, Lee, Vito, \& Walker, 2017). The current study is examining individuals who identified that they had committed at least one of the major rule violations.

\section{ANALYSIS PLAN}

The Statistical Package for the Social Sciences (SPSS) 26 was utilized to analyze the current study variables. SPSS is able to complete complex data analysis, which was necessary for completing a secondary data analysis. The original data was collected through survey instruments that required self-disclosure. Many of the items being assessed relied on retrospective recall over long periods of time. Some of the questions being asked were also sensitive and individuals had the choice to not reveal their responses. These complications led to the presence of extensive amounts of missing data. Each variable was assessed in order to understand how manipulation of the missing variable would least impact the analyses. The current study will not be utilizing these more advanced models of analysis, since this is an exploration of how combined social supports may impact the frequency of prison rule violations.

Frequency distributions and summaries were run to examine the sample demographics, frequency of rule violations, and participation in social support programs, and aid in the interpretation of the results at the higher-level analyses. Bivariate analyses were run to assess whether there were major differences between specific characteristics and total rule violations. Independent samples-t-tests were run initially in order to begin exploring whether there were significant differences between the moderator variables and the three-predictor variables, the outcome variable, and the control variable. Since the 
current study was interested in whether there were certain groups of the inmate population who participated in various social supports impacted their total rule violations, $t$-tests allowed for this initial breakdown by specific groups. Associations between men and women and people of color and Whites were further explored.

Pearson correlations and point biserial correlations then began painting another type of picture, that allowed for dynamics to emerge regarding how the predictor variables, outcome variable, and control variable related to each other. Correlations provide a way to begin describing what is occurring within all of the raw data, while also offering information about the strength of the relationship between the variables (Bermudez-Edo, Barnaghi, \& Moessner, 2018; Malgady \& Krebs, 1986; Perinetti, 2019). Pearson correlations were run between the predictor variables, outcome variable, and control variable, while point biserial correlations were run between the demographic variables and all other variables. The demographic variables, moderators, and individual social supports were dichotomous variables. The predictor variables, outcome variable, and control variable were all continuous.

The outcome variable (total rule violations) was regressed on the predictor, demographic, and control variables, in order to assess how well each independent variable was able to predict the outcome. The researcher chose to utilize hierarchical regressions, as a way to view changes in variance accounted for by the predictor variable, while wanting to control for the impacts of other variables (Cohen, Cohen, West, \& Aiken, 2003; Lewis, 2007; Schafer, 1991). Hierarchical regressions also allow the researcher to make choices on the order to enter variables based upon what was found in 
the extant literature (Lewis, 2007). Initially, the researcher considered conducting ANOVAs assessing total types of program involvement, but utilizing regressions avoids manipulating the data into artificial categories (Aiken \& West, 1991; Cohen, 1983;

Frazier, Tix, \& Barron, 2004; West, Aiken, \& Krull, 1996).

Moderator variables assess the strength of the relationship between independent and dependent variables (Baron \& Kenny, 1986; Frazier, Tix, \& Barron, 2004; James \& Brett, 1984). This type of analyses highlights whether a subgroup, of a particular variable, best predicts the outcome. The moderators were chosen based upon the extant literature and hypothesized relationships between the variables (Jaccard et al., 1990). The current study assessed the moderation effects of sex and race, on the association between social supports and rule violations. One interaction term was created for each dichotomous moderator (Aiken \& West, 1991; Cohen, Cohen, West, \& Aiken, 2003; Frazier, Tix, \& Barron, 2004). 


\section{CHAPTER IV}

\section{RESULTS}

The following chapter is organized by the type of analysis utilized in the current study. At the end of each section, where appropriate, hypotheses will be discussed. The chapter begins with descriptive statistics that describe the makeup of the sample. This is followed by chi-square, independent sample t-tests, and correlations. There are multiple types of correlations utilized based upon the measurement level of the various variables. Finally, hierarchical regressions explore the unique contributions of specific groups of variables on total rule violations. Moderation analysis was not conducted, as originally planned, due to the lack of statistically significant associations between independent variables and the outcome variable. Tables $5-13$ provide the results for each type of analysis that was conducted, while Table 14 provides each hypothesis, the analysis conducted, and a discussion of the result.

\section{Descriptive Sample Characteristics}

A total of 5,943 incarcerated participants were included in the sample (see Table 5). There were a total of 4,852 men (81.6\%) and 1,091 women (18.4\%). The participants reported an average age of almost 34 years old, with ages ranging from 16-77 years old. Almost $56 \%$ of the sample $(n=3325)$ identified as people of color. The categorical race breakdown was: $44 \%$ White $(n=2618), 44 \%$ black $(n=2630)$, and $11 \%$ other/multiracial $(n=695)$. The participants reported that $26 \%(n=1553)$ had no more than a $9^{\text {th }}$ grade education, $18 \%(\mathrm{n}=1113)$ had at least attended $10^{\text {th }}$ grade, $20 \%(\mathrm{n}=1188)$ had at least attended $11^{\text {th }}$ grade, $22 \%(n=1329)$ had at least attended through $12^{\text {th }}$ grade, and slightly 
more than $12 \%(\mathrm{n}=747)$ had more than a high school education. Only $29 \%(\mathrm{n}=1727)$ reported that they either completed a GED or high school diploma. The majority of the sample $(n=3691,62 \%)$ identified as being unmarried, while $24 \%(n=1445)$ identified as being divorced, separated, or widowed. Only slightly more than $13 \%(\mathrm{n}=807)$ of the sample identified as being currently married at the time of the interview. Finally, $40 \%$ (n $=2381)$ of the participants identified as a parent, which accounted for 9,030 children ages $0-17$. The total number of children ranged from $0-19$, and the average number of children was two children per participant. All participants reported having committed at least one rule violation.

In the current study, twelve unique Social Supports were assessed (See Table 1/Appendix A, pg. 143). On average, each individual had participated in four different programs. The responses ranged from participation in $0-11$ programs. There were six unique instrumental social supports. On average, the incarcerated individuals had participated in two of instrumental social supports. Their responses ranged from $0-6$ instrumental social support programs. Similarly, there were six unique expressive social supports. The incarcerated individuals participated in an average of two expressive social supports. The participation responses ranged from $0-6$ expressive social support programs.

Time served was utilized as a control variable. The average length of time served by this sample of participants was nearly 77 months (6.4 years). The length of time served ranged from less than one month to 523 months (43.6 years). Slightly more than $24 \%$ of the sample $(n=1454)$ had served up to two years, $47 \%(n=2806)$ had served 25 
-96 months $(2.1-8$ years $)$, and $28 \%(\mathrm{n}=1683)$ of the sample had served at least 97

months ( 8 years). The majority of the sample $(82.6 \%, \mathrm{n}=4908)$ had served at least 19 months (1.6 years) at the time of the interviews.

The dependent variable, total rule violations, was only assessed as a continuous variable. During the original interviews, participants self-disclosed being written up or found guilty of at least one major rule violation (see Table 4). The sample, by the time of the interviews in 2004 , accounted for 150,855 rule violations. On average, participants were responsible for twenty-five rule violations. The total number of rule violations ranged from $1-1109$. The range of total rule violations committed by each individual varies widely, which drastically influences the average rule violations. Thirty-five percent of the sample had committed only one major rule violation. When examining the influence of sex, the incarcerated women had an average total rule violation of twentythree, while the incarcerated men had an average of almost twenty-six rule violations. people of color had committed an average of thirty-two rule violations, while Whites reported an average of just over seventeen total rule violations.

\section{Bivariate Analysis}

\section{Chi-Square}

In an attempt to tease apart which individuals were participating in which programs, Chi-square tests of independence were run to assess whether either of the original moderators (sex and race) were associated with participation in specific social supports/programs (See Tables 6. and Table 7.). Results show significant associations between the sex of the individual and participation in any treatment for drugs/alcohol, 
interventions for future employment, work assignments, life skills and community adjustment programs, GED and other education programs, religious activities, religious study groups, inmate led activities, parenting skills, visits in the past month, and phone calls in the past week. Incarcerated women were more likely to have participated in drug and alcohol treatment $\left(X^{2}(1)=34.01, p=.000\right)$, interventions for future employment $\left(X^{2}(1)=4.36, p=.037\right)$, work assignments, $\left(X^{2}(1)=17.58, p=.000\right)$, life skills and community adjustment programs $\left(X^{2}(1)=47.22, p=.000\right)$, GED or other education programs $\left(X^{2}(1)=5.25, p=.02\right)$, religious activities $\left(X^{2}(1)=79.71, p=.000\right)$, religious study groups $\left(X^{2}(1)=33.68, p=.000\right)$, inmate led activities $\left(X^{2}(1)=21.94, p=.000\right)$, parenting skills $\left(X^{2}(1)=214.28, p=.000\right)$, visits $\left(X^{2}(1)=11.52, p=.001\right)$, and phone calls $\left(X^{2}(1)=11.09, p=.001\right)$. Incarcerated men were less likely to have participated in all of various social supports except for participation in alcohol and drug programs. There was no association between the sex of the individual and participation in alcohol and drug programs $\left(X^{2}(1)=.880, p=.348\right)$. See Table 6 . For the full table of associations between sex and social supports.

When examining associations between race and participation in various programs, the results showed significant associations between the race of the individual and participation in any treatment for drugs/alcohol, programs for alcohol and drugs, interventions for future employment, life skills and community adjustment programs, GED and other education programs, religious activities, religious study groups, inmate led activities, and visits in the past month. Table 7 illustrates a full description of the associations between race and program involvement. White participants were more likely 
to have participated in treatment for drugs and alcohol $\left(X^{2}(1)=11.14, p=.001\right)$, programs for alcohol or drugs $\left(X^{2}(1)=6.66, p=.01\right)$, and visits $\left(X^{2}(1)=17.52, p=\right.$ .000). People of color were more likely to have participated in interventions for future employment $\left(X^{2}(1)=10.27, p=.001\right)$, life skills and community adjustment programs $\left(X^{2}(1)=5.71, p=.017\right)$, GED and other education programs $\left(X^{2}(1)=15.68, p=.000\right)$, religious activities $\left(X^{2}(1)=19.85, p=.000\right)$, religious study groups $\left(X^{2}(1)=25.90, p=\right.$ $.000)$, and inmate led support groups $\left(X^{2}(1)=4.22, p=.040\right)$. There were no associations between race/ethnicity and participation in work assignments $\left(X^{2}(1)=.194, p=.659\right)$, parenting skill programs $\left(X^{2}(1)=3.28, p=.070\right)$, and phone calls in the past week $\left(X^{2}(1)\right.$ $=.228, p=.633)$.

\section{Independent Sample T-Tests}

There were significant differences in the average months served, at the time of the original interviews, between male $(\mathrm{M}=82.47, \mathrm{SD}=74.20)$ and female participants $(\mathrm{M}=$ 50.67, $\mathrm{SD}=52.21 ; t(-16.69)=-13.43, p=.000$, two tailed) (See Table 8$)$. The magnitude in the difference of the means was moderate (mean difference $=31.8,95 \% \mathrm{CI}:-35.55$ to 28.07). Four percent of the variance in total months served was explained by sex.

Similarly, there were significant differences between the number of total instrumental social supports utilized by male and female participants. While the women $(\mathrm{M}=2.49, \mathrm{SD}$ $=1.42)$ participated in slightly more instrumental social supports than the men $(\mathrm{M}=2.17$, $\mathrm{SD}=1.40 ; t(1600)=6.69, p=.000$, two tailed $)$, the magnitude of the difference in the means (mean difference $=.32,95 \% \mathrm{CI}: .22$ to .41$)$ was small $($ eta squared $=.02)$. When examining the differences between females and males and their participation in 
expressive social supports, women $(\mathrm{M}=2.44, \mathrm{SD}=1.43)$ were significantly more likely to participate in more programs than male participants $(\mathrm{M}=1.87, \mathrm{SD}=1.29 ; t(1509)=$ $12.09, p=.000)$. Sex accounts for $8 \%$ of the variance in the average participation in Expressive Social Supports. When comparing the combined total of instrumental and expressive social supports, women $(M=4.93, S D=2.41)$ had a significantly higher average of total program participation than men $(\mathrm{M}=4.04, \mathrm{SD}=2.20 ; t(1525)=11.17, p$ $=.000)$. The difference accounted for $7 \%$ of the variance in total social support participation. There was not a statistically significant difference in the average rule violations committed by male $(\mathrm{M}=25.81, \mathrm{SD}=138.88)$ and female participants $(\mathrm{M}=$ $23.49, \mathrm{SD}=131.52 ; t(1681)=-.522, p=.602)$. Table 8 presents the results regarding differences based upon the sex of the participant, and Table 9 presents the results regarding differences based upon the race of the participant.

At the time of the original interviews, People of Color $(\mathrm{M}=79.21, \mathrm{SD}=71.14)$ had spent more months incarcerated then the White participants $(\mathrm{M}=73.37, \mathrm{SD}=72.36$; $t(5941)=3.12, p=.002)$ (See table 9). While there appears to be a large difference between the means of length of incarceration (mean difference $=5.84$ ), race only accounts for $.16 \%$ of the variance in length of stay. When examining the various types of social supports, People of Color $(\mathrm{M}=2.26, \mathrm{SD}=1.40)$ had a slightly higher average of instrumental social supports, but the difference was not significantly different from White participants $(\mathrm{M}=2.20, \mathrm{SD}=1.42 ; t(5941)=1.59, p=.11)$. However, People of Color $(\mathrm{M}$ $=2.02, \mathrm{SD}=1.33$ ) had a significantly higher average of participation in expressive social supports, when compared to their White counterparts $(\mathrm{M}=1.91, \mathrm{SD}=1.34 ; t(5941)=$ 
$2.89, p=.004)$. While a statistically significant difference appeared between race and expressive social supports, race, accounts for a very small amount of variance in expressive social supports (eta squared $=.001$ ). When examining total social supports, People of Color $(\mathrm{M}=4.28, \mathrm{SD}=2.27)$ had significantly more involvement with social supports, when compared to Whites $(\mathrm{M}=4.12, \mathrm{SD}=2.27 ; t(5941)=2.69, p=.007)$. However, once again, this difference accounts for a minute amount of variance in total social supports (eta squared $=.001)$. People of Color $(\mathrm{M}=31.72, \mathrm{SD}=156.44)$ reported committing significantly more rule violations, than White participants $\operatorname{did}(\mathrm{M}=17.34$, $\mathrm{SD}=108.43 ; t(5851)=4.18, p=.000)$. The magnitude of the differences in the means $($ mean difference $=14.38)$ was very small $($ eta squared $=.002)$.

When putting sex and race aside, mixed results appeared between individuals who had participated in specific types of instrumental and expressive social supports and the outcome variable. See Table 10 for t-test results for all of the instrumental and expressive social supports. Although participation in drug and alcohol treatment was not significantly associated with total rule violations, the associations were inversely associated. Participation in drug and alcohol treatment produced fewer rule violations than non-participants, while participation in drug and alcohol programs produced more rule violations than non-participants. When assessing participation in one or both of the drug/alcohol supports, there was not a significant difference associated with total rule violations.

Individuals who had participated in employment counseling or vocational programs did not show significantly decreased rule violations. However, individuals who 
had a job assignment $(M=20.45, S D=121.26)$ had significantly fewer rule violations than those not working $(\mathrm{M}=33.94, \mathrm{SD}=161.60 ; t(3597)=3.38, p=.001)$. Interestingly, when the two types of work related supports were combined, the effect on total rule violations was not statistically significant.

Participation in life skills or community adjustment programs $(\mathrm{M}=30.56, \mathrm{SD}=$ 151.92) was associated with significantly higher rule violations than non-participants (M $=22.93, \mathrm{SD}=130.13 ; t(3286)=-1.891, p=.05)$. Participation in GED or education programs was not associated with a significantly different number of total rule violations. When participation in the combined life skills and/or GED programs was examined, the association with rule violations was not statistically significant. However, findings showed that participants with at least a GED $(M=19.80, S D=120.11)$, at the time of interview, had committed significantly fewer rule violations than those whose educational attainment was less than a GED $(\mathrm{M}=27.67, \mathrm{SD}=144.04 ; t(3816)=2.16, p$ $=.03)$.

Connection with established social supports, through visitations and phone calls, produced mixed results. Participants who had a visit in the past month $(\mathrm{M}=19.98, \mathrm{SD}=$ 117.47), at the time of the interviews, had significantly fewer rule violations than those who did not have a visit $(\mathrm{M}=27.85, \mathrm{SD}=145.75 ; \mathrm{t}(4405)=2.218, \mathrm{p}=.02)$. Individuals who had a phone call, in the past week, did not have significantly fewer rule violations. Finally, when combined, phone calls and visits were not associated with reduced rule violations. 


\section{Correlations}

Table 11 presents the bivariate correlations between the demographic variables (sex, age, race, education, marital status, and parental status), the control variable (time served), the independent variables (total instrumental social supports, total expressive social supports, and total combined social supports) and the dependent variable (total rule violations). When examining the correlations between the demographic variables and the control variable, there were significant correlations with sex $\left(r_{p b}=.172 \mathrm{p} \leq .000\right)$, age $(r$ $=.484 \mathrm{p} \leq .000)$, race $\left(r_{p b}=-.040 \mathrm{p} \leq .01\right)$, and parental status $\left(r_{p b}=.026 \mathrm{p} \leq .05\right)$. The correlations between demographic variables and the dependent variable suggested that people of color $\left(r_{p b}=-.052 \mathrm{p} \leq .000\right)$, and people with less than a GED/HS Diploma had committed more rule violations $\left(r_{p b}=-.026 \mathrm{p} \leq .05\right)$. The control variable was also significantly related to total rule violations $(r=.132 \mathrm{p} \leq .000)$.

The independent variables provided mixed results when assessed with the demographic variables, the control variable, and the dependent variable. The only demographic variable not associated with any of the independent variables was parental status. Incarcerated women were more likely to have increased expressive social supports $\left(r_{p b}=-.166 \mathrm{p} \leq .000\right)$ and total social supports $\left(r_{p b}=-.152 \mathrm{p} \leq .000\right)$. A positive relationship appeared between age and instrumental social supports $(r=.053 \mathrm{p} \leq .000)$, expressive social supports $(r=.027 \mathrm{p} \leq .05)$, and total social supports $(r=.049 \mathrm{p} \leq .000)$. People of color were significantly more likely to participate in expressive social supports $\left(r_{p b}=-.037 \mathrm{p} \leq .05\right)$, and had more total social supports $\left(r_{p b}=-.035 \mathrm{p} \leq .05\right)$. Participants who had a GED/HS diploma at the time of the interview had participated in significantly 
more expressive social supports $\left(r_{p b}=.118 \mathrm{p} \leq .000\right)$ and had more total social supports $\left(r_{p b}=.056 \mathrm{p} \leq .000\right)$. Individuals who were married also had participated in more expressive social supports $\left(r_{p b}=-.166 \mathrm{p} \leq .000\right)$ and had more total social supports $\left(r_{p b}=\right.$ $-.166 \mathrm{p} \leq .000)$. The amount of time served was significantly and positively related to instrumental social supports $(r=.224 \mathrm{p} \leq .000)$, expressive social supports $(r=.108 \mathrm{p} \leq$ $.000)$, and total social supports $(r=.203 \mathrm{p} \leq .000)$. The independent variables were all significantly and positively associated with each other. None of the independent variables were significantly related to total rule violations. However, while not statistically significant, expressive social supports $(r=-.003 \mathrm{p}=.832)$ was the only independent variable negatively related to total rule violations.

Table 12 presents the Point Biserial correlations for each of the unique social supports and total rule violations. Many of the social supports were correlated with each other. However, the results are mixed. Only three types of social supports were significantly associated with all of the other social supports. Participation in interventions for future employment, participation in inmate led support groups, and participation in parenting skills were all significantly correlated with engagement in the other social supports. When examining whether certain types of social support programs were correlated with total rule violations, three of the twelve social supports were significantly associated with total rule violations. Having a current work assignment $\left(r_{p b}=-.047 \mathrm{p} \leq\right.$ $.000)$ and having at least one visit in the past month $\left(r_{p b}=-.027 \mathrm{p} \leq .05\right)$ were associated with reduce rule violations, while participation in life skills programs $\left(r_{p b}=.026 \mathrm{p} \leq .05\right)$ was associated with increased rule violations. Participation in drug and alcohol treatment, 
and having at least one phone call in the past week showed non-significant, but negative associations with rule violations, while participation in drug and alcohol programs, interventions for future employment, education programs, religious activities, religious study groups, inmate led support groups, and parenting skills were associated with increased rule violations.

\section{Multivariate Analysis}

\section{Hierarchical Regression}

Hierarchical regressions were run in order to test the hypothesized effects of social supports on total rule violations (See Table 13). Previous correlations suggested that, having a work assignment, life skills programs, and having visits had statistically significant impacts on total rule violations. Therefore, these were the social supports included in the regression analysis. Similarly, Independent Samples t-tests concluded that race/ethnicity, educational attainment, and time served significantly affected total rule violations. The other instrumental and expressive social supports were not included in the model, since they were not significantly correlated with total rule violations. Similarly, the computed total social supports variable was also not included in the model, due to a lack of association with total rule violations. Model 1 included the social supports. Model 2 added race and educational attainment. Model 3 utilized time served as a control variable, which was a part of the original analysis plan for the current study.

As the models were being run, the researcher assessed the relevant assumptions of conducting hierarchical regressions. The following equation was utilized to assess the appropriateness of the sample size: $\mathrm{N}>50+(80 \mathrm{~m})(\mathrm{m}=$ independent variables $)$ 
(Tabachnick \& Field, 2013). The sample size is 5,943. There were a total of eight independent variables. Therefore, the following equation was utilized: $5943>50+$ $(80 * 8)=5943>690$. The assumption of generalizability was met. Second, the assumption of multicollinieraity assess correlations between the independent and dependent variables. The results showed a Tolerance levels .912--.996, which is higher than .10, and VIF (variance inflation factor) that were higher than one and less than 2. The VIF ranged from 1.004 - 1.097. Extreme outliers were removed from the analysis. When the Mahalanobis distances were examined, the critical Chi-square values of 2.73 and 15.507 were utilized. Participants who fell outside these boundaries were removed from the regression analysis. When these changes were made to the sample, whether someone had received visits in the past month was no longer statistically significant, and was, therefore, not included in the regression analysis. The final sample size was 5,808, which still met the appropriate sample size assumption. The values of the error were also independent of one another. The Durbin-Watson Test revealed a test statistic of 1.999 , which lies close to the goal of 2 . There did not appear to be problems of autocorrelation.

Table 13 shows the results of the three stage hierarchical regression. The table includes the unstandardized coefficients (B) and their standard errors (SE), standardized coefficients $(\beta)$, the amount of variance $\left(\mathrm{R}^{2}\right)$ and the amount of variance that is changed by the addition of new variables $\left(\mathrm{R}^{2}\right.$ Change). Each model produced a statistically significant contribution to the model, and the final model (the model which includes all of the variables) accounts for $2.3 \%$ of the variance in rule violations $[F(1,5,801)=$ $22.785, p \leq .000]$. 
The first model explains approximately $.3 \%$ of the variation in the outcome variable and is statistically significant $[F(3 ; 5804)=5.083, p \leq .002]$. This model includes the various social support variables: whether the had a current work assignment, whether they had taken any life skills or other pre-release courses, and whether they had any visits in the past month. Having a work assignment $\left(\mathrm{B}=-11.23, \mathrm{SE}_{\mathrm{b}}=3.69, \beta=-.04\right.$, $p=.002)$ and participating in life skills $\left(\mathrm{B}=7.66, \mathrm{SE}_{\mathrm{b}}=3.80, \beta=.03, p=.04\right)$ were significantly related to total rule violations. Having a work assignment was associated with fewer rule violations, while participation in life skills was associated with increased rule violations. Having had at least one visit in the past month $\left(\mathrm{B}=-5.89, \mathrm{SE}_{\mathrm{b}}=3.82, \beta=\right.$ $-.00, p=.12$ ) was no longer significantly related to total rule violations, when alongside the other variables.

The second model added a unique contribution of .3\% of the variation in total rule violations $[F(2,5802)=6.54, p \leq .000]$ and explains approximately $.6 \%$ of the variance in rule violations. This model includes the social support variables from Model 1 and adds the contributions of race and educational attainment. Individuals with a work assignment continued to have fewer rule violations $\left(\mathrm{B}=-10.785, \mathrm{SE}_{\mathrm{b}}=3.69, \beta=-.04, p\right.$ $=.003)$, as did White participants $\left(\mathrm{B}=-13.58, \mathrm{SE}_{\mathrm{b}}=3.57, \beta=-.05, p=.000\right)$. Individuals who had participated in life skills was again associated with increased rule violations (B $\left.=7.25, \mathrm{SE}_{\mathrm{b}}=3.80, \beta=.03, p=.056\right)$. Whether the individual had visits (or whether the individual had a GED were not significantly related to rule violations, but they did show a negative association with rule violations. 
The third model added a unique contribution of $1.7 \%$ of the variance in total rule violations. This change in the amount of variance explained is accounted for by controlling for the amount of months already served at the time of the initial interviews. This model also includes the social support variables, race/ethnicity, and educational attainment. In total, this model accounts for $2.3 \%$ of the variance in total rule violations $[F(1,5801)=22.785, \mathrm{p} \leq .000]$. Similar to the first two models, having a work assignment $\left(\mathrm{B}=-14.89, \mathrm{SE}_{\mathrm{b}}=3.68, \beta=-.05, p=.000\right)$ and race contributed statistically significant impacts on total rule violations $\left(\mathrm{b}=-11.54, \mathrm{SE}_{\mathrm{b}}=3.55, \beta=-.04, p=.001\right)$. Time served also contributed a strong and negative association with total rule violations $\left(\mathrm{B}=.30, \mathrm{SE}_{\mathrm{b}}=.03, \beta=.13, p=.000\right)$. Having had at least one visit in the past month and having earned at least a GED were not statistically significant, and they continued to show a negative association with total rule violations. Participation in life skills also maintained a non-significant but positive association with total rule violations. 


\section{CHAPTER V}

\section{DISCUSSION}

Chapter five presents summaries and interpretations of the findings as they relate to the study purpose, study aims, hypotheses, and literature regarding how social supports influence prison rule violations. Implications of the study's findings will then be examined, followed by recommendations for future research, practice, and policy.

\section{Summary and Interpretation of Findings}

The current study was designed to examine how socio-demographics and social supports influence the frequency of rule violations committed by incarcerated men and women who have already committed at least one rule violation. Cullen's (1994) social support theory was assessed and utilized as the study's theoretical framework. The theory suggests that individuals who have more social supports would be more likely to engage in prosocial behaviors and would, therefore, commit fewer rule violations (Colvin et al., 2002; Cullen, 1994; Cullen, Wright, \& Chamlin, 1999). Previous research has suggested that individuals who commit fewer rule violations are able to more successfully adapt to their prison environment, which is crucial for the safety of institutions, the incarcerated individuals, and the staff (Bell \& Lindekugel, 2015; Berk, Kriegler, \& Back, 2006; Celinska \& Sung, 2014; Jiang, 2005; Jiang, fisher-Giorlando, \& Mo, 2005; Tewksbury et al., 2014). The goals were to determine which characteristics and social supports assist in reducing the total number of official rule violations. The six research aims and the according research hypotheses are described. 


\section{Discussion of Research Aim 1:}

What are the associations between socio-demographics (sex, age, race, educational attainment, marital status, parental status, time served) and total rule violations? It was hypothesized that younger males, persons of color, individuals with less than a GED education, individuals who are not married, individuals who do not have children, and individuals who have spent more months incarcerated will have committed more rule violations. An individual did not need to maintain all of these identities, but that any of these specific identities would be associated with more rule violations. The current study found partial support for these claims. People of color and individuals who had less than a GED education had significantly higher averages of prison rule violations, as did individuals who had spent more months incarcerated. Marital status, parental status, and time already served were not significantly associated with total rule violations.

While most studies suggest that incarcerated men commit more rule violations than women (Berg \& DeLisi, 2006; Cao, Zhao, \& Van Dine, 1997; Celinska \& Sung, 2014; Craddock, 1996; Harer \& Langan, 2001; Reidy, Sorensen, \& Cunningham, 2012; Steiner, Butler, \& Ellison, 2014), some studies suggest an opposing trend (House \& Belenko, 2015; Sawyer, 2018). Reidy and colleagues (2017) suggest that there are certain sub-groups within both the male and female incarcerated populations that may be more likely to behave in ways that lead to official rule violations. This study's findings did not find a statistically significant difference in the number of rule violations committed by male and female participants. While the study sample had an overrepresentation of women compared to their representation in the entire prison population $(18.4 \%$ of the 
sample versus $7.58 \%$ of the US prison population), other dynamics may have been influencing the lack of differences between total rule violations and sex (Sawyer, 2018; Sawyer \& Wagner, 2019). Researchers argue that the higher presence of co-occurring disorders within populations of incarcerated women drastically increase the severity and frequency of rule violations (Houser \& Belenko, 2015; Moloney, van der Bergh, \& Moller, 2009; Salisbury et al., 2009; Steiner \& Wooldredge, 2009; Wright et al., 2007). The sample for the current study included men and women who had committed at least one major rule violation. The major rule violations are more egregious offenses, meaning that the participants were individuals who were engaging in more serious rule violating behaviors. Other studies suggest that correctional officers in female prisons are less likely to write official rule violations and are more lenient with the women (Goveret al., 2008; Harer \& Langan, 200). This may affect outcomes based upon whether a study utilizes official verses self-reported total rule violations. The current study relied upon the information provided by the participants. Therefore, the total rule violations may have been inflated in one direction or the other. Women may have reported higher rates of rule violations, since they recalled rule violations over their entire period of incarceration.

The current study did not find statistically significant differences in the frequency of rule violations between older and younger incarcerated individuals. The extant literature has been consistent in the argument that as age increases, rule violations decrease (e.g. Blackburn \& Trulson, 2010; Bonner, Rodriguez, \& Sorensen, 2017; Camp, Gaes, Langan, \& Saylor, 2003; Celinska \& Sung, 2014; Cunningham \& Sorensen, 2007; DeLisi et al., 2010; Gaes, Wallace, Gilman, Klein-Saffran, \& Suppa, 2002; Griffin \& 
Hepburn, 2006; Harer \& Langan, 2001; Jiang \& Winfree, 2009; Kuanliang, Sorensen, \& Cunningham, 2008; Rocheleau, 2013; Steiner, Butler, \& Ellison, 2014; Steiner \& Wooldredge, 2009; Walters \& Crawford, 2013; Valentine, Mears, \& Bales, 2015; Wooldredge, Griffin, \& Pratt, 2001). The average age of the sample was almost 34 years. Even though fifty-six percent of the sample was thirty-four and younger, age did not significantly influence the average number of rule violations. Research suggests that incarcerated individuals under the age of 25 are more likely to commit rule violations (Valentine, Mears, \& Bales, 2015). However, only $18 \%$ of the sample was younger than 25. Therefore, future studies may want to examine rule-violating behaviors with younger samples and with older samples to see if younger incarcerated individuals are engaging in more frequent rule violating behaviors. What this does not assess is whether the younger incarcerated individuals are committing more minor rule violations, or if they are committing more major violations. The sample for the current study included individuals who had committed at least one major rule violation. Younger incarcerated individuals may not start out engaging in anti-social behaviors causing more damage. This may mean that correctional agencies need to target anti-social behaviors earlier for younger incarcerated individuals.

Previous research that has assessed the role of race/ethnicity has produced mixed results. Studies have found that people of color commit more rule violations (see e.g. Benning \& Lahm, 2016; Bonner, Rodriguez, \& Sorensen, 2017; Celinska \& Sung, 2014; Jiang \& Winfree, 2006; Jiang \& Winfree, 2009; Reidy, Cihan, \& Sorensen, 2017; Steiner \& Wooldredge, 2009). While other studies suggest that rates of rule violations vary when 
people of color are separated into African American and Latino (see e.g. Bell \& Lindekugel, 2015; Bonner, Rodriguez, \& Sorenson, 2017; Celinska \& Sung, 2014), and that Hispanic males are less likely to commit rule violations (Rocheleau, 2014). The current study supported the claim that people of color commit more rule violations than Whites. Caution is needed when interpreting this result. There may be political and ideological implications affecting why people of color may be receiving more rule violations than White incarcerated individuals. The current study oversampled people of color. In particular, forty-four percent of the sample identified as Black, yet in the US, thirty-three percent of the US prison population identifies as Black (Gramlich, 2019). Unfortunately, people of color are overrepresented within the US prison population and within the current study.

Educational Attainment was also a significant predictor of rule violations. Individuals who have a lower educational attainment are more likely to commit more rule violations (see e.g. Berg \& De Lisi, 2006; Lahm, 2017; Schenk \& Fremouw, 2012). This claim was supported by the current study. Similarly, Steiner and Wooldredge (2014) argued that individuals with at least a GED, as they entered prison, committed fewer rule violations. The current study found that individuals who had at least a GED at the time of the original interview participated in more expressive social supports, but not instrumental social supports, and had significantly fewer total rule violations. Interestingly, older, White, women, who were married, were more likely to have had at least a GED at the time of the original interview. 
Marriage has often been identified as a protective factor for many different groups of people (Liu et al., 2019; Sampson \& Laub, 1993; Vanassche, Swicegood, \& Matthijs, 2013), and has even been identified, as a protective factor against criminality (Farrington \& West, 1995; Laub, Nagin, \& Sampson, 1998; Sampson \& Laub, 1993; Uggen \& Thompson, 2003; Visher \& O'Connell, 2012) However, for incarcerated individuals, who have complex histories, being married is not always a protective factor; the literature is mixed. Studies suggest that incarcerated men who are married commit fewer rule violations (Bales \& Mears, 2008; Celinska \& Sung, 2014; Jiang \& Winfree, 2006). Relational dynamics for incarcerated women are to some extent more complicated. Studies have shown that incarcerated women who are married commit more rule violations than incarcerated men who are married (Jiang \& Winfree, 2006). Wright and Salisbury, (2007) found that incarcerated women, who had non-supportive relationships at the time of their entrance into prison, had fewer rule violations than women who entered prison with supportive relationships. While other studies determined, that both incarcerated men and women are protected by being married (Celinska \& Sung, 2014; Rocheleau, 2014; Siennick, Bales, \& Mears, 2013). The current study did not find significant differences in the frequency of rule violations, when comparing individuals who were married versus not married. However, the current study did not tease apart the difference between married men versus married women.

Parenting behind prison walls is another complicated dynamic that has produced mixed results in the literature. Much of what we have come to understand about corrections has been normed on the experiences of incarcerated men. In contrast, Pierce 
(2015) suggests that what we know about parenting behind prison walls has been normed on the experiences of incarcerated mothers. This is interesting because there are assumptions about who will parent children upon release. Oftentimes the incarcerated mother was the primary caregiver before incarceration (Celinska \& Siegal, 2010; Glaze \& Maruschak, 2009; Hoffman, Byrd, \& Kightlinger, 2010; Mumola, 2000). Jiang and Winfree (2006) did find that incarcerated mothers and incarcerated fathers commit similar amounts of rule violations.

The current study did not find statistically significant differences in the total amount of rule violations committed by those who were parents versus non-parents. Parental status did not affect participation in social supports, nor did it significantly affect total social supports. In the current sample, 35.9\% $(n=390)$ of women identified as mothers and $41.1 \%(n=1940)$ of the men identified as fathers, and yet only $9 \%$ of the men (compared to $38 \%$ of the women) had participated in a parenting skills program. This may point to the way we view the role of incarcerated men and women as parents. Incarcerated men are not given the same opportunities to learn skills that help them navigate complicated relationships with their children. And even for the women, only $38 \%$ of the women reported participating in some form of parenting class.

There is a positive and significant relationship between length of time incarcerated and total rule violations, since the longer someone is incarcerated provides more opportunity to accrue rule violations. This is not a surprising relationship. The extant literature supports this finding (Berk, Kriegler, \& Back, 2006; Casey-Acevedo \& Bakken, 2001; Celinska \& Sung, 2014). However, the current study used this as a control 
variable in an attempt to minimize the likelihood that the rule violations were a result of another independent variable. Length of time already served had the strongest relationship with total rule violations in the final hierarchical regression model.

\section{Discussion of Research Aim 2:}

What are the associations between instrumental social supports (i.e., drug and alcohol programs, job/vocation related programs, and education programs) and total rule violations? Instrumental supports are people/support networks that can be relied upon to assist with securing employment, housing, financial resources, etc. (Colvin et al., 2002; Cullen, 1994). For incarcerated individuals, this means involvement in programs that prepare them for life in the outside world. Having the skills to be successful in a job, having the education to prepare for a job, or finding the necessary treatment in order to be successful with a job, assist individuals as they prepare for life on the outside. When examining whether participation in more instrumental social supports was associated with fewer rule violations, the opposite was found. Engagement in more instrumental social supports was associated with more rule violations. The association, however, was not statistically significant. Participation in drug and alcohol treatment and drug and alcohol programs were not associated with reduced rule violations. The other four instrumental social supports were correlated with rule violations. Having a current work assignment was the only instrumental social support associated with significantly fewer rule violations. Participation in vocational programs, life skills, and education programs were all significantly associated with increased rule violations. 
Many prisons utilize the risk-need-responsivity model, which puts individuals at the highest risk of recidivating in programs that will assist in meeting the specific needs of individuals (Andrews \& Bonta, 2010; Gendreau, Smith, \& French, 2006; Smith, Gendreau, \& Swartz, 2009). This means that individuals who are more likely to be engaging in rule violating behaviors are the ones most likely to be participating in many of the available programs. What the current study is unable to tease apart is the timeline between the rule violating behaviors and program participation. For individuals who had spent more than three years incarcerated, their rule violating behaviors may have occurred years prior to their being able to participate in certain social supports. Being able to establish a timeline of events would be an important consideration for future research. In addition, the current study is unable to determine whether individuals completed certain programs. The survey question asked whether the individual had participated in a certain social support. Therefore, there may be differences in rule violating behaviors between those who completed and those who only participated in social supports.

\section{Discussion of Research Aim 3:}

What are the associations between expressive social supports (i.e., religious programs, support programs, and connection with established support networks) and total rule violations? Expressive social supports include people with whom the incarcerated individual is able to express and process his/her emotions. This may be having family or friends visit, or joining in prison programs designed to address and process experiences. When examining the combined impacts of all of the expressive 
social supports, participation in more expressive social supports was associated with decreased rule violations. The association was not statistically significant. Only one of the expressive social supports make a significant impact on rule violations. Individuals who participated in inmate led support groups committed more rule violations. While not statistically significant, individuals who participated in religious study groups and parenting skills programs also committed more rule violations. Religious activities, visits, and phone calls were associated with reduced rule violations, but the associations were not statistically significant. Visitations created an interesting dynamic. When initially examining visitations, they were associated with decreased rule violations. However, when individuals with extreme numbers of rule violations were excluded from the regression analysis, visitations were no longer associated with significantly fewer rule violations.

Participation in these types of social supports may be challenging for incarcerated populations if the goals are to explore feelings, emotions, relational dynamics, etc. For example, incarcerated parents who participated in parenting skills programs committed more rule violations. This may support previous studies that suggest the separation from children increases negative behaviors from incarcerated parents (Thompson \& Loper, 2005; Wright \& Salisbury, 2007). Future studies will want to tease apart what exactly was included within inmate led support groups, and whether this means there is no staff or facilitator guiding dialogues between incarcerated individuals. 


\section{Discussion of Research Aim 4:}

\section{What are the aggregate impacts of instrumental and expressive supports} (total social supports), and the associations with rule violations? Social support research has suggested that as individuals enter prison, the loss of support networks is devastating (Adams, 1992; Cochran, 2014; La Vigne, Naser, Brooks, \& Castro, 2005; Liebling, 1999; Monahan et al., 2011; Tasca et al., 2010). Prosocial bonds can be built through visitations and involvement in various programs, which strengthens the sense of being able to maintain important social supports (Cullen, 1994). These supports may assist incarcerated individuals in adjusting to their prison environment, as well as decreasing rule violations through the strengthening of their self-control (Cochran, 2014; Cullen et al., 1999; Meyers et al., 2017). Alternatively, inconsistent connection with social supports may decrease self-control, which may lead to increased rule violations (Colvin et al., 2002; Cullen, 1994). Therefore, the current study set out to assess whether increased social supports would strengthen these bonds and in turn decrease the likelihood of rule violations. While the association was not statistically significant, the findings suggest that increased social supports are associated with increased rule violations.

The current study did find, however, that there were specific types of instrumental and expressive social supports that were significantly associated with total rule violations. Participation in vocational programs, having a current work assignment, life skills, other education programs, and inmate led support groups were all significantly associated with total rule violations. Having a current work assignment was the only type of social 
support related to reduced rule violations. The other four were associated with increased rule violations. However, when included in the regression model together, the only type of social support that remained statistically significant was having a current work assignment. One of the similarities between the four social supports, that were positively related to rule violations, is that these supports may take up one or two hours of the day. Whereas, an individual with a work assignment may be busy for multiple hours throughout the day. This may also include the weekends when many programs do not take place. Individuals with a work assignment may have less opportunity to violate rules and may have more of an incentive to behave in ways that allow them to keep their work assignment.

Martinson's (1974) 'nothing works' campaign on correctional rehabilitation caused a major shift in how correctional rehabilitation is studied and understood. His works shifted the ideology from one of rehabilitation and reintegration back to a model of social control and deterrence. Research regarding the impacts of correctional rehabilitative efforts continue to provide contradicting results, which continues to challenge efforts to provide effective rehabilitation. One study will suggest that a particular curriculum or intervention is effective, and then another study suggests that the same curriculum or intervention does not produce statistically significant outcomes or that the outcomes are significant but in the opposite direction. There are so many potential variables that influence the outcomes of prison evaluation studies. The current study utilized data from prisons throughout the United States. Program availability is different at each prison, let alone at prisons in different states. Caution must be used 
when attempting to apply the results of the current study to general prison populations. Outcome studies continue to suggest that connections with prosocial social supports assist free and incarcerated populations. Future research needs to more closely examine this dynamic. Instead of taking the broad view and look at corrections across the United States, researchers need to examine what is happening with a certain prison and then what is happening within a certain state. Similarly, with the new addition of private prisons, research needs to examine the differences between the impact of social supports for state, private, and federal prisons (Sawyer \& Wagner, 2019; Wagner, 2015).

\section{Discussion of Study Aim 5:}

What are the associations between aggregated instrumental and expressive social supports and rule violations, when controlling for time served? Time served was the strongest predictor of rule violations. Individuals that had served more time had committed more rule violations. This is not a surprising outcome. What is surprising is how the inclusion of time served affected the direction of the associations with rule violations. Prior to the inclusion of time served, having a work assignment was the only type of social support that was associated with decreased rule violations. When time served was included in the model, participation in vocational programs and inmate led support groups were associated with decreased rule violations. The association was not statistically significant, but the direction had changed. Life skills and education programs were still associated with increased rule violations, and remained non-statistically significant. Vocational programs and inmate led support groups may be more effective at certain times during periods of incarceration. This should be explored in future research, 
and could examine whether these types of social supports are most effective at certain points during a period of incarceration.

\section{Discussion of Study Aim 6:}

Do sex and race moderate the association between aggregated social supports and total rule violations, when controlling for the amount of time already served?

Total social supports were not significantly associated with total rule violations.

Therefore, the moderation analysis, which would have utilized sex and race as moderators, was not conducted. As previously described, there were specific types of instrumental and expressive social supports that were regressed on total rule violations, but the combined total social supports were not significantly associated with total rule violations. However, there are some major implications that will be further explored in the following section, related to race and sex.

\section{STUDY STRENGTHS AND LIMITATIONS}

The current study utilized a nationally representative data set that allowed for an examination of variables that assessed the way social supports are able to influence total rule violations. There are challenges in using a nationally representative data set, and there are challenges in utilizing rule violations as an outcome.

First, prisons are all very unique. The location, size of the facility, age of the facility, size of the inmate population, number of correctional officers and other staff, and custody level of the inmate population are all factors that may influence rule violations and which types of programs are available in any particular institution. Similarly, how the interviewers worded the questions and the potential responses may have influenced 
whether a participant thought they may or may not have participated in a certain program. There are also multiple programs that institutions may choose from, in order to target certain issues, and program availability varies widely from institution to institution. The current study was unable to control for all of these variables, since incarcerated individuals throughout the country were being interviewed. .

Self-report data were utilized; multiple factors potentially influenced the way in which individuals report committing rule violations. Each state has a unique way of categorizing and labeling various types of rule violations (see Table 3). The current study was concerned with what were considered major rule violations. However, the way in which the original interviewers asked about and labeled the various types of rule violations may have influenced the total number reported by each individual. Similarly, the participants may not have felt comfortable being completely honest. They may have felt a need to over or under report their total rule violations. There was also a wide range in the amount of time already served by participants. Each individual was asked to recall his or her rule violations over their entire incarceration, which may have drastically affected accuracy.

Alternatively, the study contributed to the literature by assessing how multiple social supports influence total rule violations. Studies have only examined the impact of single programs, and have not examined the role of multiple social supports. This line of inquiry may assist in the development of research protocols that may aide in being able to examine the role of social supports in various correctional agencies. As previously discussed, examining rule violations and social supports is complicated, since the 
availability of programs varies widely and also reflects the variety of influences impacting how rule violations are enforced. In Oregon, as previously discussed there are more vocational programs available in men's prisons. However, the current study found that women were significantly more likely to participate in all of the social supports, except for drug and alcohol programs. This may also mean that while there may be more variety within men's prisons, more women may be participating in a smaller variety of programs. Similarly, this study shows the importance of being able to establish a timeline between rule violating behavior and program participation. There may be certain programs that best assist individuals at different time points during their long periods of incarceration. Finally, while using a dataset that provides information about incarcerated individuals throughout the country, the goal of this line of inquiry is not about being able to generalize to the entire prison population. Future studies will want to examine smaller units by potentially conducting case studies at individual prisons. The current study is attempting to begin a new line of inquiry.

\section{IMPLICATIONS AND RECOMMENDATIONS}

\section{Implications and Recommendations for Future Research}

The data utilized for the current study was collected in 2004 and represents prisons throughout the country. Future studies should examine the associations between social supports and rule violations on a much smaller scale. Explore what is happening within individual prisons within a single state, and then potentially replicate the study by examining all prisons within a state. The custody level, sex, location, region, age of facility, etc. are all going to effect the outcomes and availability of certain programs. 
Similarly, individual states are more likely to utilize the same curriculum for drug and alcohol, cognitive behavioral, parenting classes, etc. throughout all of their prisons. The custody level and availability of space will also influence which programs are available within each prison. Future studies need to more closely detail which programs are being assessed, instead of trying to overgeneralize a type of program.

Griffin and colleagues (2017) suggest that research on prison rule violations has compared individuals who have committed at least one rule violation to those who have committed no rule violations (i.e. Colvin, 2014; Jiang, Fisher-Giorlando, 2005; Steiner \& Meade, 2016; Steiner \& Wooldredge, 2014; Van Voorhis, 1994). They argue that individuals who are committing rule violations are behaving in ways that contrast individuals who have committed no rule violations. The current study examined only individuals who had committed one major rule violation. Even within the sample that only included individuals who had committed one major rule violation, there is a distinct difference between these individuals. The majority of the sample (53\%) committed only one or two major rule violations. However, the number of major rule violations ranged from 1 to 1,109 . The major rule violations more closely mimic behaviors that would require a reaction from the legal system outside of prison walls. In order to understand whether social supports are able to impact rule violating behaviors, future studies will want to continue examining the differences between individuals who are committing the major rule violations, versus those who are committing rule violations that would not require legal action outside of prison walls. Future studies may want to focus on individuals who are committing multiple major rule violations, since these individuals 
cause more chaos within prison facilities. Teasing apart these dynamics will aide correctional agencies in better understanding which types of social supports best assist individuals who are engaging in antisocial behaviors, in the hopes that these social supports will provide the motivation to begin engaging in more prosocial behaviors.

The current study relied on self-reports. The length of time served, for the current sample, ranged from less than a month to over forty-three years. Individuals were asked to recall how many rule violations, and whether they had been written up or found guilty of at least one major rule violation, throughout their entire incarceration. In an effort to depict a more accurate reality, future studies may consider examination of official records, especially to glean information about specific types of rule violations and how different types of rule violations are impacted by participation in various types of social supports and connections with outside support networks. Similarly, official records will allow future research to examine individuals who had received an official major rule violation, versus being written up for a major rule violation. Correctional officers have a huge impact on whether someone is forced through official channels as the result of a behavior, versus a correctional officer using unofficial and less stringent consequences for certain behaviors. Future studies may also provide correctional officers with more concrete guidelines for how and when it may be more appropriate to use official sanctions versus unofficial sanctions.

Another major consideration is that many of the social supports, included in the current study, are structured to include a graduation or a ceremony at the completion of the program. Drug and alcohol treatment and drug and alcohol programs, vocational 
programs, life skills, education programs, and parenting classes tend to utilize curriculums that culminate in some sort of ending ceremony. Future studies will want to examine whether completion of certain programs reduces rule violations in comparison to participation without completion. Individuals who engage in rule violating behaviors may not be the ones graduating or completing certain programs. This may point to a need for correctional agencies to determine whether certain programs are still effective with their population, or whether they may need to consider other versions of similar programs.

Along with better understanding the types of programs, Cullen (1994) does not provide guidance on whether instrumental social supports or expressive social supports have a bigger impact on prosocial behaviors. The current study found an interesting dynamic. When combined, the total expressive social supports were associated with a reduction in rule violations, while the combined instrumental social supports were associated with increased rule violations. These outcomes were not statistically significant, but future studies may want to examine the unique contributions of instrumental social supports versus expressive social supports. Expressive social supports, which are the emotional connections with others, may provide a more powerful control over antisocial behaviors. This form of social support also requires give and take between people (Cullen, 1994). Cullen argues that expressive social supports are both something an individual receives from others, and requires the individual to provide this same sort of support to others.

Finally, many institutions rely on programs being offered by volunteers, along with programs that are facilitated by other incarcerated individuals. Lazzari, Miller, and 
Lee (2019), who surveyed and conducted focus groups with incarcerated mothers, learned about the importance of the peer relationships for the incarcerated women. The women suggested that when they get to see each other as mothers instead of inmates, it changes the way they engage with each other. Instead of viewing each other as inmates, they engage with each other as mothers (Lazzari, Miller, \& Lee, 2019). Similarly, surveys conducted with incarcerated fathers led to the discovery that the men were also looking for ways to connect with each other that took them out of their roles as inmates and allowed them to engage with each other as fathers (ODOC, 2015). These type of interactions are more challenging to measure, but future research needs to begin more fully evaluating the impacts of peer relationships, which may be a cost effective way to offer more opportunities to engage with prosocial social supports.

\section{Implications and Recommendations for Practice}

When incarcerated individuals engage in prosocial behaviors, the result is a prison environment that is safer not only for the inmate population, but for staff and volunteers. We need better guidance in how to decide which types of programs and social supports best assist incarcerated populations in making the choice to engage in prosocial behaviors. Future research should also explore whether there are certain programs that best assist certain subgroups of incarcerated populations, since certain groups of incarcerated populations have distinct differences that need to be more fully explored (Miller et al., 2017). Knowing what programs work best for whom will provide tools to correctional agencies that will be most effective with their prison population. 
Participation in any drug/alcohol program was associated with lower rule violations. The association was not statistically significant. One of the things this study was unable to tease apart was what exactly the programs entailed and whether they included therapeutic communities. Similarly, participants were asked about participation and not completion of the drug/alcohol treatment or program. Taylor and colleagues (2019) found that incarcerated individuals who participated in drug and alcohol programs in therapeutic communities, where they are housed in an area separate from general population and live and eat with the others in that therapeutic community, committed fewer rule violations. Individuals who participated in drug education, support groups, or other "outpatient" modalities were not associated with a lower likelihood of committing rule violations. Correctional agencies need to know which types of programs are most effective for their population. Research has shown know that more than half (58\%) of state prisoners qualify as being drug addicted (Bronson, Zimmer, \& Berofsky, 2017), and yet only $7.8 \%$ of the males and $13.4 \%$ of the women participated in drug and alcohol programs. The current study supports the idea that participation in drug and alcohol programs may influence rule-violating behaviors. Correctional agencies need to provide these types of programs to larger proportions of their populations.

Individuals who identified that they had a work assignment and individuals who participated in visitations had significantly fewer rule violations. Having a work assignment was the only social support that remained statistically significant within the regression models. This means that individuals who have a work assignment have significantly fewer rule violations. Research has found that individuals who participate in 
prison work programs are less likely to commit rule violations (Celinska \& Sung, 2014; Jiang et al., 2005). This may indicate they have less idle time on their hands. Having a job also means that, while the individual will not be making a lot of money, there is some form of compensation for the work provided. The incentive of being able to put money on their books in order to purchase items off a canteen may influence how individuals are behaving in the prisons. Employment also provides a form of status for incarcerated individuals, may decrease stress on correctional officers (Batchelder \& Pippert, 2002), and may decrease operational costs for prison facilities (Batchelder \& Pippert, 2002; Flanagan, 1989; National Institute of Corrections, 1992).

Work skills have also been identified as a key component of successful prison rehabilitation and reintegration (Cullen \& Johnson, 2011). Individuals, who are able to maintain work, during incarceration, are also able to utilize those skills as they look for employment outside prison walls (Flanagan, 1989; Thompson, 2011). Many scholars argue that work assignments have been made available to the "appropriate" or select gender or racial/ethnic group (Crittenden, Koons-Witt, \& Kaminski, 2018; Franklin, 2008; Grana, 2010; Morash, Haar, \& Rucker, 1994). There are obvious limitations to which prisons are able to offer which jobs. When examining state prisons, some locations offer a multitude of work opportunities, while others many only a few. Similarly, the current study found that women $(68.9 \%)$ were significantly more likely to be in a work assignment, when compared to the men $(62.2 \%)$. Correctional agencies need to examine how they can successfully "employ" more of their prison population, and examine the decision processes behind which individuals are given which jobs. 
The incarcerated women were able to participate in all of the instrumental and expressive social supports at significantly higher rates for all except for one program. Women participated at a higher frequency in drug/alcohol programs, but the difference between the males' participation was not statistically significant. Throughout the US, there are 1.3 million people incarcerated in state prisons (Sawyer \& Wagner, 2019). Approximately 99,000 of these individuals are women (Kajtsura, 2018). There are significantly more men incarcerated, but the rate at which women are being incarcerated continues to increase. The current study's findings suggest there may be less program availability for incarcerated men. Prison overcrowding impacts space, availability of staff, availability of volunteers, and even having enough hours during the day to provide effective programs for all of the incarcerated men. If studies continue to suggest that participation in certain social supports assist in reducing rule violating behaviors, which may in turn make prisons safer and increase chances for successful reintegration, correctional agencies should ensure that the majority of their populations participate in these programs. When examining the social supports that were included in the current study (see Table 6), at least half of the males and half of the women participated in work assignments and religious activities. Less than half of both the male and female participants engaged with the other social supports (drug and alcohol treatment, drug and alcohol programs, interventions for future employment/job training, life skills, education programs, religious study groups, ethnic/racial support groups, parenting skills, visits, and phone calls). 
Along with the fact that women are able to participate in more social supports, it is worth discussing the frequency of their rule violations. The average length of incarceration for the men in the sample was almost 7 years, while for the women it was just over 4 years, and yet there was no a statistically significant difference in the amount of rule violations committed by men versus women. Correctional agencies may want to explore how women are being "policed" within prisons. Are correctional officers overreacting to female deviance and continuing to punish incarcerated women for breaking away from societal norms of what it means to be female?

Another point that the current study makes is that race matters. Race was the only demographic variable that remained statistically significant in each regression model. Prisons are microcosms of our society. Racial bias is present in police work and is also very present behind prison walls. Correctional officers may need more training around interpretation of culturally relevant behaviors. Prisons also operate within a hierarchical structure, which may mean that certain ideologies, designed to target certain individuals, is trickling down from the top executive level to the correctional officers on the front line.

Correctional agencies are faced with many complications in attempting to provide opportunities for incarcerated individuals to engage with social supports. Many incarcerated individuals are not able to participate in various programs due to overcrowding, lack of "classroom" space in a facility, not enough facilitators, and long wait-lists for certain programs (Chamberlain, 2012). Correctional agencies are also limited by the number of correctional officers in a facility, and whether providing certain programs may introduce other security risks. Correctional agencies, researchers, and 
policy makers need to work together to more fully understand what the very specific needs of the institutions are, in order to provide more opportunities for incarcerated individuals to continue building and rebuilding their social support networks.

\section{Implications and Recommendations for Policy}

Cullen and colleagues (1999) suggest that we need to shift how we approach dealing with criminal behaviors. They argue that while many of the control theories have explanatory power and have been able to reform through "Get Tough" policies, these control theories are missing huge components of important human relationships that exist for incarcerated populations. There are multitudes of interactions occurring between various groupings of people, within a prison, that have the ability to impact and transform whether incarcerated populations are engaging in criminal behaviors. What is missing from our current understanding is how these important connections to others, through the establishment of various social supports, impact behaviors.

Previous research has suggested that behaviors that lead to rule violations behind prison walls mimic those behaviors that lead to criminal charges when not incarcerated (Gendreau, Goggin, \& Law, 1997; Homant \& Witkowski, 2003; Jiang, Fisher-Giorlando, \& Mo, 2005). Every year, almost 81 billion dollars are spent on prisons and probation/parole systems, while almost one billion dollars is spent on prison programming (Wagner \& Rabuy, 2017). Policy makers want to ensure that the one billion dollars dedicated to education, employability and job training, as well as family-based programs (Sedgley, Scott, Williams, \& Derrick, 2010) is funneled towards programs that have the most significant impact. 
Cullen and colleagues (1999) suggest that one of the ways we can impact bigger policy changes is by appealing to some of those shared experiences we all have. Not everyone is able to relate to engaging in criminal behaviors. Everyone is able to relate to the importance of relationships with others, the availability of resources, and the need to learn skills for growth and success in life. By appealing to some of these shared experiences, and by providing evidence from research suggesting that social supports are able to positively affect experiences during incarceration and potential positive impacts on recidivism, we may be able to better engage with policy makers on a level that appeals to a more humanistic approach to prison rehabilitative efforts.

We also need to more fully explore how social supports impact men versus women, in order to provide the most effective treatment for each subgroup of the prison population. Many studies have found that incarcerated men and women have unique needs based upon their gender and the variations in their prison environments (Salisbury \& Van Voorhis, 2009; Steffensmeier \& Allan, 1996; Van Voorhis, Wright, Salisbury, \& Bauman, 2010). These dynamics need to be explored in order to continue assisting incarcerated individuals as they build and strengthen their support networks, which may assist in creating a safer prison environment. The current study was able to support the idea that incarcerated women have more social supports. This finding confirms what Jiang and Winfree (2006) found. They suggested that incarcerated women are more relationship orientated, and that male institutions are deeply steeped in power and coercion dynamics, that they are not as focused on building relationships with others. Therefore, incarcerated women may be more likely to have increased opportunities in 
being able to strengthen and build their support networks (Jiang \& Winfree, 2006; Zingraff, 1980).

Policies that impact correctional populations also need to examine the impact of race. The current study found that People of Color had significantly more rule violations than Whites. This may be due to how prisons enforce certain rules with certain populations of incarcerated individuals. This may also point to the fact the current supports for incarcerated individuals are not appropriate for People of Color. People of Color are adversely impacted by policies regarding discipline and punishment from school age through adulthood (Cole, 2019; Morris, 2016). Black men have a 1 in 3 chance of becoming incarcerated. Black women have a 1 in 18 chance of becoming incarcerated. White men have a 1 in 17 chance of becoming incarcerated. White women have a 1 in 111 chance of becoming incarcerated (The Sentencing Project, 2019). Correctional policies need to account for the disproportionate representation of People of Color. This means that interventions and strategies used may need to be normed on the experiences of People of Color versus just examining the differences between men and women.

\section{CONCLUSIONS}

The current study was designed to further expand our understanding of how social supports influence prison rule violations. The study produced results that partially supported Cullen's (1994) ideas that as social supports increase, we should be able to expect more prosocial behaviors. The impact of increased social supports was then applied to prison dynamics, and utilized prison rule violations as the way to assess how 
social supports impacted behaviors. The limitations of the data and how the data was collected challenged interpretations of the results. The current study supports the idea that there are certain types of social supports that affect rule violations. Similarly, future studies may want to implement a way to assess at what point during a period of incarceration certain types of social supports have the most impact.

Prison itself has the ability to create better criminals (Nagin, Cullen, \& Johnson, 2005). Therefore, correctional agencies must be challenged to create prison environments that are better suited for rehabilitation. Similarly, incarcerated populations should be given opportunities to build social empathy and engagement with social networks both inside and outside of prison. If community social service agencies provide environments that are safe and allow for growth, then correctional agencies may be held to similar standards (Harding, 2014). As individuals work to adjust to the new routines of prison life, rehabilitation occurs when the environment is one that allows for personal growth and development (Harding, 2014). This means that incarcerated individuals must feel safe enough in order to allow themselves to be vulnerable and allow change to occur. Incarcerated individuals who are able to rely upon their instrumental and expressive social supports are less likely to engage in violent behaviors (Rocheleau, 2015).

One of the goals of the current study was to assess the role of race and sex as moderators in the relationship between total social supports and total rule violations. The current study was unable to conduct moderation analysis, since total social supports and total rule violations were not significantly related. However, People of Color had significantly more rule violations than Whites. People of color had almost two times as 
many rule violations as Whites. As previously discussed, the role of race is very important to tease apart in the correctional system, since People of Color are disproportionately impacted by contact within the criminal justice system. This disproportionate contact starts as young as preschool and continues throughout the educational system and into adulthood (Cole, 2019; Morris, 2016). This dynamic needs to be furthered explored in order to create programs and social supports best suited to assist People of Color, since the majority of our current correctional programs have not been normed on the experiences of People of Color, but rather on the experiences of men versus women.

Miller and colleagues (2017) suggest that collapsing groups of people into these categories may not be the best way to understand some of these dynamics. Future studies may want to examine the role of political ideology at the time of the study, community beliefs, regional attitudes, religious beliefs, etc., that would require creating samples that pooled individuals from diverse regions throughout the US. Similarly, when examining the role of sex, studies have only focused on the role of binary, biological sex. While the current study did not find a significant difference in total rule violations between men and women, differentiating sexual identities and the various nuances may develop a much deeper understanding of how sexual identity influences behaviors during incarceration. Prisons throughout the US are just beginning to explore how to better care for transgender incarcerated individuals who tend to be exploited and abused by other incarcerated individuals and staff (Matricardi, 2016; Sumner \& Sexton, 2016). 
The current study sought to explore new ways to think about what contributes to some individuals' commission of rule violations compared to their counterparts who engage in fewer to no violations while incarcerated. Previous studies examined the unique impacts of parenting programs (Eddy, Martinez, Burraston, 2013; Eddy et al., 2008; Harris \& Pettway, 2007; Jarvis, Graham, Hamilton, \& Tyler, 2004; Loper \& Yuerk, 2006; Meek, 2007; Sandifer, 2008), drug and alcohol treatment (Orrick et al., 2011; Ray et al., 2017), education programs (Brazzell et al., 2009; Cho \& Tyler, 2013; Kim \& Clark, 2013; Pompoco et al., 2017), job training (Celinska \& Sung, 2014; Jiang et al., 2005), and religious programs (Camp, Daggett, Kwon, \& Kelin-Saffran, 2008; Celinska \& Sung, 2014; Clear \& Sumter, 2008; Jiang et al., 2005; Kerley, Copes, Tewksbury, \& Dabney, 2011; Kerley, Matthews, \& Blanchard, 2005). The current study created a new line of inquiry that may assist in beginning to conduct research that examines how the combination of multiple social supports impact the frequency of rule violating behaviors, in the hopes that a better understanding of which types of prison programs and other social supports encourage incarcerated populations to engage in prosocial behaviors. 


\section{References}

Adams, K. (1992). Adjusting to prison life. Crime and Justice, 16, 275-359.

Aiken, L.S., \& West, S.G. (1991). Multiple regression: Testing and interpreting interactions. Newbury Park, CA: Sage.

Alexander, M. (2010). The new Jim Crow: Mass incarceration in the age of colorblindness. New York, NY: The New Press.

Allred, S.L., Harrison, L.D., \& O’Connell, D.J. (2013). Self-efficacy: An important aspect of prison-based learning. The Prison Journal, 93(2), 211-233.

Andrews, D. A., \& Bonta, J. (2010). The psychology of criminal conduct (5th ed.). Cincinnati, OH: Andersson.

Andrews, D.A., Bonta, J., \& Hoge, R.D. (1990). Classification for effective rehabilitation: Rediscovering psychology. Criminal Justice \& Behavior, 17(1), 19-52.

Andrews, D.A., Bonta, J., \& Wormith, S.J. (2004). The level of service/case management inventory (LS/CMI). Toronto, Ontario, Canada: Multi-Health Systems.

Arditti, J.A. (2003). Locked doors and glass walls: Family visiting at a local jail. Journal of Loss and Trauma, 8(2), 115-138.

Arditti, J.A., \& Few, A.L. (2008). Maternal distress and women's reentry into family and community life. Family Process, 47(3), 303-321.

Arditti, J.A., \& Few, A.L. (2006). Mothers' reentry into family life following incarceration. Criminal Justice Policy Review, 17(1), 103-123.

Arditti, J.A., Lambert-Shute, J., \& Joest, K. (2003). Saturday morning at the jail: Implications of incarceration for families and children. Family Relations, 52(3), 
195-204.

Arrindell, W. A., \& van der Ende, J. (1985). An empirical test of the utility of the observations to variables ratio in factor and components analysis. Applied Psychological Measurement, 9(2), 165-178.

Baćak, V., \& Ridgeway, G. (2018). Availability of health-related programs in private and public prisons. Journal of correctional Health Care, 24(1), 62-70.

Bales, W.D., \& Mears, D.P. (2008). Inmate social ties and the transition to society: Does visitation reduce recidivism? Journal of Research in Crime and Delinquency, 45(3), 287-321.

Baron, R.M., \& Kenny, D.A. (1986). The moderator-mediator variable distinction in social psychological research: Conceptual, strategic, and statistical considerations. Journal of Personality \& Social Psychology, 51(6), 1173-1182.

Barrick, K., Lattimore, P.K., \& Visher, C.A. (2014). Reentering women: The Impact of social ties on long-term recidivism. The Prison Journa,l 94(3), 1-26.

Batchelder, J.S., \& Pippert, J.M. (2002). Hard time for the idle: Factors affecting inmate choices between participation in prison work and education programs. The Prison Journal, 82(2), 269-280.

Beckmeyer, J.J., \& Arditti, J.A. (2014). Implications of in-person visits for incarcerated parents' family relationships and parenting experience. Journal of Offender Rehabilitation, 53(2), 129-151.

Bell, K.E. (2017). Prison violence and the intersectionality of race/ethnicity and gender. Criminology, Criminal Justice, Law \& Society, 18(1), 106-121.

Bell, K.E., \& Lindekugel, D.M. (2015). Correlates of violence within Washington State prisons. Criminology, Criminal Justice Law, \& Society, 16(1), 21-34. 
Bentler, P. M., \& Kano, Y. (1990). On the equivalence of factors and components. Multivariate Behavioral Research, 25(1), 67-74.

Berg,M. T., \& DeLisi, M. (2006). The correctional melting pot: Race, ethnicity, citizenship, and prison violence. Journal of Criminal Justice, 34(6), 631-642.

Berg, M.T., \& Huebner, B.M. (2011). Reentry and the ties that bind: An examination of social ties, employment, and recidivism. Justice Quarterly, 28(2), 382-410.

Berk, R.A., Kriegler, B., \& Baek, J. (2006). Forecasting dangerous inmate misconduct: An applications of ensemble statistical procedures. UCLA: Department of Statistics, UCLA. Retrieved from https://escholarship.org/uc/item/2xk8s2dh

Bermudez-Edo, M., Barnaghi, P., \& Moessner, K. (2018). Analysing real world data streams with spatio-temporal correlations: Entropy vs. Pearson correlation. Automation in Construction, 88(1), 87-100.

Blackburn, A.G., \& Trulson, C.R. (2010). Sugar and spice and everything nice? Exploring institutional misconduct among serious and violent female delinquents. Journal of Criminal Justice, 38(6), 1132-1140.

Blevins, K. R., Listwan, S. J., Cullen, F. T., \& Jonson, C. L. (2010). A general strain theory of prison violence and misconduct: An integrated model of inmate behavior. Journal of Contemporary Criminal Justice, 26(2), 149-166.

Bloom, B., \& Covington, S. (2009). Addressing the mental health needs of women offenders. In R. L. Gido \& L. P. Dalley (Eds.), Women's mental health issues across the criminal justice system (pp. 160-176). Upper Side River, NJ: Pearson Prentice Hall.

Boman, J.H., \& Mowen, T.J. (2017). Building the ties that bind, breaking the ties that don’t: Family support, criminal peers, and reentry success. Criminology \& Public Policy, 16(3), 753-774. 
Bonner, H.S., Rodriguez, F.A., Sorensen, J.R. (2017). Race, ethnicity, and prison disciplinary misconduct. Journal of Ethnicity in Criminal Justice, 15(1), 36-51.

Bouchet,S.M. (2008). Children and families with incarcerated parents: Exploring development in the field and opportunities for growth. Retrieved from Annie E. Casey Foundation website https://folio.iupui.edu/bitstream/handle/10244/138/Children\%20and\%20families $\% 20$ with $\% 20$ incarcerated $\% 20$ parents.pdf? sequence $=1$

Britton, D.M. (1997). Perceptions of the work environment among correctional officers: Do race and sex matter? Criminology, 35(1), 85-106.

Brazzell, D., Crayton, A., Mukamal, D.A., Solomon, A.L., \& Lindahl, N. (2009). From the classroom to the community: Exploring the role of education during incarceration and reentry. Washington DC: Urban Institute.

Bronson, J., Zimmer, S., \& Berzofsky, M. (2017, June). Drug use, dependence, and abuse among state prisoners and jail inmates, 2007-2009 (NCJ 250546). Retrieved from the U.S. Department of Justice website: https://www.bjs.gov/content/pub/pdf/dudaspji0709.pdf

Brosens, D., DE Donder, L., Dury, S., \& Verté, D. (2016). Participation in prison activities: An analysis of the determinants of participation. European Journal of Criminology Policy Research, 22(4), 669-687.

Bui, H.N., \& Morash, M. (2010). The impact of network relationships, prison experiences, and internal transformation on women's success after prison release. Journal of Offender Rehabilitation, 49(1), 1-22.

Bureau of Justice Statistics. (2003). Education and Correctional Populations. (U.S. Department of Justice, NCJ 95670). pp. 1-5. Washington, D.C. 
Bureau of Justice Statistics. (2007). Survey of Inmates in state and federal correctional facilities, 2004: Description (ICPSR 4572). Ann Arbor, MI: Inter-university Consortium for Political and Social Research.

Bureau of Justice Statistics. (2017, September 28). Reentry trends in the US. Retrieved from https://www.bjs.gov/content/reentry/releases.cfm\#number

Byrne, J.M., Hummer, D., \& Stowell, J. (2008). Prison violence, prison culture, and offender change: New directions for research, theory, policy, and practice. In J. Byrne, D. Hummer, \& F.X. Taxman (Eds.), The culture of prison violence (pp.202-219). Boston, MA: Pearson/Allyn \& Bacon.

Camp, S.D., Daggett, D.M., Kwon, O., \& Klein-Saffran, J. (2008). The effect of faith program participation on prison misconduct: The Life Connections Program. Journal of Criminal Justice, 36(5), 389-395.

Camp, S.D., Gaes, G.G., Langan, N.P., \& Saylor, W.G. (2003). The influence of prisons on inmate misconduct: A multi-level investigation. Justice Quarterly, 20(3), 501533.

Cao, L., Zhao, J., \& Van Dine, S. (1997). Prison disciplinary tickets: A test of the deprivation and importation models. Journal of Criminal Justice, 25(2), 103-113.

Carson, E.A. (2014). Prisoners in 2013. Retrieved from Bureau of Justice Statistics website. https://www.bjs.gov/content/pub/pdf/p13.pdf

Casey-Avecedo, K., \& Bakken, T. (2002). Visiting women in prison: Who visits and who cares. Journal of Offender Rehabilitation, 34(3), 67-83. 
Casey-Acevedo, K., Bakken, T., \& Karle, A. (2004). Children visiting mothers in prison: The effects on mothers' behavior and disciplinary adjustment. The Australian and New Zealand Journal of Criminology, 37(3), 418-430.

Celinska, K., \& Siegel, J.A. (2010). Mothers in trouble: Coping with actual or pending separation from children due to incarceration. The Prison Journal, 90(4), 447474. doi: $10.1177 / 00.28855103282218$

Celinska, K., \& Sung, H.E. (2014). Gender differences in the determinants of prison rule violations. The Prison Journal, 94(2), 220-241.

Center on Addiction and Substance Abuse. (February 2010). Behind bars II: Substance abuse and America's prison population. Retrieved from CASAColumbia website: https://www.centeronaddiction.org/addiction-research/reports/behind-bars-iisubstance-abuse-and-america's-prison-population.

Chamberlain, A.W. (2012). Offender rehabilitation: Examining changes in inmate treatment characteristics, program participation, and institutional behavior. Justice Quarterly, 29(2), 183-228.

Cho, R.M., \& Tyler, J.H. (2013). Does prison-based adult basic education improve postrelease outcomes for male prisoners in Florida? Crime \& Delinquency, 59(7), 975-1005.

Cid, J., \& Martí, J. (2017). Imprisonment, social support, and desistance: A theoretical approach to pathways of desistance and persistence for imprisoned men. International Journal of Offender Therapy and Comparative Criminology, 61(13), $1433-1454$. 
Cihan, A., Davidson, M., \& Sorensen, J. (2017). Analyzing heterogeneous nature of inmate behavior: Trajectories of prison misconduct. The Prison Journal, 97(4), 431-450.

Clear, T.R., \& Sumter, M.T. (2008). Prisoners, prison, and religion: Religion and adjustment to prison. Journal of Offender Rehabilitation, 35(3), 122-156.

Clemmer, D. (1940). The prison community. Boston, MA: Christopher.

Cobbina, J.E., Huebner, B.M., \& Berg, M.T. (2012). Men, women, and postrelease offending: An examination of the nature of the link between relational ties and recidivism. Crime \& Delinquency, 58(3), 331-361.

Cochran, J.C. (2014). Breaches in the wall: Imprisonment, social support, and recidivism. Journal of Research in Crime and Delinquency, 51(2), 200-229.

Cochran, J.C. (2012). The ties that bind or the ties that break: Examining the relationship between visitation and prisoner misconduct. Journal of Criminal Justice, 40(5), 433-440.

Cochran, J.C., \& Mears, D.P. (2013). Social isolation and inmate behavior: A conceptual framework for theorizing prison visitation and guiding and assessing research. Journal of Criminal Justice, 41(4), 252-261.

Cohen, J. (1983). The cost of dichotomization. Applied Psychological Measurement, 7(3), 249-253.

Cohen, J., \& Cohen, P. (1983). Applied multiple regression/correlation analysis for the behavioral sciences. Hillsdale, NJ: Lawrence Erlbaum Associates, Inc.

Cohen, J., Cohen, P., West, S.G., \& Aiken, L.S. (2003). Applied multiple regression/correlation analysis for behavioral sciences (3rd ed.). Mahwah, NJ: 
Erlbaum.

Cole, N.L. (May 30, 2019). Understanding the school to prison pipeline. Retrieved from https://www.thoughtco.com/school-to-prison-pipeline-4136170

Colvin, M. (2007). Applying differential coercion and social support theory to prison organizations: The case of the penitentiary of New Mexico. The Prison Journal, 87(3), 367-387.

Colvin, M., Cullen, F.T., \& Vander Ven, T. (2002). Coercion, social support, and crime: An emerging theoretical consensus. Criminology, 40(1), 19-42.

Costello, A.B., \& Osborne, J.W. (2005). Best practices in exploratory factor analysis: Four recommendations for getting the most from your analysis. Practical Assessment, Research, \& Evaluation, 10(7), 1-9.

Craddock, A. (1996). A comparative study of male and female prison misconduct careers. The Prison Journal, 76(1), 60-80.

Crayton, A., \& Neusteter, S.R. (2008). The current state of correctional education. Paper presented at the Reentry Roundtable on Education, John Jay College of Criminal Justice, New York, March 31.

Crittenden, C.A., \& Koons-Witt, B.A. (2017). Gender and programming: A comparison of program availability and participation in U.S. Prisons. International Journal of Offender Therapy and Comparative Criminology, 61(6), 611-644.

Crittenden, C.A., Koons-Witt, B.A., \& Kaminski, R.J. (2018). Being assigned work in prison: Do gender matter? Feminist Criminology, 13(4), 359-381/.

Cullen, F.T. (2013). Rehabilitation: Beyond nothing works. Crime and Justice, 42(1), 299-376.

Cullen, F.T. (2012). Taking rehabilitation seriously: Creativity, science, and the challenge 
of offender change. Punishment \& Society, 14(1), 94-114.

Cullen, F.T. (1994). Social supports as an organizing concept for criminology: Presidential address to the Academy of Criminal Justice Sciences. Justice Quarterly, 11(4). 527-559.

Cullen, F.T., \& Gendreau, P. (2000). Assessing correctional rehabilitation: Policy, practice, and prospects. In J. Horney (Ed.), Criminal justice 2000 ( $3^{\text {rd }}$ ed., pp. 109-175). Washington DC: US Department of Justice.

Cullen, F.T., \& Jonson, C.L. (2011). Rehabilitation and treatment programs. In J.Q. Wilson \& J. Petersilia (Eds.), Crime and public policy (2nd ed., pp 23-34). New York, NY: Oxford University Press.

Cullen, F.T., Jonson, C.L., \& Nagin, D.S. (2011). Prisons do not reduce recidivism: the high cost of ignoring science. The Prison Journal, 91(3), 485-655.

Cullen, F.T., Link, B., Wolfe, N., \& Frank, J. (1985). The social dimensions of correctional officer stress. Justice Quarterly, 2(4), 505-533.

Cullen, F.T., Smith, P., Lowenkamp, C.T., \& Latess, E.J. (2009). Nothing works revisited: Deconstructing Farabees's rethinking rehabilitation. Victims \& Offenders, 4, 11-123.

Cullen, F.T., Wright, J.P., \& Chamlin, M.B. (1999). Support and social reform: A progressive crime and control agenda. Crime and Delinquency, 45(2), 188-207.

Cunningham, A. (2001). Forgotten families: The impacts of imprisonment. Family Matters, 59, 35-38.

Cunningham, M. D., Reidy, T. J., \& Sorensen, J. R. (2016). Wasted resources and gratuitous suffering: The failure of a security rationale for death row. Psychology, Public Policy and Law, 22(2), 185-199. 
Cunningham, M. D., \& Sorensen, J. R. (2007). Predictive factors for violent misconduct in close custody. The Prison Journal, 87(2), 241-253.

Daggett, D.M., \& Camp, S.D. (2009). Do official misconduct data tell the same story as the individuals who live in prison? Criminal Justice Review, 34(3), 428-449.

Dallaire, D.H., Ciccone, A., \& Wilson, L.C. (2010). Teachers' experiences with and expectations of children with incarcerated parents. Journal of Applied Developmental Psychology, 31(4), 281-290.

Dalley, L. P., \& Michels, V. (2009). Women destined to failure: Policy implications of the lack of proper mental health and addiction treatment for female offenders. In R. L. Gido \& L. P. Dalley (Eds.), Women's mental health issues across the criminal justice system (pp. 160-176). Upper Side River, NJ: Pearson Prentice Hall.

Day, J.C., Brauer, J.R., \& Butler, H.D. (2015). Coercion and social support behind bars: Testing an integrated theory of misconduct and resistance in U.S. prisons. Criminal Justice And Behavior, 42(2), 133-155.

De Claire, K., \& Dixon, L. (2017). The effects of prison visits from family members on prisoners' well-being, prison rule breaking, and recidivism: A review of the research since 1991. Trauma, Violence, \& Abuse, 18(2), 185-199.

DeHart, D. D. (2008). Pathways to prison. Impact of victimization in the lives of incarcerated women. Violence Against Women, 14(12), 1362-1381.

DeLisi, M. (2016). Career criminals and the antisocial life course. Child Development Perspectives, 10(1), 53-58.

DeLisi, M. (2003). Criminal careers behind bars. Behavioral Sciences and the Law, 21(5), 653-669.

DeLisi, M., Berg, M. T., \& Hochstetler, A. (2004). Gang members, career criminals, and Prison violence: Further specification of the importation model of inmate 
behavior. Criminal Justice Studies, 17, 369-383.

DeLisi, M., Caudill, J.W., Trulson, C.R., Marquart, J.W., Vaughn, M.G., \& Beaver, K.M. (2010). Angry inmates are violent inmates: A Poisson regression approach to youthful offenders. Journal of Forensic Psychology Practice, 10(5), 419-439.

Dietz, E.F., O’Connell, D.J., \& Scarpitti, F.R. (2003). Therapeutic communities and prison management: An examination of the effects of operating an in-prison therapeutic community on levels of institutional disorder. International Journal of Offender Therapy and Comparative Criminology, 47(2), 210-223.

Dilulio, J.J. (1991). No escape: The future of American Corrections. New York, NY: Basic Books.

Durkheim, E. (1951). Suicide: a study in sociology [1897]. Translated by JA Spaulding and G. Simpson. Glencoe, Illinois: The Free Press, 1951.

Durose, M.R., Cooper, A.D., \& Snyder, H.N. (2014). Recidivism of prisoners released in 30 States in 2005: Patterns from 2005-2010. U.S. Department of Justice. Retrieved from: https://www.bjs.gov/content/pub/pdf/rprts05p0510.pdf

Duwe, G., \& Clark, V. (2013). Blessed be the social ties that bind: The effects of prison visitation on offender recidivism. Criminal Justice Policy Review, 24(3), 271-296.

Duwe, G., \& Johnson, B.R. (2016). The effects of prison visits from community volunteers on offender recidivism. The Prison Journal, 96(2), 279-303.

Dye, M.H., Aday, R.H., Farney, L., \& Raley, J. (2014). “The rock I cling to”: Religious engagement in the lives of life-sentenced women. The Prison Journal, 94(3), 388408.

Eddy, J.M., Martinez, C.R., \& Burraston, B. (2013). VI. A randomized controlled trial of a parent management training program for incarcerated parents: Proximal 
impacts. Monographs of the Society for Research in Child Development, 78(3), $75-93$.

Eddy, J.M., Martinez, C.R., Schiffmann, T., Newton, R., Olin, L., Leve, L., Foney, D.M., \& Shortt, J.W. (2011). Development of a multisystemic parent management training intervention for incarcerated parents, their children and families. Clinical Psychologist, 12(3), 86-98.

Ellis, D., Grasmick, H. G., \& Gilman, B. (1974). Violence in prisons: A sociological analysis. The American Journal of Sociology, 80(1), 16-43.

Farrington, D. P., \& West, D. J. (1995). Effects of marriage, separation, and children on offending by adult males. In Z. S. Blau (Ed.), Current perspectives on aging and the life cycle (Vol. 4, pp. 249-281). Greenwich, CI: JAI Press Inc.

Feeley, M.M., \& Simon, J. (1992). The new penology: Notes on the emerging strategy of corrections and its implications. Criminology, 30(4), 449-474.

Flanagan, T.J. (1980). Time served and institutional misconduct: Patterns of involvement in disciplinary infractions among long-term and short-term inmates. Journal of Criminal Justice, 8(6), 357-367.

Flanagan, T.J. (1989). Prison labor and industry. In L. Goodstein \& D.L. MacKenzie (Eds.), The American prison: Issues in research and policy (pp. 135-161). New York, NY: Plenum Press

Floyd, F. J., \& Widaman, K. F. (1995). Factor analysis in the development and refinement of clinical assessment instruments. Psychological Assessment, 7(3), 286-299.

Ford, J. K., MacCallum, R. C., \& Tait, M. (1986). The application of exploratory factoranalysis in applied psychology: A critical-review and analysis. Personnel Psychology, 39(2), 291-314. 
Foster, H. (2012). The strain of maternal imprisonment: Importation and deprivation stressors for women and children. Journal of Criminal Justice, 40(3), 221-229.

Franklin, C.A. (2008). Women offenders, disparate treatment, and criminal justice: A theoretical, historical, and contemporary overview. Criminal Justice Studies, 21(4), 341-360.

Frazier, P.A., Tix, A.P., \& Barron, K.E. (2004). Testing moderator and mediator effects in counseling psychology. Journal of Counseling Psychology, 51(1), 115-134.

French, S.A., \& Gendreau, P. (2006). Reducing prison rule violations: What works! Criminal Justice And Behavior, 33, 185-218.

Gaes, G.G., Wallace, S., Gilman, E., Klein-Saffran, J., \& Suppa, S. (2002). The influence of prison gang affiliation on violence and other prison misconduct. The Prison Journal, 82(3), 359-385.

Geller, A. (2013). Paternal incarceration and father-child contact in fragile families. Journal of Marriage and Family, 75(5), 1288-1301.

Gendreau, P., \& Goggin, C., \& Law, M.A. (1997). Predicting prison rule violations. Criminal Justice \& Behavior, 24, 414-431.

Gendreau, P., Smith, P., \& French, S. A. (2006). The theory of effective correctional intervention: Empirical status and future directions. In F. T. Cullen, J. P. Wright, \& K. R. Blevins (Eds.), Advances in Criminological Theory: Taking stock: The status of criminological theory (Vol. 15, pp. 419-446). New Brunswick, NJ: Transaction.

Glaze, L.E., \& Maruschak, L.M. (2010). Parents in prison and their minor children. Retrieved from Bureau of Justice Statistics https://bjs.gov/content/pub/pdf/pptmc.pdf 
Gonzalez, P., Romero, T., \& Cerbana, C.B. (2007). Parent education programs for incarcerated mothers in Colorado. The Journal of Correctional Education, 58(4), 357-373.

Gorsuch, R. L. (1990). Common factor-analysis versus component analysis: Some well and little known facts. Multivariate Behavioral Research, 25(1), 33-39.

Gover, A. R., Perez, D. A., \& Jennings, W. G. (2008). Gender differences in factors contributing to institutional misconduct. The Prison Journal, 88(3), 378-403.

Gramlich, J. (April 30, 2019). The gap between the number of blacks and Whites in prison is shrinking. Retrieved from the PEW Research Center website: https://www.pewresearch.org/fact-tank/2019/04/30/shrinking-gap-betweennumber-of-blacks-and-Whites-in-prison/

Gray, T., Mays, G.L., \& Stohr, M.K. (1995). Inmate needs and programming in exclusively women's jails. The Prison Journal, 75(2), 186-202.

Greenburg, E., Dunleavy, E., \& Kutner, M. (2007). Literacy behind bars: Results from the 2003 national assessment of adult literacy prison survey. Washington, DC: National Center for Education Statistics.

Griffin, M.L., \& Hepburn, J.R. (2006). The effect of gang affiliation on violent misconduct among inmates during the early years of confinement. Criminal Justice and Behavior, 33(4), 419-466.

Griffin, V.W., Lee, G.M., Vito, A.G., \& Walker, J.T. (2017). It's not black and White: A conjunctive analysis of racial differences in incidents of prison misconduct. Corrections: Policy, Practice, and Research, 1-27.

Grinstead, O., Faigeles, B., Bancroft, C., \& Zack, B. (2001). The financial cost of 
maintaining relationships with incarcerated African American men: A survey of women prison visitors. Journal of African American Men, 6(1), 59-70.

Guadagnoli, E., \& Velicer, W. F. (1988). Relation of sample size to the stability of component patterns. Psychological Bulletin, 103(2), 265-275.

Hairston, C.F. (1988). Family ties during imprisonment: Do they influence future criminal activity? Federal Probation, 88, 48-52.

Hairston, C.F. (2002, January). Prisoners and families: Parenting issues during incarceration. Paper presented at the U.S. Department of Health and human services conference, "From Prison to Home" Paper retrieved from http://aspe.hhs.gov/hsp/prison2home02/Hairston.htm

Harding, R. (2014). Rehabilitation and prison social climate: Do 'what works' rehabilitation programs work better in prisons that have a more positive social climate? Australian \& New Zealand Journal of Criminology, 47(2), 163-175.

Hardyman, P. L., \& Van Voorhis, P. (2004).Developing Gender-specific Classification Systems for Women Offenders. Washington, DC: USDOJ, National Institute of Corrections. Retrieved from https://nicic.gov/developing-gender-specificclassification-systems-women-offenders.

Harer, M. D., \& Langan, N. P. (2001). Gender differences in predictors of prison violence: Assessing the predictive validity of a risk classification system. Crime and Delinquency, 47(4), 513-536

Harlow, C.W. (2003). Education and correctional populations. Washington DC: Bureau of Justice Statistics.

Harris, M., \& Pettway, C. (2007). Best practices tool-kit: Incarcerated parents and parenting programs. Ohio Institute on Correctional Best Practices. Retrieved from 
Ohio Department of Rehabilitation and Correction https://kb.osu.edu/bitstream/handle/1811/32498/ToolKit\%20Incarcerated\%20Parents\%20and\%20Parenting\%20Programs.pdf?sequenc $\mathrm{e}=1$

Harris, M.S. (2017). Incarcerated mothers: Trauma and attachment issues. Smith College Studies in Social Work, 87(1), 26-42.

Hensely, C., Kocheski, M., \& Tewksbury, R. (2002). Does participation in conjugal visitations reduce prison violence in Mississippi? An exploratory study. Criminal Justice Review, 27(1), 52-65.

Hepburn, J.R. (1985). The exercise power in coercive organizations: A study of prison guards. Criminology, 23(1), 145-164.

Hogarty, K.Y., Hines, C.V., Kromrey, J.D., Ferron, J.M., Mumford, K.R. (2005). The quality of factor solutions in exploratory factor analysis: The influence of sample size, communality, and overdetermination. Educational \& Psychological Measurement, 65(2), 202-226.

Homant, R.J., \& Witkowski, M.J. (2003). Prison deviance as a predictor of general deviance: Some correlational evidence from Project GANGMILL. Journal of Gang Research, 10(2), 65-75. Retrieved from https://www.ncjrs.gov/App/Publications/abstract.aspx?ID=199862

Houck, K.D.F., \& Loper, A.B. (2002). The relationship of parenting stress to adjustment among mothers in prison. American Journal of Orthopsychiatry, 72(4), 548-558.

Houser, K., \& Belenko, S. (2015). Disciplinary responses to misconduct among female prison inmates with mental illness, substance use disorders, and co-occurring disorders. American Psychological Association, 38(1), 24-34. 
Huebner, B.M. (2003). Administrative determinates of inmate violence: A multi-level analysis. Journal of Criminal Justice, 31(2), 107-117.

Irwin, J., \& Cressey, D.R. (1962). Thieves, convicts, and the inmate culture. Social Problems, 10(2), 142-155.

James, L.R., \& Brett, J.M. (1984). Mediators, moderators, and tests for mediation. Journal of Applied Psychology, 69(2), 307-321.

Jarvis, J., Graham, S., Hamilton, P., \& Tyler, D. (2004). The role of parenting classes for young fathers in prison: A case study. Probation Journal: The Journal of Community and Criminal Justice, 51(1), 21-33.

Jensen, E.L., \& Reed, G.E. (2006). Adult correctional education programs: An update on current status based on recent studies. Journal of Offender Rehabilitation, 44(1), 81-98.

Jacobs, J.B., \& Kraft, L.J. (1978). Integrating the keepers: A comparison of black and White prison guards in Illinois. Social Problems, 25(3), 304-318.

Jiang, S. (2005). Impact of drug use on inmate misconduct: A multi-level analysis. Journal of Criminal Justice, 33(2), 153-163.

Jiang, S., Fisher-Giorlando, M., \& Mo, L. (2005). Social support and inmate rule violations: A multi-level analysis. American Journal of Criminal Justice, 30(1), 72-86.

Jiang, S., \& Winfree, L.T. (2006). Social support, gender, and inmate adjustment to prison life: Insights from a national sample. The Prison Journal, 86(1), 32-55.

Kahl, D.T. (1998). A social worker's dilemma: Should children visit incarcerated parents? (Master's thesis). Available from ProQuest Dissertations and Theses database. (UMI No. 1392026) 
Kajstura, A. (November 13, 2018). Women's mass incarceration: The whole pie 2018. Retrieved from Prison Policy Initiative website: https://www.prisonpolicy.org/reports/pie2018women.html

Kazemian, L., \& Travis, J. (2015). Imperative for inclusion of long termers and lifers in research policy. Criminology \& Public Policy, 14(2), 355-395.

Kerley, K. R., Copes, H., Tewksbury, R., \& Dabney, D. A. (2011). Examining the relationship between religiosity and self-control as predictors of prison deviance. International Journal of Offender Therapy and Comparative Criminology, 55(8), $1251-1271$.

Kerley, K. R., Matthews, T. L., \& Blanchard, T. C. (2005). Religiosity, religious participation, and negative prison behaviors. Journal for the Scientific Study of Religion, 44(4), 443-457.

Kigerl, A., \& Hamiltion, Z. (2016). The impact of transfers between prisons on inmate misconduct: Testing importation, deprivation, and transfer theory models. The Prison Journal, 96(2), 232-257.

Kim, R.H., \& Clark, D. (2013). The effect of prison-based college education programs on recidivism: Propensity score matching approach. Journal of Criminal Justice, 41(3), 196-204.

Kuanliang, A., Sorensen, J.R., \& Cunningham, M.D. (2008). Juvenile inmates in an adult prison system: Rate of disciplinary misconduct and violence. Criminal Justice and Behavior, 35(9), 1186-1201.

Lahm, K.F. (2017), Violent and nonviolent misconduct among female inmates: An exploration of competing theories. Victims \& Offenders, 12(2), 175-204.

Lahm, K.F. (2009a). Inmate assaults on prison staff: A multilevel examination of an overlooked form of prison violence. The Prison Journal, 89(2), 131-150. 
Lahm, K.F. (2009b). Educational participation and inmate misconduct. Journal of Offender Rehabilitation, 48(1), 37-52.

Lahm, K. (2008). Inmate-on-inmate assault: A multilevel examination of prison violence. Criminal Justice and Behavior, 35(1), 120-137.

Langan, N.P., \& Pelissier, B.M. (2001). Gender differences among prisoners in drug treatment. Journal of Substance Abuse, 13(3), 291-301.

Laub, J.H., Nagin, D.S., \& Sampson, R.J. (1998). Trajectories of change in criminal offending: Good marriages and the desistance process. American Sociological Review, 63(2), 225-238.

Latessa, E.J., Lugo, M., Pompoco, A., Sullivan, C., \& Wooldredge, J. (2015). Evaluation of Ohio's prison programs. Cincinnati, OH: Center for Crime Justice Research, University of Cincinnati

La Vigne, N.G., Davies, E., \& Brazzell, D. (2008, February). Broken bonds: Understanding and addressing the needs of children with incarcerated parents. Urban Institute Justice Policy Center. Retrieved from www.urban.org

La Vigne, N.G., Naser, R.L., Brooks, L.E., \& Castro, J.L. (2005). Examining the effect of incarceration and in-prison family contact on prisoners' family relationships. Journal of Contemporary Criminal Justice, 21(4), 314-350.

Lazzari, S.R., Miller, K.M., \& Lee, J. (2019). Opening the 'black box': Exploring an enhanced visitation at a women's prison. Journal of Social Service Research, 45(5), 684-695.

Leban, L., Cardwell, S.M., Copes, H., \& Brezina, T. (2016). Adapting to prison life: A qualitative examination of the coping process among incarcerated offenders. Justice Quarterly, 33(6), 943-969. 
Lee, J.A. (2000). Women prisoners, penological interests, and gender stereotyping: An application of equal protection norms to female inmates. Columbia Human Rights Review, 32, 251-288.

Lee, C.B., Sansone, F.A., Swanson, C., Tatum, K.M. (2012). Incarcerated fathers and parenting: Importance of the relationship with their children. Social Work in Public Health, 27(1-2), 165-186.

Lewis, M. (2007). Stepwise versus hierarchical regression: Pros and cons. Retrieved from http://www.academia.edu/1860655/Stepwise_versus_hierarchical_regression_Pro s_and_cons

Liebling, A. (1999). Prison suicide and prisoner coping. Crime and Justice, 26, 283-359.

Light, S.C. (1990). Measurement error in official statistics: Prison rule infraction data. Federal Probation, December, 63-68.

Lindsey, A.M., Mears, D.P., Cochran, J.C., Bales, W.D., \& Stults, B.J. (2017). In prison and far from home: Spatial distance effects on inmate misconduct. Crime \& Delinquency, 63(9), 1043-1065.

Listwan, S. J., Sullivan, C. J., Agnew, R., Cullen, F. T., \& Colvin, M. (2013). The pains of imprisonment revisited: The impact of strain on inmate recidivism. Justice Quarterly, 30(1), 144-168.

Liu, S., Pickett, J.T., \& Baker, T. (2014). Inside the black box: Prison visitation, the costs of offending, and inmate social capital. Criminal Justice Policy Review, 27(8), 766-790.

Liu, Y., Xia, Q., Xia, J., Zhu, H., Jiang, H., Chen, X., Zheng, Y., Zhang, F., \& Li, S. (2019). The impact of marriage on the overall survival of prostate cancer patients: A surveillance, epidemiology, and end results (SEER) analysis. Canadian 
Urological Association Journal, 13(5), 135-139.

Lombardo, L.X. (1981). Guards imprisoned. New York, NY: Elsevier.

Loper, A.B., \& Tuerk, E.H. (2006). Parenting programs for incarcerated parents: Current research and future directions. Criminal Justice Policy Review, 17(4), 407-427.

Loper, A.B., Carlson, L.W., Levitt, L., \& Scheffel, K. (2009). Parenting stress, alliance, child contact, and adjustment of imprisoned mothers and fathers. Journal of Offender Rehabilitation, 48(6), 483-503.

Lovell, D., \& Jemelka, R. (1996). When inmates misbehave: The costs of discipline. The Prison Journal, 76(2), 165-179.

Mai, C., \& Subramanian, R. (2017). Price of prisons 2015: Examining state spending trends, 2010-2015. New York: Vera Institute of Justice.

Malgady. R.G., \& Krebs, D.E. (1986). Understanding correlation coefficients and regression. Physical Therapy 66(1), 110-120.

Martos-García, D., Devís-Devís, J., \& Sparkes, A.C. (2009). Sport and physical activity in a high security Spanish prison: An ethnographic study of multiple meanings. Sport, Education, \& Society, 14(1), 77-96.

Martin, S.J. (2000). Inside looking out: Perceptions of jailed fathers regarding separation from children (Doctoral Dissertation). Retrieved from UMI (9959144).

Martin, M. D., \& Kaledas, R. J. (2010). Programs and activities: tools for managing inmate behavior. US Department of Justice, National Institute of Corrections.

Martinson, R. (1974). What works? Questions and answers about prison reform. Public Interest, 35, 22-54.

Martricardi, D. (2016). Binary imprisonment: Transgender inmates ensnared within the 
system and confined to assigned gender. Mercer Law Review, 67(3), 707-739.

May, C., Sharma, N., \& Stewart, D. (2008). Factors linked to reoffending: A one year follow up of prisoners who took part in resettlement surveys 2001, 2003 and 2004. Research Summary 5. London, England: Ministry of Justice.

Mears, D.P. (2008). Accountability, efficiency, and effectiveness in corrections: Shining a light on the black box of prison systems. Criminology \& Public Policy, 7, 143152.

Mears, D.P., Cochran, J.C., Siennick, S.E., \& Bales, W.D. (2012). Prison visitation and recidivism. Justice Quarterly, 29(6), 888-918.

Meek, R. (2007). Parenting education for young fathers in prison. Child and Family Social Work, 12(3), 239-247.

Meek, R., \& Lewis, G. (2014). The impact of a sports initiative for young men in prison: Staff and participant perspectives. Journal of Sports \& Social Issues, 38(2), 95123.

Meyers, T.J., Wright, K.A., Young, J.T.N., \& Tasca, M. (2017). Social support from outside the walls: Examining the role of relationship dynamics among inmates and visitors. Journal of Criminal Justice, 52, 57-67.

Miller, K.M., Eddy, J.M., Borja, S., \& Lazzari, S.R. (2017). Variations in the life histories of incarcerated parents by race and ethnicity: Implications for service provision. Smith College Studies in Social Work, 87(1), 59-77.

Mitchell, M.M., Spooner, K., Jia, D., \& Zhang, Y. (2016). The effect of prison visitation on reentry success: A meta-analysis. Journal of Criminal Justice, 47, 74-83.

Moffitt, T. (1993). Adolescence-limited and life-course-persistent antisocial behavior: A developmental taxonomy. Psychological Review, 100(4), 674-701. 
Moloney, K.P., van den Bergh, B.J.., \& Moller, L.F. (2009). Women in prison: The central issues of gender characteristics and trauma history. Public Health, 123(6), 426-430.

Monahan, K.C., Goldweber, A.,\& Cauffman, E. (2011). The effects of visitations on incarcerated juvenile offenders: How contact with the outside impacts adjustment on the inside. Law and Human Behavior, 35(2), 143-151.

Morris, M.W. (2016). Pushout: The criminalization of black girls in schools. New York: The New Press.

Morris, R.G., Carriga, M.L., Diamond, B., Pieuqero, N.L., \& Piquero, A.R. (2012). Does prison strain lead to misbehavior? An application of general strain theory to inmate misconduct. Journal of Criminal Justice, 40(3), 194-201.

Morris, R.G., \& Worrall, J.L. (2014). Prison architecture and inmate misconduct: a multilevel assessment. Crime \& Delinquency, 60(7), 1083-1109.

Nagin, D., Cullen, F., \& Jonson, C. (2009). Imprisonment and reoffending. Crime \& Justice, 38(1), 115-200.

National Center on Addiction and Substance Abuse. (2010). Behind bars II: Substance abuse and America's prison population. New York, NY: National Center on Addiction and Substance Abuse at Columbia University.

National Institute of Corrections. (1992). Inmate work programs: A review of the literature. Aurora, CO: US Department of Justice, Information Center, National Institute of Corrections.

National Institute of Justice. (2018). An overview of offender reentry (NIJ Publication No. 251554). Retrieved from https://www.ncjrs.gov/pdffiles1/nij/251554.pdf

Newsome, J., \& Cullen, F. T. (2017). The risk-need-responsivity model revisited: Using 
biosocial criminology to enhance offender rehabilitation. Criminal Justice \& Behavior, 44(8), 1030-1049.

Ocen, P.A. (2013). Unshackling intersectionality. Du Bois Review, 10(2), 471-483.

O'Keefe, M. L., \& Schnell, M. J. (2007). Offenders with mental illness in the correctional system. Journal of Offender Rehabilitation, 45(1-2), 81-104. http://dx.doi.org/10.1300/J076v45n01_08.

Oregon Correctional Enterprises. (2019). About us. Retrieved from https://oce.oregon.gov/content/OCE_About_Us.asp

Oregon Department of Corrections. (2015). Snake River Correctional Institution's Kids' Camp: Providing opportunities for adults in custody to be fathers. Salem, OR: S.R. Lazzari

Oregon Department of Corrections. (n.d.a). About us: information on the history and structure of Oregon DOC. Retrieved from https://www.oregon.gov/doc/about/Pages/history.aspx.

Oregon Department of Corrections. (n.d.b). Inmate programs: Information on training, education, and social opportunities. Retrieved from https://www.oregon.gov/doc/inmate- programs/pages/home.aspx

Oregon Secretary of State. (n.d.). Department of corrections: Prohibited inmate conduct and processing disciplinary actions. Retrieved from https://secure.sos.state.or.us/oard/viewSingleRule.action;JSESSIONID_OARD=L 2q398FQt6IJ0t8vMAZhxlxuMuY0nrHIn7GfjFXaOmpo5i97KODT!924259904?ruleVrsnRsn=40158

Orrick, E.A., Worrall, J.L., Morris, R.G., Piquero, A.R., Bales, W.D., \& Wang, X. 
(2011). Testing social support theory: A multilevel analysis of recidivism. Journal of Criminal Justice, 39(6), 499-508.

Perinetti, G. (2019). StaTips part VI: Bivariate correlation. South European Journal of Orthodontics and Dentofacial Research, 6(1), 2-5.

Phelps, M. (2011). Rehabilitation in the punitive era: The gap between rhetoric and reality in U.S. prison programs. Law \& Society Review, 45(1), 33-68.

Poehlmann, J. (2005). Representations of attachment relationships in children of incarcerated mothers. Child Development, 76(3), 679-696.

Poehlmann, J., Dallaire, D., Loper, A.B., \& Shear, L.D. (2010). Children's contact with their incarcerated parents: Research findings and recommendations. American Psychologist, 65(6), 575-598.

Pollock, S. (2004). Anti-oppressive social work with women in prison: Discursive reconstructions and alternative practices. British Journal of Social Work, 34(5), 693-707.

Pompoco, A., Wooldredge, J., Lugo, M., Sullican, C., \& Latessa, E.J. (2017). Reducing inmate misconduct and prison returns with facility education programs. Criminology and Public Policy, 16(2), 515-548.

Poole, E.D., \& Regoli, R.M. (1980). Race, institutional rule breaking, and disciplinary response: A study in discretionary decision making in prison. Law \& Society Review, 14, 931-946.

Rampey, B.D., Keiper, S., Mohadjer, L., Krenzke, T., Li, J., Thornton, N., and Hogan, J. (2016). Highlights from the U.S. PIAAC survey of incarcerated adults: Their skills, work experience, education, and training: Program for the international assessment of adult competencies: 2014 (NCES 2016-040). U.S. Department of Education. Washington, DC: National Center for Education Statistics. Retrieved 
from http://nces.ed.gov/pubsearch.

Ray, B., Grommon, E., Buchanan, V., Brown, B., \& Watson, D.P. (2017). Access to recovery and recidivism among former prison inmates. International Journal of Offender Therapy and Comparative Criminology, 61(8), 874-893.

Reidy, T.J., Cihan, A., \& Sorensen, J.R. (2017). Women in prison: Investigating trajectories of institutional female misconduct. Journal of Criminal Justice, 52, 49-56.

Reidy, T. J., \& Sorensen, J. R. (2018). The Influence of Sentence Length on the Commission of Serious and Violent Prison Infractions by Female Inmates. Criminal Justice and Behavior, 45(9), 1420-1434.

Reidy, T.J., \& Sorensen, J.R. (2017). Prison homicides: A multidimensional comparison of perpetrators and victims. Journal of Forensic Psychology Research and Practice, 17(2), 99-116.

Reidy, T.J., Sorensen, J.R., \& Cunningham, M.D. (2012). Community violence to prison assault: A test of the behavior continuity hypothesis. Law and Human Behavior, 36(4), 356-363. http://dx.doi.org/10.1037/h0093934.

Richie, B.E. (2012). Arrested justice: Black women, violence, and America's prison nation. New York, NY: The New York Press.

Rocheleau, A. M. (2013). An empirical exploration of the "pains of imprisonment" and the level of prison misconduct and violence. Criminal Justice Review, 38(3), 354374.

Rocheleau, A.M. (2015). Ways of coping and involvement in prison violence. International Journal of Offender Therapy and Comparative Criminology, 59(4), 359-383.

Rocheleau, A.M. (2014). Prisoners' coping skills and involvement in serious prison rule violations. Victims \& Offenders, 9(2), 149-177. 
Rose, C. (2004). Women's participation in prison education: What we know and what we don't know. Journal of Correctional Education, 55, 78-100.

Ross, T., Khashu, A., \& Wamsley. (2004). Hard data on hard times: An empirical analysis of maternal incarceration, foster care, and visitation. Retrieved from: http://www.vera.org/content/hard-data-hard-times-empirical-analysis-maternalincarceration-foster-care-and-visitation

Salisbury, E. J., \& Van Voorhis, P. (2007, March). Gendered pathways: An investigation of women offenders' unique paths to crime. Paper resented at the Annual Meeting of the Academy of Criminal Justice Sciences, Seattle, WA.

Salisbury, E.J., \& Van Voorhis, P. (2009). Gendered pathways: A quantitative investigation of women probationers' paths to incarceration. Criminal Justice and Behavior, 36(6), 541- 566.

Salisbury, E.J., Van Voorhis, P., \& Spiropoulos, G.V. (2009). The predictive validity of a gender-responsive needs assessment: An exploratory study. Crime \& Delinquency, 55(4), 550-585.

Sampson, Robert J. and John H. Laub. 1993. Crime in the making: Pathways and turning points through life. Boston, MA: Harvard University Press.

Sandifer, JI. (2008). Evaluating the efficacy of a parenting program for incarcerated mothers. The Prison Journal, 88(3), 423-445.

Sawyer, W. (November 13, 2018). Women's mass incarceration: The whole pie 2018. Retrieved from the Prison Policy Initiative website: https://www.prisonpolicy.org/reports/pie2018women.html

Sawyer, W., \& Wagner, P. (March 19, 2019). Mass incarceration: The whole pie. Retrieved from Prison Policy Initiative website: 
https://www.prisonpolicy.org/reports/pie2019.html

Schafer, W.D. (1991). Reporting hierarchical regression results. Measurement and Evaluation in Counseling and Development, 24(3), 98-100.

Schenk, A.M., \& Fremouw, W.J. (2012). Indivdiual characteristics related to prison violence: A critical review of the literature. Aggression \& Violent Behavior, 17(5). 430-442.

Schonemann, P. H. (1990). Facts, fictions, and common sense about factors and components. Multivariate Behavioral Research, 25(1), 47-51.

Sedgley, N.H., Scott, C.E., Williams, N.A., \& Derrick, F.W. (2010). Prison's dilemma: Do education and job programmes affect recidivism? Economica, 77(307), 497517.

Siennick, S.E., Mears, D.P., \& Bales, W.D. (2013). Here and gone: Anticipation and separation effects of prison visits on inmate infractions. Journal of Research in Crime and Delinquency, 50(3), 417-444.

Smith, P., Gendreau, P., \& Swartz, K. (2009). Validating the principles of effective intervention: A systematic review of the contributions of meta-analysis in the field of corrections. Victims and Offenders, 4(2), 148-169.

Sorensen, J., Wrinkle, R., \& Gutierrez, A. (1998). Patterns of rule-violating behaviors and adjustment to incarceration among murderers. The Prison Journal, 78(3), 222-231.

Steiger, J. H. (1990). Some additional thoughts on components, factors, and factor indeterminacy. Multivariate Behavioral Research, 25(1), 41-45.

Steiner, B., Butler, H.D., \& Ellison, J.M. (2014). Causes and correlates of prison inmate misconduct: A systematic review of the evidence. Journal of Criminal Justice, 42(6), 462-470.

Steiner, B., \& Meade, B. (2016). Assessing the link between exposure to a violent prison 
context and inmate maladjustment. Journal of Contemporary Criminal Justice, 32(4), 328-356.

Steiner, B., \& Wooldredge, J. (2014). Comparing self-report to official measures of inmate misconduct. Justice Quarterly, 31(6), 1074-1101.

Steiner, B., \& Wooldredge, J. (2013). Implications of different outcome measures for understanding inmate misconduct. Crime \& Delinquency, 59(8), 1234-1262.

Steiner, B., \& Wooldredge, J. (2009). Individual and environmental effects on assaults and nonviolent rule breaking by women in prison. Journal of Research in Crime \& Delinquency, 46(4), 437-467.

Steuer, S.J., Smith, L., \& Tracy, A. (2001). Three state recidivism study. Lanham, MD: Correctional Educational Association.

Sumner, J., \& Sexton, L. (2016). Same difference: the 'dilemma of difference' and the incarceration of transgender prisoners. Law \& Social Inquiry, 41(3), 616-642.

Sykes, G.M. (1958). The society of captives. Princeton, NJ: Princeton University.

Tabachnick, B.G., \& Fidell, L.S. (1996). Using multivariate statistics. New York: Harper Collins.

Tabachnick, B.G., \& Fidell, L.S. (2013). Using multivariate statistics (6 ${ }^{\text {th }}$ ed.). Boston: Pearson Education.

Tasca, M., Griffin, M.L., \& Rodriguez, N. (2010). The effect of importation and deprivation factors on violent misconduct: An examination of black and Latino youth in prison. Youth Violence and Juvenile Justice, 8(3), 234-349.

Taylor, L.R., Lee, J., \& Taxman, S. (2019). Participant and program characteristics: Correlates of substance abuse treatment participation and prison misconducts. The Prison Journal, 99(1), 3-25.

Tewksbury, R., Connor, D.P., \& Denney, A.S. (2014). Disciplinary infractions behind bars: An exploration of importation and deprivation theories. Criminal Justice 
Review, 39(2), 201-218.

The Pew Charitable Trusts. (2010). Collateral Costs: Incarceration's Effect on Economic Mobility. Washington, DC: The Pew Charitable Trusts.

The Sentencing Project. (2019). Trends in U.S. corrections: U.S. state and federal prison populations, 1925-2017. Retrieved from https://sentencingproject.org/wpcontent/uploads/2016/01/Trends-in-US-Corrections.pdf

Thomas, C. W., \& Foster, S. C. (1973). The importation model perspective on inmate social roles: An empirical test. The Sociological Quarterly, 14(2), 226-234

Thompson, H.A. (2011). Re-thinking working class struggle through the lens of the carceral state: toward a labor history of inmates and guards. Labor: Studies of Working Class Histories of Americas, 8(2), 15-45.

Toman, E.L., Cochran, J.C., Cochran, J.K., \& Bales, W.D. (2015). The implications of sentence length for inmate adjustment to prison life. Journal of Criminal Justice, 43(6), 510-521.

Travis, J. (2005). But they all come back: Facing the challenges of prisoner reentry. Washington, D.C.: The Urban Institute Press.

Tuerk, E.H., \& Loper, A.B. (2006) Contact between incarcerated mothers and their children: Assessing parenting stress. Journal of Offender Rehabilitation, 43(1), 23-43.

Uggen, C., \& Thompson, M. (2003). The socioeconomic determinants of ill-gotten gains: Within-person changes in drug use and illegal earnings. American Journal of Sociology, 109(1), 146-185.

United States Census Bureau. (2017). America's education: Population 25 and over by educational attainment. Retrieved from https://www.census.gov/library/visualizations/2017/comm/americas- 
education.html

Valentine, C.L., Mears, D.P., \& Bales, W.D. (2015). Unpacking the relationship between age and prison misconduct. Journal of Criminal Justice, 43(5), 418-427.

Vanassche S, Swicegood G, Matthijs K. (2013). Marriage and children as a key to happiness? Cross-national differences in the effects of marital status and children on wellbeing. Journal of Happiness Studies, 14(2), 501-524.

Van Voorhis, P. (1994). Measuring prison disciplinary problems: A multiple indicators approach to understanding prison adjustment. Justice Quarterly, 11(4), 679-709.

Van Voorhis, P., Salisbury, E. J., Wright, E. M., \& Bauman, A. (2008).Achieving accurate pictures of risk and identifying gender responsive needs: Two new assessments for women offenders. Washington, DC: USDOJ, National Institute of Corrections. Retrieved from https://nicic.gov/achieving-accurate-pictures-risk-and-identifying-genderresponsive-needs-two-new-assessments-women

Van Voorhis, P., Wright, E.M., Salisbury, E., \& Bauman, A. (2010). Women's risk factors and their contributions to existing risk/needs assessment: The current status of a gender-responsive supplement. Criminal Justice and Behavior, 37(3), 261-288.

Viglione, , J., Lerch, J., Rudes, D.S., \& Taxman, F.S. (2017). Big stick management: Rule violations as discipline within a correctional reentry facility. Criminal Justice and Behavior, 44(2), 163-183.

Visher, C. A., \& O’Connell, D. J. (2012). Incarceration and inmates' self perceptions about returning home. Journal of Criminal Justice, 40(5), 386-393.

Visher, C.A., \& Travis, J. (2003). Transitions from prison to community: Understanding 
individual pathways. Annual Review of Sociology, 29(1), 89-113.

Wade, B. (2007). Studies of correctional education programs. Adult Basic Education and Literacy, 1(1), 27-31.

Wagner, P. (October 7, 2015). Are private prisons driving mass incarceration? Private prisons are more like a parasite on a publicly owned prison system, not the root cause of mass incarceration. Retrieved from Prison Policy Initiative website: https://www.prisonpolicy.org/blog/2015/10/07/private_prisons_parasite/

Wagner, P., \& Rabuy, B. (2017). Following the money of mass incarceration. Prison Policy Initiative. Retrieved from https://www.prisonpolicy.org/reports/money.html

Walters, G.D., \& Crawford, G. (2013). In and out of prison: Do importation factors Predict all forms of misconduct or just the more serious ones? Journal of Criminal Justice, 41(6), 407-413.

Warren, J.I., Hurt, S., Loper, A.B., Bale, R., Friend, R., \& Chauhan, P. (2002). Psychiatric symptoms, history of victimization, and violent behavior among incarcerated female felons: An American perspective. International Journal of Law and Psychiatry, 25(2), 129-149.

Warren, J. I., Hurt, S., Loper, A. B., \& Chauhan, P. (2004). Exploring prison adjustment among female inmates: Issues of measurement and prediction. Criminal Justice and Behavior, 31(5), 624-645.

Warren, K.L., Doogan, N., De Leon, G., Phillips, G.S., Moody, J., \& Hodge, A. (2013). Short-run prosocial behavior in response to receiving corrections and affirmations in three therapeutic communities. Journal of Offender Rehabilitation, 52(4), 270286.

West, S.G., Aiken, L.S., \& Krull, J.L. (1996). Experimental personality designs: Analyzing categorical by continuous variable interactions. Journal of Personality, 
64(1), 1-49.

Wolf, N., Blitz, C.L., Shi, J., Siegel, J., \& Bachman, R. (2007). Physical violence inside prisons: Rates of criminalization. Criminal Justice \& Behavior, 34(5), 588-599.

Wolf, N., \& Draine, J. (2004). Dynamics of social capital of prisoners and community reentry: Ties that bind? Journal of Correctional Health Care, 10(3), 457-490.

Wooldredge, J., Griffin, T., \& Pratt, T. (2001). Considering hierarchical models for Research on inmate behavior: Predicting misconduct with multilevel data. Justice Quarterly, 18(1), 203-231.

Wright, E.M., Salisbury, E.J., Van Voorhis, P. (2007). Predicting the prison misconducts of women offenders: The importance of gender-responsive needs. Journal of Contemporary Criminal Justice, 23(4), 310-340.

Wright, E.M., Van Voorhis, P., Salisbury, E.J., \& Bauman, A. (2012). Gender-responsive lessons learned and policy implications for women in prison. Criminal Justice and Behavior, 39(12), 1612-1632.

Zingraff, M.T. (1980). Inmate assimilation: A comparison of male and female delinquents. Criminal Justice and Behavior, 7(3), 275-292. 
Appendix A

Table 1. Instrumental and Expressive Social Supports

\section{Instrumental Supports}

Drug and Alcohol Programs

Any treatment for alcohol or drug use

Participated in any alcohol or drug program

Job/Vocation related Programs

Intervention for Future Employment

Work Assignment

Education Programs

Life skills, Community Adjustment, or other Pre-Release Program

Completed GED or any other Education Program

\section{Expressive Supports}

Religious Programs

Religious activities

Religious study group

Support Programs

Inmate led support groups

Classes in parenting or childrearing skills

Connection with Established Support Networks

Visits

Phone Calls 
Appendix B

Figure 1. Overall Model

\begin{tabular}{|l|}
\hline \multicolumn{1}{|c|}{ Demographics } \\
Sex \\
Age \\
Race \\
Educational Attainment \\
Marital Status \\
Parental Status \\
\hline
\end{tabular}

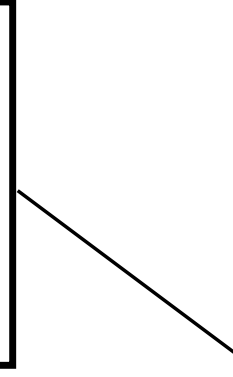

Instrumental Social Supports
Drug \& Alcohol Treatment
Drug or Alcohol Program
Intervention for Future Employment
Work Assignment
Life Skills and Community Adjustment
GED/Other Education Program

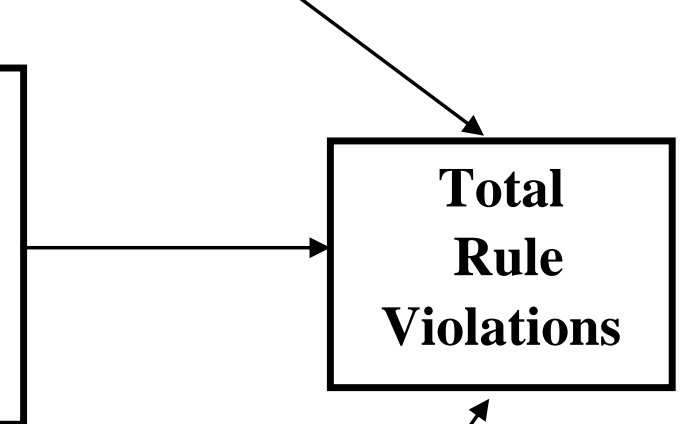

Expressive Social Supports

Religious Activities

Religious Study Group

Inmate led Support Group

Parenting Skills

Visits

Phone Calls 
Appendix C

Table 2. Cullen's (1994) Social Support Paradigm

Proposition

1 The more a society is deficient in the support needed, the higher its crime rate will be.

2 The less social support there is in a community, the higher the crime rate will be.

3 The more support a family provides, the less likely it is that a person will engage in crime.

4 The more social support in a person's social network, the less crime will occur.

5 Social support lessens the effects of exposure to criminogenic strains.

6 Across the life cycle, social support increases the likelihood that offenders will turn away from a criminal pathway.

7 Anticipation of a lack of social support increases criminal involvement.

8 Giving social support lessens involvement in crime.

9 Crime is less likely when social support for conformity exceeds social support for crime.

10 Social support often is a precondition for effective social control.

11 A supportive correctional system lessens crime.

12 Social support leads to more effective policing.

13 Social support lessens criminal victimization.

14 Social supports lessens the pains of criminal victimization. 


\section{Appendix D}

Table 3. Rule Violations and the Resulting Disciplinary Actions

\begin{tabular}{|c|c|c|c|}
\hline Oregon & & California & \\
\hline Rule violations & Disciplinary & $\underline{\text { Rule Offenses Divisions }}$ & Disciplinary Actions \\
\hline & Actions & & \\
\hline Major I & & Division A-1 & Loss of good time \\
\hline Extortion I & DSU: $60-120$ days & Battery causing serious & 181-360 days and \\
\hline Inmate Assault I & LOP: 28 days max & injury & subject to a hearing \\
\hline Sexual Assault & Fine: $\$ 200 \max$ & Assault & \\
\hline Staff Assault & & $\begin{array}{l}\text { Possession of deadly } \\
\text { weapon }\end{array}$ & \\
\hline Major II & & Division A-2 & Loss of good time \\
\hline Extortion II & DSU: $20-30$ days & Possession of flammable & 151-180 days and \\
\hline Inmate Assault II & LOP: 21 days $\max$ & explosive & subject to a hearing \\
\hline Sexual Coercion & Fine: $\$ 100 \max$ & Arson & \\
\hline & & $\begin{array}{l}\text { Attempted escape with } \\
\text { violence }\end{array}$ & \\
\hline Major III & & Division B & Loss of good time \\
\hline Inmate Assault III & DSU: 14 days max & Battery on staff & 121-150 days and \\
\hline & LOP: 14 days $\max$ & Threatening to kill staff & subject to a hearing \\
\hline & Fine: $\$ 75 \max$ & or their family & \\
\hline & & Theft & \\
\hline & & Escape & \\
\hline Major IV & DSU: 7 days max & Division $\mathrm{C}$ & Loss of good time \\
\hline Sexual Solicitation & LOP: 7 days max & Attempted escape & 91-120 days \\
\hline Forgery & Fine: $\$ 50$ max & without force & and subject to a \\
\hline Fraud & & Bribery & hearing \\
\hline False Information to & & Possession of Drugs or & \\
\hline Employees I & & alcohol & \\
\hline Minor V & LOP: 10 days max & Division D & Loss of good time \\
\hline Disobedience III & Fine: $\$ 25 \max$ & Participation in a riot & 61-90 days and \\
\hline Property II & & Inciting a riot & subject to a hearing \\
\hline & & Fighting & \\
\hline & & $\begin{array}{l}\text { Assault on an officer not } \\
\text { causing injury }\end{array}$ & \\
\hline Minor VI & LOP: 7 days $\max$ & Division $\mathrm{E}$ & Loss of good time \\
\hline Contraband III & Fine: $\$ 15 \max$ & Damage to another's & 31-60 days and \\
\hline Gambling & & property & subject to a hearing \\
\hline Unauthorized Area & & Gambling & \\
\hline & & $\begin{array}{l}\text { Sexual disorderly } \\
\text { conduct }\end{array}$ & \\
\hline & & Division F & Loss of good time \\
\hline & & $\begin{array}{l}\text { Refusing to provide urine } \\
\text { samples }\end{array}$ & 0-30 days and subject \\
\hline & & Possession of a cell & \\
\hline & & phone & \\
\hline & & $\begin{array}{l}\text { Refusal to complete work } \\
\text { assignments }\end{array}$ & \\
\hline
\end{tabular}

Note: DSU = disciplinary segregation unit; LOP = loss of privileges 


\begin{tabular}{l} 
Appendix E \\
Table 4. Rule Violations Included in the Study \\
\hline Drug Violations \\
Alcohol Violations \\
Possession of a Weapon \\
Possession of other Unauthorized Item or Substance \\
Stolen Property \\
Verbal Assault on Staff \\
Physical Assault on Staff \\
Verbal Assault on an Inmate \\
Physical Assault on an Inmate \\
Escape Attempt \\
Being out of Place \\
Disobeying Orders \\
Any other Major Violations
\end{tabular}


Appendix F

Table 5. Sample Descriptive Statistics

\begin{tabular}{|c|c|c|c|c|}
\hline Variable & $\underline{\mathbf{n}}$ & $\underline{\%}$ & $\overline{\bar{X}}$ & $\underline{\text { SD }}$ \\
\hline \multicolumn{5}{|l|}{ Independent Variables } \\
\hline \multicolumn{5}{|l|}{ Demographics } \\
\hline \multicolumn{5}{|l|}{ Sex } \\
\hline Female & 1091 & 18.4 & & \\
\hline Male & 4852 & 81.6 & & \\
\hline \multicolumn{5}{|l|}{ Race } \\
\hline People of Color & 3325 & 55.9 & & \\
\hline White & 2618 & 44.1 & & \\
\hline White & 2618 & 44.0 & & \\
\hline Black & 2630 & 44.3 & & \\
\hline Other/Multiracial & 695 & 11.7 & & \\
\hline Age & & & 34 & 10.0 \\
\hline 26 and younger & 1701 & 28.6 & & \\
\hline $27-33$ & 1437 & 24.2 & & \\
\hline $34-41$ & 1466 & 24.7 & & \\
\hline At least 42 & 1339 & 22.5 & & \\
\hline \multicolumn{5}{|l|}{ Educational Attainment } \\
\hline $9^{\text {th }}$ grade or less & 1553 & 26.1 & & \\
\hline $10^{\text {th }}$ grade & 1113 & 18.7 & & \\
\hline $11^{\text {th }}$ grade & 1188 & 20.0 & & \\
\hline $12^{\text {th }}$ grade & 1329 & 22.4 & & \\
\hline Beyond high school & 747 & 12.6 & & \\
\hline No GED & 4216 & 70.9 & & \\
\hline GED/HS Diploma & 1727 & 29.1 & & \\
\hline \multicolumn{5}{|l|}{ Marital Status } \\
\hline Not married/unknown & 3691 & 62.1 & & \\
\hline Divorced, separated, or widowed & 1445 & 24.3 & & \\
\hline Married & 807 & 13.6 & & \\
\hline Parental Status & 9030 & & 2.4 & 1.7 \\
\hline No children & 3562 & 59.9 & & \\
\hline Have children & 2381 & 40.1 & & \\
\hline \multicolumn{5}{|l|}{ Control Variable } \\
\hline Time Served & & & 76.6 & 71.7 \\
\hline 0-24 Months & 1454 & 24.5 & & \\
\hline 25-96 Months & 2806 & 47.2 & & \\
\hline At least 97 months & 1683 & 28.3 & & \\
\hline 18 months or less & 1035 & 17.4 & & \\
\hline At least 19 months & 4908 & 82.6 & & \\
\hline \multicolumn{5}{|l|}{ Dependent Variable } \\
\hline Rule Violations & 150855 & & 25.4 & 137.5 \\
\hline
\end{tabular}

Note. Some totals do not add up to 5943 because of missing data. See Analysis section for description of how missing data was treated. 


\section{Appendix G}

Table 6. Chi Square Tests between Sex and Social Supports

\begin{tabular}{|c|c|c|c|c|}
\hline \multirow[b]{2}{*}{ Variable } & \multicolumn{2}{|c|}{ \% of Males } & \multicolumn{2}{|c|}{ \% of Females } \\
\hline & $\underline{\text { Yes }}$ & No & Yes & No \\
\hline \multicolumn{5}{|l|}{ Instrumental Social Supports } \\
\hline \multicolumn{5}{|l|}{ Drug and Alcohol Programs } \\
\hline $\begin{array}{l}\text { Any treatment for } \\
\text { alcohol/drugs }\end{array}$ & 7.8 & 92.2 & $13.4 * *$ & 86.6 \\
\hline $\begin{array}{l}\text { Any program for } \\
\text { alcohol/drugs }\end{array}$ & 35.6 & 64.4 & 37.1 & 62.9 \\
\hline \multicolumn{5}{|c|}{ Job/Vocation Related Programs } \\
\hline \multicolumn{5}{|l|}{ Employment } \\
\hline Work Assignment & 62.2 & 37.8 & $68.9 * *$ & 31.1 \\
\hline \multicolumn{5}{|l|}{ Education Programs } \\
\hline Life Skills & 30.2 & 69.8 & $41.0^{* *}$ & 59.0 \\
\hline GED/Other Education & 40.3 & 59.7 & $44.1 *$ & 55.9 \\
\hline \multicolumn{5}{|l|}{ Expressive Social Supports } \\
\hline \multicolumn{5}{|l|}{ Religious Programs } \\
\hline Religious Activities & 52.5 & 47.5 & $67.4 * *$ & 32.6 \\
\hline Religious Study Group & 32.0 & 68.0 & $41.2^{* *}$ & 58.8 \\
\hline \multicolumn{5}{|l|}{ Support Programs } \\
\hline $\begin{array}{l}\text { Ethnic/Racial and other } \\
\text { Support Programs }\end{array}$ & 18.9 & 81.1 & $25.2 * *$ & 74.8 \\
\hline Parenting Skills & 9.2 & 90.8 & $38.1 * *$ & 15.6 \\
\hline \multicolumn{5}{|l|}{ Connection with Established } \\
\hline Visits & 30.4 & 69.6 & $35.7 * *$ & 64.3 \\
\hline Phone Calls & 44.1 & 55.9 & $49.7 * *$ & 50.3 \\
\hline
\end{tabular}

$* \mathrm{p} \leq .05$

$* * \mathrm{p} \leq .000$ 


\section{Appendix $\mathrm{H}$}

Table 7. Chi Square Tests between Race and Social Supports

\begin{tabular}{|c|c|c|c|c|}
\hline \multirow[b]{2}{*}{ Variable } & \multicolumn{2}{|c|}{ \% of People of Color } & \multicolumn{2}{|c|}{ \% of Whites } \\
\hline & $\underline{\text { Yes }}$ & No & Yes & No \\
\hline \multicolumn{5}{|l|}{ Instrumental Social Supports } \\
\hline \multicolumn{5}{|l|}{ Drug and Alcohol Programs } \\
\hline $\begin{array}{l}\text { Any treatment for } \\
\text { alcohol/drugs }\end{array}$ & 7.8 & 92.2 & $10.2 * *$ & 89.8 \\
\hline $\begin{array}{l}\text { Any program for } \\
\text { alcohol/drugs }\end{array}$ & 34.5 & 65.5 & $37.7 *$ & 62.3 \\
\hline \multicolumn{5}{|l|}{ Job/Vocation Related Programs } \\
\hline $\begin{array}{l}\text { Intervention for Future } \\
\text { Employment }\end{array}$ & $43.5^{* *}$ & 56.5 & 39.4 & 60.6 \\
\hline Work Assignment & 63.2 & 36.8 & 63.7 & 36.3 \\
\hline \multicolumn{5}{|l|}{ Education Programs } \\
\hline Life Skills & $33.5 *$ & 66.5 & 30.6 & 69.4 \\
\hline GED/Other Education & $43.2 * *$ & 56.8 & 38.2 & 61.8 \\
\hline \multicolumn{5}{|l|}{ Expressive Social Supports } \\
\hline \multicolumn{5}{|l|}{ Religious Programs } \\
\hline Religious Activities & $57.8^{* *}$ & 42.2 & 52.0 & 48.0 \\
\hline Religious Study Group & $36.4 * *$ & 63.6 & 30.1 & 69.9 \\
\hline \multicolumn{5}{|l|}{ Support Programs } \\
\hline Inmate led Support Groups & $21.0 *$ & 79.0 & 18.9 & 81.1 \\
\hline Parenting Skills & 12.8 & 87.2 & 11.3 & 88.7 \\
\hline \multicolumn{4}{|l|}{ Connection with Established } & \\
\hline Visits & 29.1 & 70.9 & $34.2 * *$ & 65.8 \\
\hline Phone Calls & 44.9 & 55.1 & 45.5 & 54.5 \\
\hline
\end{tabular}

$$
\begin{aligned}
& *=\mathrm{p} \leq .05 \\
& * *=\mathrm{p} \leq .001
\end{aligned}
$$


Appendix I

Table 8. Independent-Sample T-Tests Comparing Males and Females

\begin{tabular}{|c|c|c|c|c|c|}
\hline \multirow[b]{2}{*}{ Variables } & \multicolumn{2}{|c|}{ Female } & \multicolumn{2}{|c|}{ Male } & \multirow[b]{2}{*}{ t-test } \\
\hline & M & $\mathrm{SD}$ & $\underline{M}$ & $\underline{\mathrm{SD}}$ & \\
\hline Time Served & $\overline{50.67}$ & $\overline{52.21}$ & $8 \overline{2.47}$ & $\overline{74.20}$ & $-16.687 * * *$ \\
\hline Instrumental Supports & 2.49 & 1.42 & 2.17 & 1.40 & $6.69 * * *$ \\
\hline Expressive Supports & 2.44 & 1.43 & 1.87 & 1.29 & $12.09 * * *$ \\
\hline Total Social Supports & 4.93 & 2.41 & 4.04 & 2.20 & $11.17 * * *$ \\
\hline Total Rule Violations & 23.49 & 131.52 & 25.81 & 138.88 & -.522 \\
\hline
\end{tabular}

$* \mathrm{p} \leq .05$

$* * \mathrm{p} \leq .01$

$* * * \mathrm{p} \leq .001$ 
Appendix J

Table 9. Independent Sample T-Tests Comparing People of Color and Whites

\begin{tabular}{lrrrrr}
\hline & \multicolumn{2}{c}{ People of Color } & \multicolumn{2}{c}{ White } & \\
Variable & $\underline{\mathrm{M}}$ & $\underline{\mathrm{SD}}$ & $\underline{\mathrm{M}}$ & $\mathrm{SD}$ & t-test \\
$\quad$ Time Served & 79.21 & 71.14 & 73.37 & 72.36 & $3.12^{* *}$ \\
Instrumental Supports & 2.26 & 1.40 & 2.20 & 1.42 & 1.59 \\
Expressive Supports & 2.02 & 1.33 & 1.91 & 1.34 & $2.89^{* *}$ \\
Total Social Supports & 4.28 & 2.27 & 4.12 & 2.27 & $2.69^{* *}$ \\
$\quad$ Total Rule Violations & 31.72 & 156.44 & 17.34 & 108.43 & $4.18^{* * *}$ \\
\hline$* \mathrm{p} \leq .05$ & & & & & \\
$* * \mathrm{p} \leq .01$ & & & & & \\
$* * * \mathrm{p} \leq .001$ & & & & &
\end{tabular}


Appendix K

Table 10. Whether Participation in Social Supports Influence Rule Violations

\begin{tabular}{|c|c|c|c|c|c|}
\hline \multirow[b]{2}{*}{ Type of Social Support } & \multicolumn{2}{|c|}{ Non-participant } & \multicolumn{2}{|c|}{$\underline{\text { Participant }}$} & \multirow[b]{2}{*}{$\underline{\text { t-test }}$} \\
\hline & $\underline{\mathrm{M}}$ & $\underline{\mathrm{SD}}$ & $\underline{\mathrm{M}}$ & $\underline{\mathrm{SD}}$ & \\
\hline \multicolumn{6}{|l|}{ Instrumental Social Supports } \\
\hline $\begin{array}{l}\text { Any treatment for alcohol or } \\
\text { drug use }\end{array}$ & 25.82 & 138.91 & 20.84 & 122.77 & .793 \\
\hline $\begin{array}{l}\text { Participated in any alcohol or } \\
\text { drug program }\end{array}$ & 24.90 & 136.66 & 26.25 & 139.15 & -.364 \\
\hline $\begin{array}{l}\text { Combined alcohol/drugs } \\
\text { programs or treatment }\end{array}$ & 24.80 & 136.41 & 26.29 & 139.31 & -.406 \\
\hline $\begin{array}{l}\text { Intervention for future } \\
\text { employment }\end{array}$ & 23.44 & 132.79 & 28.10 & 143.915 & -1.287 \\
\hline Work assignment & 33.94 & 161.61 & 20.45 & 121.26 & $3.382 * *$ \\
\hline Combined work/vocational & 31.29 & 155.45 & 23.61 & 131.67 & 1.661 \\
\hline $\begin{array}{l}\text { Life skills, community } \\
\text { adjustment, or other pre- } \\
\text { release program }\end{array}$ & 22.93 & 130.127 & 30.56 & 151.91 & $-1.891 *$ \\
\hline $\begin{array}{l}\text { Completed GED or any other } \\
\text { education program }\end{array}$ & 22.65 & 130.21 & 29.31 & 147.40 & -1.796 \\
\hline Combined Education Program & 22.57 & 130.74 & 27.67 & 142.81 & -1.435 \\
\hline \multicolumn{6}{|l|}{ Expressive Social Supports } \\
\hline Religious activities & 25.44 & 137.62 & 25.34 & 137.51 & .027 \\
\hline Religious study groups & 24.27 & 134.27 & 27.57 & 143.80 & -.873 \\
\hline Combined religious supports & 24.41 & 135.89 & 25.89 & 138.42 & -.393 \\
\hline Inmate led support groups & 25.07 & 137.37 & 26.62 & 138.31 & -.347 \\
\hline $\begin{array}{l}\text { Classes in parenting or } \\
\text { childrearing skills }\end{array}$ & 24.70 & 135.40 & 30.37 & 152.20 & -1.038 \\
\hline Combined support groups & 24.47 & 135.48 & 27.87 & 143.05 & -.845 \\
\hline Visits & 27.85 & 145.75 & 19.98 & 117.47 & $2.218 *$ \\
\hline Phone calls & 26.07 & 138.315 & 24.55 & 136.63 & .422 \\
\hline $\begin{array}{l}\text { Combined connection with } \\
\text { established support }\end{array}$ & 27.57 & 143.86 & 23.81 & 132.82 & 1.041 \\
\hline
\end{tabular}




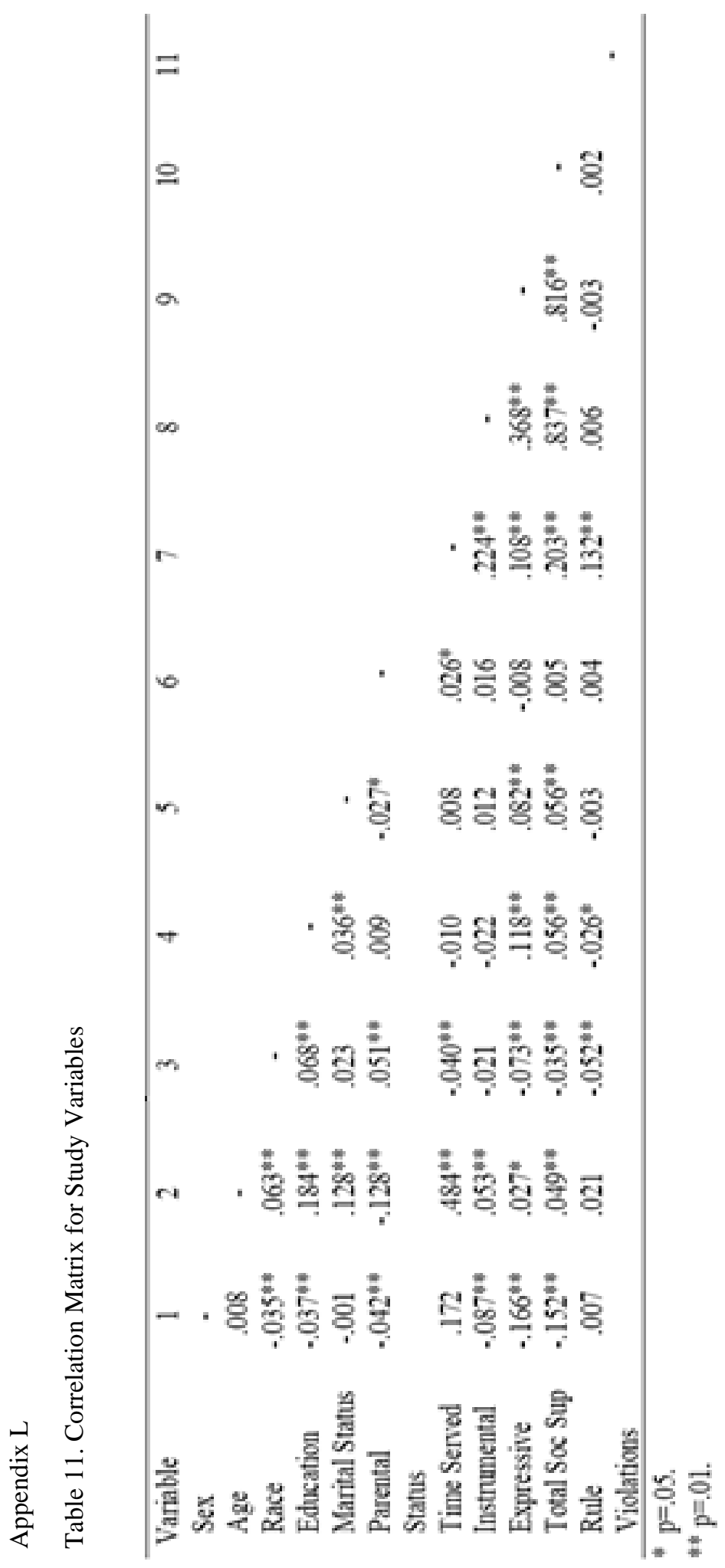




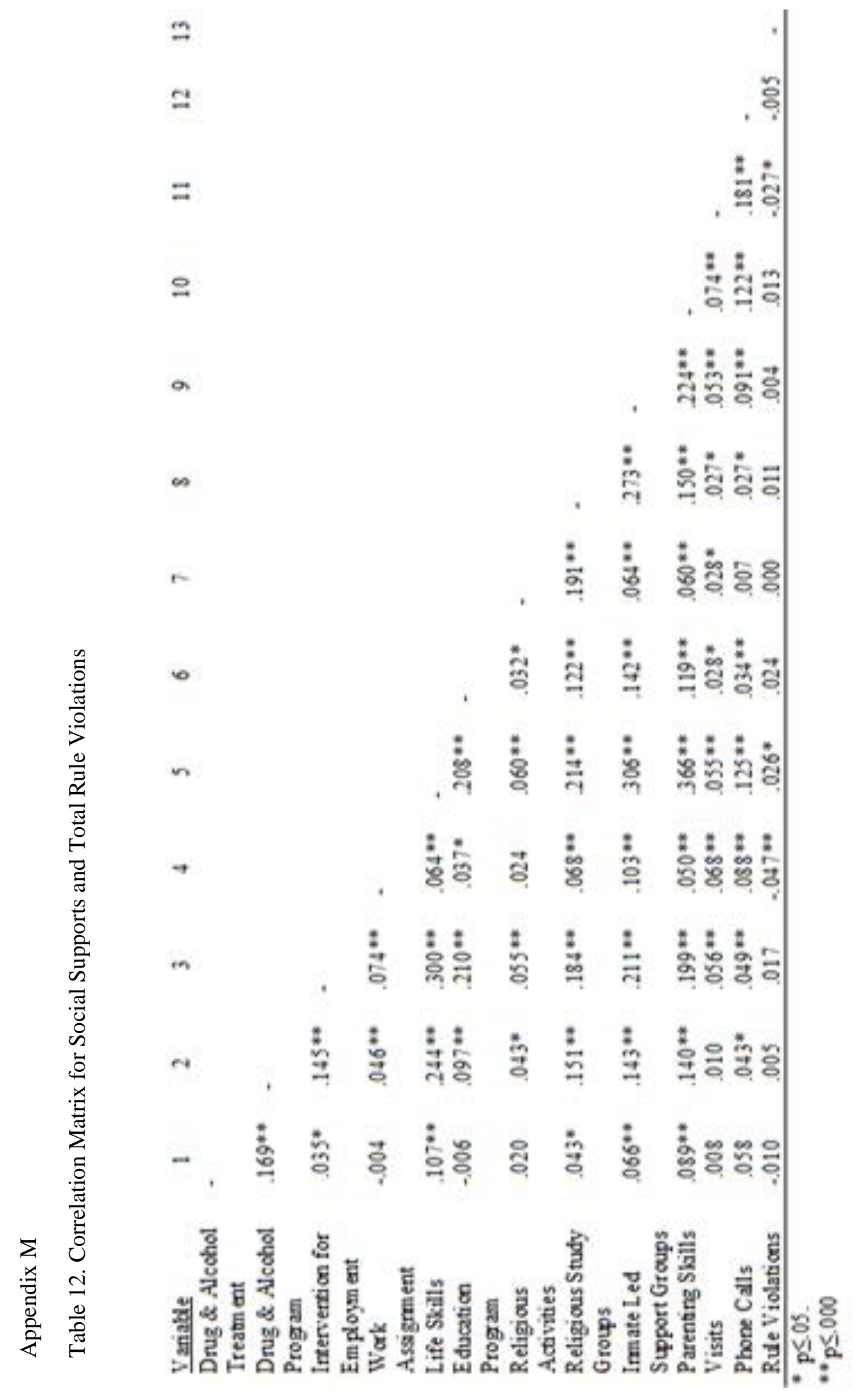


Appendix N

Table 13. Hierarchical Regression Predicting Total Rule Violations

\begin{tabular}{|c|c|c|c|c|c|c|}
\hline & $\underline{B}$ & $\underline{S E}$ & $\underline{\beta}$ & $\underline{\mathrm{R}^{2}}$ & $\underline{\mathrm{R}^{2} \text { Change }}$ & $\underline{F}$ \\
\hline Model 1 & & & & .003 & & $5.083 *$ \\
\hline Constant & 31.03 & 3.26 & & & & \\
\hline Current Work & -11.23 & $3.69^{*}$ & $-.04 *$ & & & \\
\hline Assignment $^{1}$ & & & & & & \\
\hline Life Skills ${ }^{2}$ & 7.66 & 3.80 & $.03 *$ & & & \\
\hline Visit $^{3}$ & -5.89 & 3.82 & $.03 *$ & & & \\
\hline Model 2 & & & & .006 & $.003 *$ & $6.547 * *$ \\
\hline Constant & 38.13 & 3.68 & & & & \\
\hline Current Work Assignment & -10.76 & 3.69 & $-.04 *$ & & & \\
\hline Life Skills & 7.25 & 3.81 & $.03 *$ & & & \\
\hline Visit & -4.68 & 3.83 & -.02 & & & \\
\hline Race $^{4}$ & -13.57 & 3.57 & $-.05 * *$ & & & \\
\hline Educational Attainment ${ }^{5}$ & -5.79 & 3.93 & -.02 & & & \\
\hline Model 3 & & & & .023 & $.017 * *$ & $22.79 * *$ \\
\hline Constant & 19.63 & 4.07 & & & & \\
\hline Current Work Assignment & -14.89 & 3.68 & $-.05 * *$ & & & \\
\hline Life Skills & 3.06 & 3.79 & .01 & & & \\
\hline Visit & -4.29 & 3.80 & -.02 & & & \\
\hline Race & -11.54 & 3.55 & $-.04 *$ & & & \\
\hline Educational Attainment & -4.32 & 3.90 & -.02 & & & \\
\hline Time Served 6 & .30 & .03 & $.13 * *$ & & & \\
\hline \multicolumn{7}{|l|}{$* \mathrm{p} \leq .01$} \\
\hline \multicolumn{7}{|l|}{$* * p \leq .000$} \\
\hline \multirow{2}{*}{\multicolumn{7}{|c|}{$\begin{array}{l}{ }^{1} \text { Current Work Assignment was dichotomized as: } 0=\text { did not have a current work assignment } / 1= \\
\text { does have a current work assignment. } \\
{ }^{2} \text { Life Skills was dichotomized as: } 0=\text { did not participate in any Life skills, Community } \\
\text { adjustment, or other Pre-release program } / 1=\text { did participate. }\end{array}$}} \\
\hline & & & & & & \\
\hline \multicolumn{7}{|c|}{$\begin{array}{l}{ }^{3} \text { Visits were dichotomized as: } 0=\text { did not have a visit in the past month } / 1=\text { Had at least one visit } \\
\text { in the past month. }\end{array}$} \\
\hline \multirow{2}{*}{\multicolumn{7}{|c|}{$\begin{array}{l}{ }^{4} \text { Race/Ethnicity was dichotomized as: } 0=\text { Person of Color } / 1=\text { White } \\
{ }^{5} \text { Educational Attainment was dichotomized as: } 0=\text { Does not have at least a GED/ } 1=\text { has at least } \\
\text { a GED }\end{array}$}} \\
\hline & & & & & & \\
\hline \multicolumn{7}{|c|}{$\begin{array}{l}{ }^{6} \text { Time served was a continuous variable assessing the total number of months served at the time } \\
\text { of the initial interview. }\end{array}$} \\
\hline
\end{tabular}


Appendix $\mathrm{O}$

Table 14. Hypotheses Testing

Results

\begin{tabular}{|c|c|c|c|}
\hline \multicolumn{2}{|c|}{ Hypothesis } & \multirow[t]{2}{*}{ Analysis } & \multirow{2}{*}{$\frac{\text { Discussion }}{\text { Partially Supported }}$} \\
\hline$\overline{\mathrm{H1}}$ & $\begin{array}{l}\text { Individual demographics } \\
\text { will have significant effects } \\
\text { on total rule violations. }\end{array}$ & & \\
\hline $\mathrm{H} 1_{\mathrm{a}}$ & $\begin{array}{l}\text { Females will have } \\
\text { committed fewer rule } \\
\text { violations than males. }\end{array}$ & $\begin{array}{l}\text { Independent } \\
\text { samples t-test }\end{array}$ & Not supported \\
\hline $\mathrm{H} 1_{\mathrm{b}}$ & $\begin{array}{l}\text { Older individuals will have } \\
\text { committed fewer rule } \\
\text { violations than younger } \\
\text { incarcerated individuals. }\end{array}$ & $\begin{array}{l}\text { Pearson } \\
\text { Correlation }\end{array}$ & Not supported \\
\hline $\mathrm{H} 1_{\mathrm{c}}$ & $\begin{array}{l}\text { White individuals will have } \\
\text { committed fewer rule } \\
\text { violations than individuals of } \\
\text { color. }\end{array}$ & $\begin{array}{l}\text { Independent } \\
\text { samples t-test }\end{array}$ & $\begin{array}{l}\text { White participants }(\mathrm{M}=17.34, \mathrm{SD}=108.43) \text { had } \\
\text { committed significantly fewer rule violations } \\
\text { than people of color }(\mathrm{M}=31.72, \mathrm{SD}=156.44 \\
\mathrm{t}(5851)=4.177, \mathrm{p}=.000)\end{array}$ \\
\hline $\mathrm{H} 1_{\mathrm{d}}$ & $\begin{array}{l}\text { Individuals who have at least } \\
\text { a GED will have fewer rule } \\
\text { violations than those with } \\
\text { less than a GED. }\end{array}$ & $\begin{array}{l}\text { Independent } \\
\text { samples t-test }\end{array}$ & $\begin{array}{l}\text { Individuals who had at least a GED }(\mathrm{M}=19.80 \text {, } \\
\mathrm{SD}=120.11) \text {, at the time of interview, had } \\
\text { committed significantly fewer rule violations } \\
\text { than those whose educational attainment was less } \\
\text { than a GED }(\mathrm{M}=27.67, \mathrm{SD}=144.04 ; \mathrm{t}(3816)= \\
2.16, \mathrm{p}=.03) .\end{array}$ \\
\hline $\mathrm{H} 1_{\mathrm{e}}$ & $\begin{array}{l}\text { Incarcerated individuals who } \\
\text { are married will have fewer } \\
\text { rule violations than those not } \\
\text { married. }\end{array}$ & $\begin{array}{l}\text { Independent } \\
\text { samples t-test }\end{array}$ & Not supported \\
\hline $\mathrm{H} 1_{\mathrm{f}}$ & $\begin{array}{l}\text { Incarcerated parents will } \\
\text { have committed fewer rule } \\
\text { violations than non-parents. }\end{array}$ & $\begin{array}{l}\text { Independent } \\
\text { samples t-test }\end{array}$ & Not supported \\
\hline $\mathrm{H} 1_{\mathrm{g}}$ & $\begin{array}{l}\text { Individuals with longer } \\
\text { periods of time already } \\
\text { served behind bars will have } \\
\text { more rule violations with } \\
\text { those who have spent less } \\
\text { time behind bars. }\end{array}$ & $\begin{array}{l}\text { Pearson } \\
\text { Correlation }\end{array}$ & $\begin{array}{l}\text { Individuals who had served more time had } \\
\text { significantly more rule violations }(r=.132, \mathrm{p} \leq \\
.000) \text {. }\end{array}$ \\
\hline H2 & $\begin{array}{l}\text { Various types of } \\
\text { Instrumental social } \\
\text { supports will decrease total } \\
\text { rule violations }\end{array}$ & & Partially supported \\
\hline $\mathrm{H} 2 \mathrm{a}$ & $\begin{array}{l}\text { Participation in drug and } \\
\text { alcohol programs will } \\
\text { decrease total rule violations. }\end{array}$ & $\begin{array}{l}\text { Independent } \\
\text { samples t-test }\end{array}$ & Not supported \\
\hline
\end{tabular}




\footnotetext{
Participation in

$\mathrm{H} 2$ b job/vocational related programs will decrease total rule violations.
}

$\mathrm{H} 2$ c Participation in education programs will decrease total rule violations.

H3 Various types of Expressive social supports will decrease the total rule violations.

$\mathrm{H} 3$ a Participation in religious programs will decrease total rule violations.

$\mathrm{H} 3$ b Participation in support programs will decrease rule violations.

$\mathrm{H} 3_{\mathrm{c}} \quad$ Connection with established support networks will decrease rule violations.

H4 Individuals who are engaged with more instrumental social supports will have committed fewer rule violations.

H5 Individuals who are engaged with more expressive social supports will have committed fewer rule violations.

H6 Individuals who are engaged with more instrumental and expressive social supports will have committed fewer rule violations.

H7 When controlling for time already served, women, who are engaged with more social supports, will have committed fewer rule violations.
Independent

samples t-test

When assessed on its own, individuals who had a job assignment $(\mathrm{M}=20.45, \mathrm{SD}=121.26)$ had significantly fewer rule violations than those not working $(\mathrm{M}=33.94, \mathrm{SD}=161.60 ; \mathrm{t}(3597)=$ $3.38, \mathrm{p}=.001)$.

Independent

samples t-test

Not supported

Partially supported

Independent

samples t-test

Independent

samples t-test

Independent

samples t-test

When combined (visits and phone calls), there were no statistically significant impacts on rule violations. When separated, the results varied. Phone calls did not significantly impact rule violations. Participants who had a visit in the past month $(\mathrm{M}=19.98, \mathrm{SD}=117.47)$, at the time of the interview, had significantly fewer rule violations than those who did not have a visit (M $=27.85, \mathrm{SD}=145.75 ; \mathrm{t}(4405)=2.218, \mathrm{p}=.02)$.

Pearson Not supported

Correlations

Pearson

Correlations

Not supported

Pearson

Correlations

Not supported

Not completed

Moderation was not completed, and sex was not included in the hierarchical regression model, since there was not a significant association between sex and total rule violations. Nor is there an association between total social supports and rule violations. 
H8 When controlling for time already served, Whites, who are engaged with more social supports, will have committed fewer rule violations.
Hierarchical regression
Moderation was not completed. Race and specific social supports were included in the final model. Whites $(b=-11.54, \mathrm{SEb}=3.55, \beta=-.04$, $\mathrm{p}=.001)$ and individuals with a work assignment $(b=-14.88, \mathrm{SEb}=3.68, \beta=-.05, \mathrm{p}=.000)$ had significantly fewer rule violations, as did individuals who had served less time $(\mathrm{b}=.30$, $\mathrm{SEb}=.03, \beta=.13, \mathrm{p}=.000$ ). 